\title{
Article \\ Proof of Concept Study for Fuselage Boundary Layer Ingesting Propulsion
}

\author{
Arne Seitz ${ }^{1, *(\mathbb{D})}$, Anaïs Luisa Habermann ${ }^{1}$, Fabian Peter ${ }^{1}$, Florian Troeltsch ${ }^{1}$, Alejandro Castillo Pardo ${ }^{2}(\mathbb{D}$, \\ Biagio Della Corte ${ }^{3}$, Martijn van Sluis ${ }^{3}$, Zdobyslaw Goraj ${ }^{4}{ }^{\circ}$, Mariusz Kowalski ${ }^{4}{ }^{\oplus}$, Xin Zhao ${ }^{5}$, \\ Tomas Grönstedt ${ }^{5}$, Julian Bijewitz ${ }^{6}$ and Guido Wortmann ${ }^{7}$
}

1 Bauhaus Luftfahrt e.V., Willy-Messerschmitt-Str. 1, 82024 Taufkirchen, Germany; anais.habermann@bauhaus-luftfahrt.net (A.L.H.); fabian.peter@bauhaus-luftfahrt.net (F.P.); florian.troeltsch@bauhaus-luftfahrt.net (F.T.)

2 Whittle Laboratory, University of Cambridge, 1 JJ Thomson Av., Cambridge CB30DY, UK; ac2181@cam.ac.uk

3 Faculty of Aerospace Engineering, Delft University of Technology, 2629 Delft, The Netherlands; b.dellacorte@tudelft.nl (B.D.C.); m.vansluis@tudelft.nl (M.v.S.)

4 Faculty of Power and Aeronautical Engineering, Warsaw University of Technology, Pl. Politechniki 1, 00-661 Warsaw, Poland; goraj@meil.pw.edu.pl (Z.G.); mkowalski@meil.pw.edu.pl (M.K.)

5 Division of Fluid Dynamics, Department of Mechanics and Maritime Sciences, Chalmers University of Technology, 41296 Gothenburg, Sweden; xin.zhao@chalmers.se (X.Z.); tomas.gronstedt@chalmers.se (T.G.)

6 Engineering Advanced Programs, MTU Aero Engines AG, 80995 Munich, Germany; julian.bijewitz@mtu.de

7 Rolls-Royce Electrical, Rolls Royce Deutschland Ltd., 91058 Erlangen, Germany; guido.wortmann@rolls-royce-electrical.com

* Correspondence: arne.seitz@bauhaus-luftfahrt.net

check for updates

Citation: Seitz, A.; Habermann, A.L.; Peter, F.; Troeltsch, F.; Castillo Pardo,

A.; Della Corte, B.; van Sluis, M.;

Goraj, Z.; Kowalski, M.; Zhao, X.; et al. Proof of Concept Study for Fuselage Boundary Layer Ingesting Propulsion. Aerospace 2021, 8, 16. https://doi.org/10.3390/aerospace 8010016

Received: 14 December 2020 Accepted: 9 January 2021 Published: 13 January 2021

Publisher's Note: MDPI stays neutral with regard to jurisdictional clai$\mathrm{ms}$ in published maps and institutional affiliations.

Copyright: (C) 2021 by the authors. Licensee MDPI, Basel, Switzerland. This article is an open access article distributed under the terms and conditions of the Creative Commons Attribution (CC BY) license (https:// creativecommons.org/licenses/by/ $4.0 /)$.

\begin{abstract}
Key results from the EU H2020 project CENTRELINE are presented. The research activities undertaken to demonstrate the proof of concept (technology readiness level-TRL 3) for the so-called propulsive fuselage concept (PFC) for fuselage wake-filling propulsion integration are discussed. The technology application case in the wide-body market segment is motivated. The developed performance bookkeeping scheme for fuselage boundary layer ingestion (BLI) propulsion integration is reviewed. The results of the $2 \mathrm{D}$ aerodynamic shape optimization for the bare PFC configuration are presented. Key findings from the high-fidelity aero-numerical simulation and aerodynamic validation testing, i.e., the overall aircraft wind tunnel and the BLI fan rig test campaigns, are discussed. The design results for the architectural concept, systems integration and electric machinery pre-design for the fuselage fan turbo-electric power train are summarized. The design and performance implications on the main power plants are analyzed. Conceptual design solutions for the mechanical and aerostructural integration of the BLI propulsive device are introduced. Key heuristics deduced for PFC conceptual aircraft design are presented. Assessments of fuel burn, NOx emissions, and noise are presented for the PFC aircraft and benchmarked against advanced conventional technology for an entry-into-service in 2035. The PFC design mission fuel benefit based on 2D optimized PFC aero-shaping is $4.7 \%$.
\end{abstract}

Keywords: boundary layer ingestion; propulsive fuselage; wake-filling; turbo-electric; proof-ofconcept; wind tunnel; fan rig; multi-disciplinary aircraft design; collaborative research

\section{Introduction}

Novel propulsion systems and their synergistic integration with the airframe are expected to play a key role in achieving aviation's long-term sustainability targets [1,2]. Therefore, significant further improvements in propulsion system overall efficiency will be required [3]. This includes the need for both, an ultra-efficient power supply to the propulsive devices as well as an ultra-efficient production of the required thrust by the propulsive devices. In order to achieve maximum propulsive efficiencies, the realization of extremely low specific thrust configurations is required. Under conventional propulsion 
system integration paradigms, the associated large propulsor diameters create a complex array of issues at the vehicular level including geometric installation challenges, aircraft drag penalties due to increased nacelle wetted areas, as well as airframe structural weight penalties in case under-wing power plant installation becomes impossible.

A particularly promising approach to elude these drawbacks and to achieve significant further improvements in overall vehicular propulsive efficiency is known from the field of marine propulsion. Ship propellers are installed at the stern of the vessel in order to utilize the kinetic energy that is contained in the boundary layer flow around the vessel's body for the production of thrust. This principle of energy recuperation via boundary layer ingesting (BLI) propulsion is also applicable to airborne systems [4]: the kinetic energy in the boundary layer flow is induced by surface skin friction as the body moves relative to the fluid. The reactive force on the body is known as viscous or skin-friction drag. In order to maintain a steady motion, the total drag of the vehicle needs to be balanced by the thrust force delivered by the propulsor. In conventional aircraft propulsion installation, propulsive thrust is produced against still air. Looking from a stationary perspective, in this case, any produced thrust results in a jet excess momentum flow in opposite direction of the vehicular motion, i.e., kinetic energy lost in the wake of the vehicle. At the same time, the kinetic energy content of the boundary layer flow around the wetted body is lost in the vehicular wake, too. By ingesting the boundary layer flow at the aft of the vehicle's body, the required thrust force is produced against the fluid being in motion together with the body. For the given thrust force, the jet flow excess momentum, and thus, the jet kinetic energy loss in the wake is reduced. At the same time, the wake kinetic energy loss associated with the ingested share of the boundary layer flow is reduced or totally eliminated, a mechanism also referred to as wake-filling.

For large commercial aircraft, the share of viscous drag in cruise typically ranges between $60-70 \%$ of the total drag. Almost half of this share may be attributed to the fuselage body, making it the most interesting airframe component to be utilized for the purpose of wake-filling propulsion integration [5]. A most straightforward way to realize fuselage wake-filling is by full annular $\left(360^{\circ}\right)$ BLI through a single propulsor encircling the very aft-section of the fuselage-also referred to as propulsive fuselage Concept (PFC). This paper summarizes the key results and findings obtained from technology readiness level (TRL) 3 research and innovation activities for a PFC aircraft featuring a turbo-electrically powered BLI fuselage fan (FF) that were performed as part the recently completed European Commission (EC) funded project CENTRELINE.

\subsection{Literature Survey of Fuselage BLI Propulsion}

The utilization of BLI as a means to increase aircraft propulsive efficiency through wake-filling has been subject to theoretical treatise over several decades (e.g., Smith and Roberts [6] (1947), Goldschmied [7] (1954), Smith [4] (1993) and Drela [8] (2009)). A first patent based on the effect of BLI and wake-filling propulsion was filed by Betz and Ackeret in 1923 [9]. A first patent describing an explicit concept for fuselage wakefilling propulsion integration was filed in 1941 [10]. Initial experimental studies related to fuselage BLI and wake-filling were conducted for the boundary layer-controlled airship body concept proposed by Goldschmied in 1957 [11]. More recently, low-speed wind tunnel experiments were performed on generic streamlined body by ONERA [12] and TU Delft [13]. Experiments have also been performed at MIT for the D8 configuration [14]. A detailed analysis of the aerodynamics of a boundary layer ingesting fan was performed in a low-speed experimental fan rig at the University of Cambridge [15]. Examples of existing aircraft utilizing aft-fuselage propulsion integration, however not explicitly designed to maximize wake-filling, include the Douglas XB-42 (1944), the RFB Fantrainer (1978), the LearAvia LearFan 2100 (1981), and the Grob GF 200 (1991).

Over the last two decades, a variety of concepts and low-TRL studies featuring propulsive devices to exploit the effect of fuselage wake-filling by BLI have been published. Beside blended wing body designs with integrated BLI propulsion such as the Silent Aircraft Ini- 
tiative "SAX-40" [16] and NASA's "N3-X" configuration [17], a number of tube-and-wing aircraft layouts equipped with fuselage BLI propulsors have been presented. Noted examples include NASA's "FuseFan" concept [18], the MIT "D8" concept [19], Bauhaus Luftfahrt "Claire Liner" [20] and "Propulsive Fuselage" [5] concepts, the EADS/AGI "VoltAir" [21], the Boeing "SUGAR Freeze" [22], and the NASA "STARC-ABL" [23,24]. The first multidisciplinary design study for large transport category aircraft featuring full annular fuselage BLI propulsion was performed as part of the EC funded research project DisPURSAL [25].

In parallel to the CENTRELINE project, an increasing level of research effort in the field of tightly-coupled wake-filling propulsion has been observed. The focus of recent research activities can be found in the aerodynamic optimization of affected aircraft components (e.g., [26-29]) and the design and optimization of the BLI propulsion system (e.g., [30-35]). With most studies still based on numerical simulation by computational fluid dynamics (CFD), also the development of dedicated experimental testing capabilities has been progressing significantly [36].

\subsection{Outline of the CENTRELINE Project}

Funded as part of the European Union's Horizon 2020 Framework Programme, the "ConcEpt validatioN sTudy foR fusElage wake-filLIng propulsioN integration", in short "CENTRELINE" (grant agreement no. 723242) was dedicated to perform the proof-ofconcept and initial experimental validation for the PFC approach. Coordinated by Bauhaus Luftfahrt, the collaborative research during the 42-month project was conducted by a consortium of key stakeholders from European industry, research, and academia. The partners involved Airbus Defence and Space, Airbus Operations, Chalmers Tekniska Hoegskola, MTU Aero Engines, Politechnika Warszawska, Rolls Royce Deutschland Ltd., Siemens AG, Delft University of Technology, the University of Cambridge, and ARTTIC. The consortium was accompanied by a technical advisory board (TAB) of senior experts from industry and research including representatives from the German Aerospace Center DLR and ONERA, the French Research Lab.

The specific PFC configuration investigated in CENTRELINE (cf. Figure 1), features a twin-engine, turbo-electric PFC systems layout with the aft-fuselage BLI fan being powered through generator offtakes from advanced Geared TurboFan (GTF) power plants podded under the wing. When compared to a mechanical drive train concept such as focused on in the previous DisPURSAL project (cf. [37]), the FF electric drive approach facilitates the BLI propulsive device to be installed at the very aft-end of the fuselage body. Consequently, the aero-structural integration at the aft fuselage is simplified, while maximizing the wake-filling potential attainable from fuselage BLI. Aft-fuselage internal thermal shielding requirements are relieved, internal and external noise and vibration is reduced, and overall system maintenance costs decrease, as the third gas turbine engine used for the mechanical FF drive in DisPURSAL is omitted. At the same time, the design complexity due to relevant rotor burst scenarios is reduced.

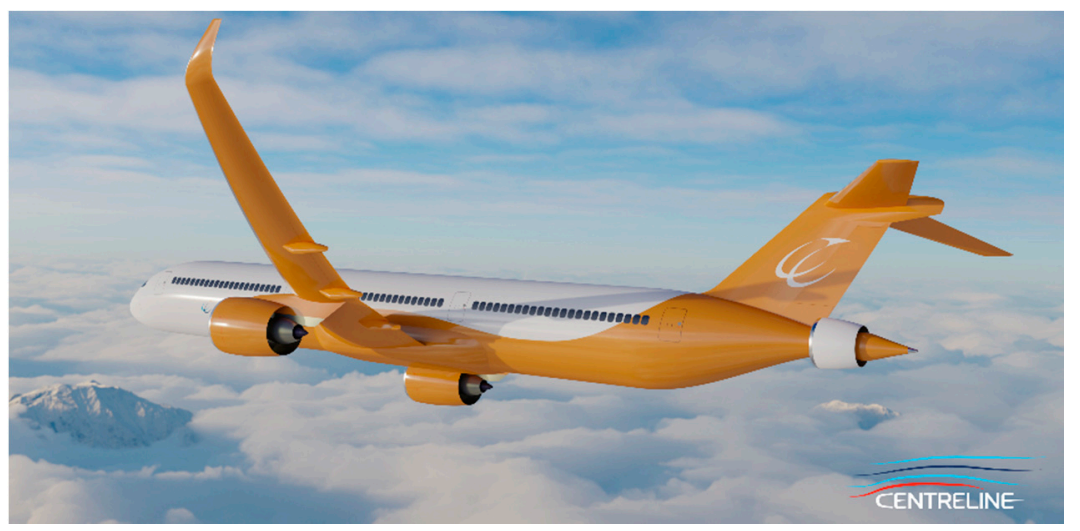

Figure 1. Artist view of the CENTRELINE turbo-electric propulsive fuselage aircraft design. 
Pursuing the conceptual proof, the main challenges associated with turbo-electric propulsive fuselage aircraft design (cf. [38]) were addressed in CENTRELINE. These included the obtainment of a thorough understanding of the aerodynamic effects of fuselage wake-filling propulsion integration, the development of suitable aero-structural design integration solutions for the BLI propulsor, the design elaboration of the FF turbo-electric drive train, as well as the multi-disciplinary systems design integration and optimization at aircraft level. As such, the CENTRELINE project aim was to maximize the benefits of fuselage wake-filling propulsion integration under realistic systems design and operating conditions. The high-level objectives at the beginning of the project stated a TRL goal of 3 to 4 at the end of the project, together with ambitions performance targets of $11 \%$ $\mathrm{CO}_{2}$ and $\mathrm{NO}_{\mathrm{x}}$ emission reductions against an advanced conventional reference aircraft equipped with aerodynamic, structural, power plant, and systems technologies suitable for a potential entry-into-service (EIS) year 2035.

\subsection{Overall Methodological Approach}

In order to address the identified key challenges for the PFC conceptual proof, in CENTRELINE, a set of problem-tailored analytical, numerical and experimental methods was employed. This included high-end and high-fidelity simulation techniques for the aerodynamics of the overall aircraft and the FF, for key structural elements as well as the components of the turbo electric drive train. For the purpose of initial experimental validation, low speed wind tunnel and BLI fan rig testing campaigns were performed. The work was organized in collaborative work packages handling the multi-disciplinary concept integration and design optimization, the detailed aerodynamic design simulation and testing, and the pre-design and integration of the FF turbo-electric power train. The TRL3 research activities were framed by a work package dedicated to deriving a realistic technology application scenario at the beginning of the project and the later critical systemlevel evaluation of the detailed research results. A visualization of the basic work logic followed is provided in Figure 2.

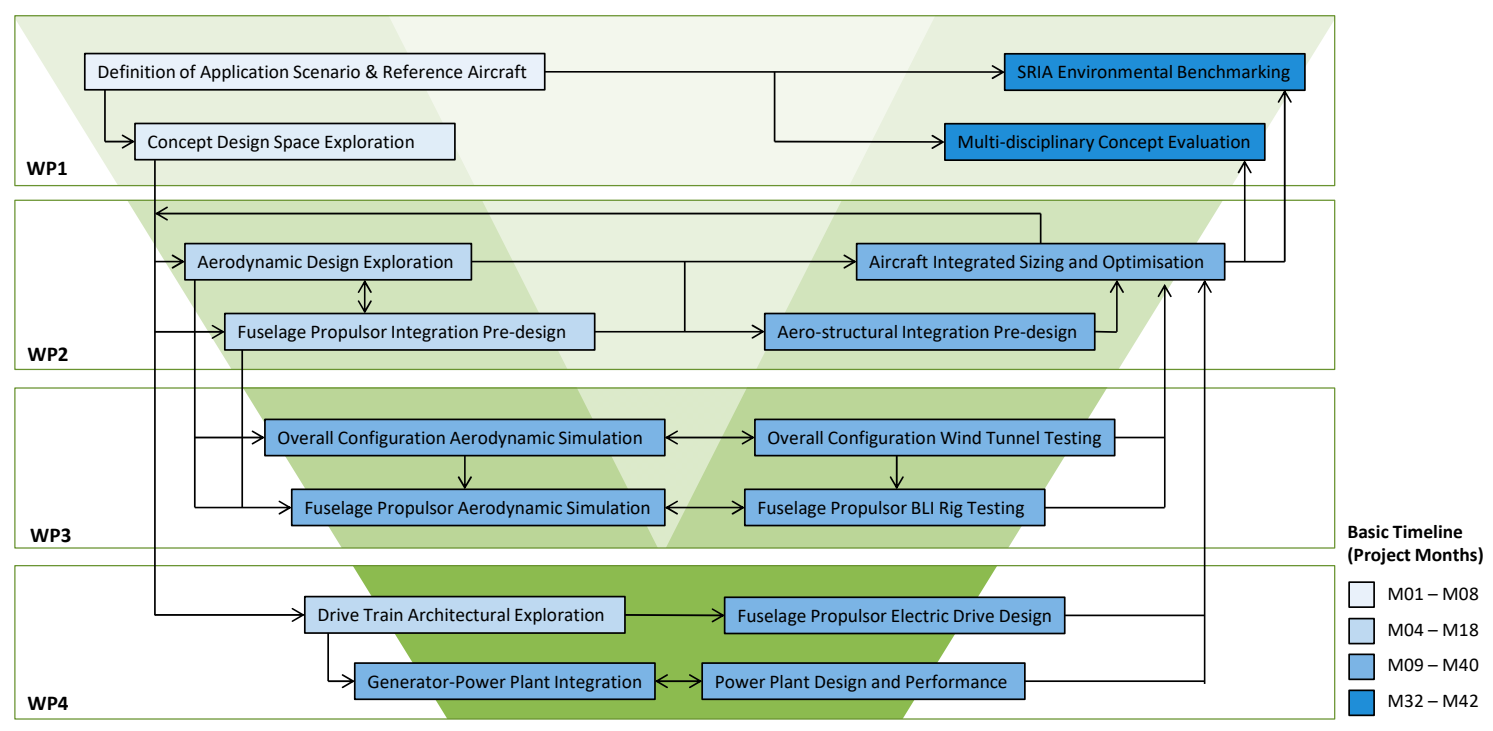

Figure 2. The basic CENTRELINE work logic.

Based on market outlook perspectives, anticipated socio-economic development trends and required transport capacities in the targeted EIS timeframe for a PFC aircraft, a most impactful market segment was identified and translated into Top Level Aircraft Requirements (TLARs). In order to allow for a rigorous evaluation of the PFC technology, two families of conventional reference aircraft were defined, reflecting year 2000 in-service aircraft, dubbed "R2000", and an advanced reference equipped with technologies suitable 
for an EIS year 2035, the "R2035". While the R2035 served as the immediate benchmark for the PFC technology, the R2000 represented the baseline for the PFC evaluation against the 2035 environmental targets set by the Strategic Research and Innovation Agenda (SRIA) [3] of the Advisory Council for Aeronautics Research in Europe (ACARE).

As part of an initial design space exploration, a most suitable aircraft layout for the PFC proof-of-concept was identified, and an initial aircraft target design was developed using simplified analytical and semi-empirical sizing methods. Completed within the first eight project months, the PFC aircraft target design served as a consistent starting point for the detailed multi-disciplinary design and analysis work, providing guidelines for key design parameters in both the numerical and experimental domains.

Starting from the derivation of unified performance bookkeeping standards for the BLI PFC and non-BLI reference aircraft, the aerodynamic design and analysis work included a comprehensive 2D numerical optimization of the axisymmetric bare PFC configuration, i.e., the isolated fuselage with installed aft-propulsive device, as well as a systematic 3D numerical analysis of the PFC aerodynamic performance properties and flow field characteristics. Based on the obtained PFC-specific FF inflow patterns, 3D numerical design for a distortion tolerant BLI fan was performed. All aero-numerical activities were closely accompanied by low-speed aerodynamic validation testing at the overall aircraft level as well as specifically for the BLI FF. The experimentally verified aerodynamic design and performance characteristics of the FF were integrated together with the 3D numerically refined aero-structural design for the key elements of the aft-fuselage propulsion installation. The FF turbo-electric power train design was elaborated under multi-disciplinary consideration, including the transmission system architectural definition, the electromagnetic and mechanical design of the involved electric machinery and the conceptual integration of the turbo-electric generators within the gas turbine environment. The impact of the significant generator power offtakes on the main engines' sizing and operational behavior was investigated through sophisticated design and performance modeling. Conceptual solutions for the thermal management of all power train components were developed and incorporated in the overall system design and performance simulation. The entireness of knowledge obtained from the detailed design and analysis activities were continuously incorporated for overall system sizing and optimization at the aircraft level. Finally, the optimized PFC aircraft family design was subjected to a comprehensive multi-disciplinary assessment against the R2035 and R2000 aircraft families.

\subsection{Technology Application Case}

The technology application case was tailored to maximize the leverage of the PFC efficiency potentials on the reduction of aviation's climate impact. To maximize the PFC technology impact at aircraft fleet level, existing forecasts of market and route development were analyzed in order to identify a most influential aircraft market segment with regard to reductions in fuel consumption. Similar to preceding analyses performed in the DisPURSAL project [25], the medium to long-range wide-body aircraft segment was determined to be particularly impactful. Judging the forecasted numbers of revenue passenger kilometers according to the specific regions, the highest demand for the aspired EIS in 2035 was identified for the Europe-Asia/Pacific inter regional connections, leading to a projected design range of $6500 \mathrm{~nm}$. At the same time, a peak demand of aircraft installed seat for this mid-to-long range market segment was identified at 340 passengers [39]. A condensed list of the CENTRELINE TLARs is given in Table 1.

As a best suited in-service aircraft with reasonably similar design mission specifications the Airbus A330 was selected as a starting point for the creation of the CENTRELINE reference aircraft models. In order to obtain the year 2000 reference aircraft, R2000, the payload-range capacity of the A330 was slightly increased by a stretch of the fuselage length and a corresponding reinforcement of key structural components such as the landing gear. In order to maintain appropriate low-speed performance, the wing planform was geometrically scaled for the increased aircraft gross weight. The tail planforms were 
adapted to retain the aircraft stability and control characteristics. The propulsion system for the R2000 is based on the most common engine option for the A330, the Rolls Royce Trent 772B. The Trent 700 series is a three-spool turbofan featuring a long duct mixed-flow nacelle. The design and performance characteristics of the Trent $772 \mathrm{~B}$ were reproduced and subsequently scaled for the R2000 thrust requirements using a design synthesis model created in Bauhaus Luftfahrt's in-house Aircraft Propulsion System Simulation (APSS) software [40-42].

Table 1. CENTRELINE top level aircraft requirements.

\begin{tabular}{cc}
\hline Parameter & Value \\
\hline Range and PAX & $6500 \mathrm{nmi}, 340 *$ PAX in 2-class \\
TOFL (MTOW, SL, ISA) & $\leq 2600 \mathrm{~m}$ \\
Second climb segment & 340PAX, $100 \mathrm{~kg}$ per PAX, DEN, ISA + 20 K \\
Time-to-climb (1500 ft to ICA, ISA + 10 K) & $\leq 25$ min \\
Initial cruise altitude (ISA + 10 K) & $\geq$ FL 330 \\
Design cruise Mach number & 0.82 \\
Maximum cruise altitude & FL410 \\
Approach speed (MLW, SL, ISA) & 140 KCAS
\end{tabular}

* Baseline family member; 296 PAX for shrink and 375 PAX for stretch version.

The R2035 advanced reference aircraft was directly derived from the R2000 aircraft. Therefore, a comprehensive technology scenario was devised, including advanced multidisciplinary technological developments in the fields of aerodynamics, structures, systems and equipment considered realistic for aircraft product integration by $2035[39,43]$. Figure 3 shows a simplified three-view drawing of the R2035 with selected aircraft dimensions annotated. Compared to the R2000, the R2035 features a larger cabin cross section with a nine-abreast (two-five-two) economy seating arrangement. An obvious feature of the R2035 aircraft design is the slender wing featuring an aspect ratio of 12 enabled by an advanced composite design and improved aero-elastic tailoring capabilities.

In order to facilitate a realistic evaluation of the PFC technology, aircraft family design considerations were taken into account throughout the aircraft design and benchmarking process. The R2000 and R2035 aircraft were designed as families consisting of a baseline, shrink, and stretch version. The family design was conducted in accordance to common industry practice and the goal of sharing common components as empennage, landing gear and engines. The stretch and shrink versions of the baseline aircraft feature $+10 \%$ and $-15 \%$ payload capacity, respectively. The R2035 power plant systems are Ultra-High Bypass Ratio (UHBR) $>16$ geared turbofan engines, sized to serve the entire aircraft family. Power plant thermodynamic cycle parameters and component design properties were selected appropriately to reflect advanced aerodynamics, materials, and manufacturing technologies for an EIS 2035 [42]. At typical cruise conditions, i.e., FL350, M0.82 and a lift coefficient $C_{L}=0.5$, the baseline member of the R2035 family features a lift-to-drag ratio of 20.7 , with an induced drag share of $28 \%$ and a wave drag share of $5 \%$. The fuselage share of the total is approximately $26 \%$. Further characteristics including aircraft weight component breakdowns and block fuel values for the R2000 and R2035 aircraft are provided in Section 7.3 in comparison to the corresponding PFC aircraft properties. More detailed descriptions of the CENTRELINE reference aircraft families were presented by [39].

In order to set a consistent basis for the more detailed design and analysis activities, in CENTRELINE, an initial PFC aircraft design was specified through qualitative configurational down-selection and a subsequent preliminary multidisciplinary design loop for the selected PFC aircraft layout. From an initial cloud of configurational candidates featuring alternative approaches to the aero-structural integration of the aft-fuselage BLI propulsive device as well as different empennage integration options, a PFC aircraft configuration comprising a T-tail arrangement with the ducted BLI fan integrated behind the vertical fin was selected as a most suitable basis for the further detailed studies in CENTRELINE (cf. [44]). With the basic configurational layout identified, an initial PFC aircraft target 
design was derived from a multi-disciplinary design study based on simplified analytical and semi-empirical methodology (cf. [43]). The design synthesis included estimated properties of the FF turbo-electric power train, PFC airframe structural weight and main power plant design implications, as well as performance targets for the PFC aero-shaping in order to meet the project's performance goal in terms $\mathrm{CO}_{2}$ reduction. As a result, an operating empty weight (OEW) increase of $5.7 \%$ relative to the R2035 was predicted, which together with a target design block fuel improved of $11 \%$ yielded an almost identical maximum take-off weight (MTOW) as for the R2035 aircraft [43]. Key design features of the initial PFC aircraft design are illustrated in Figure 4.

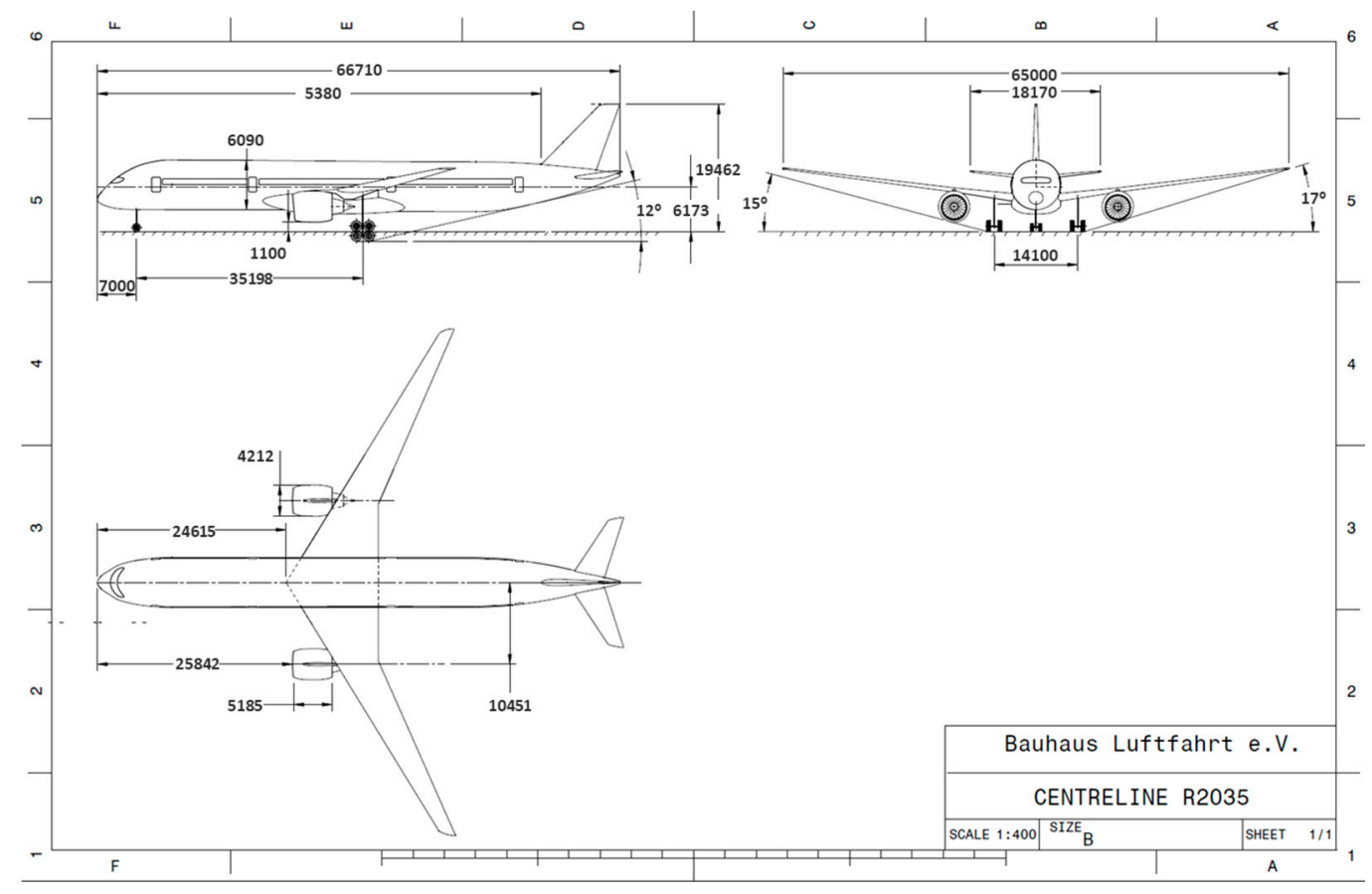

Figure 3. Schematic three-view of the CENTRELINE R2035 baseline aircraft.

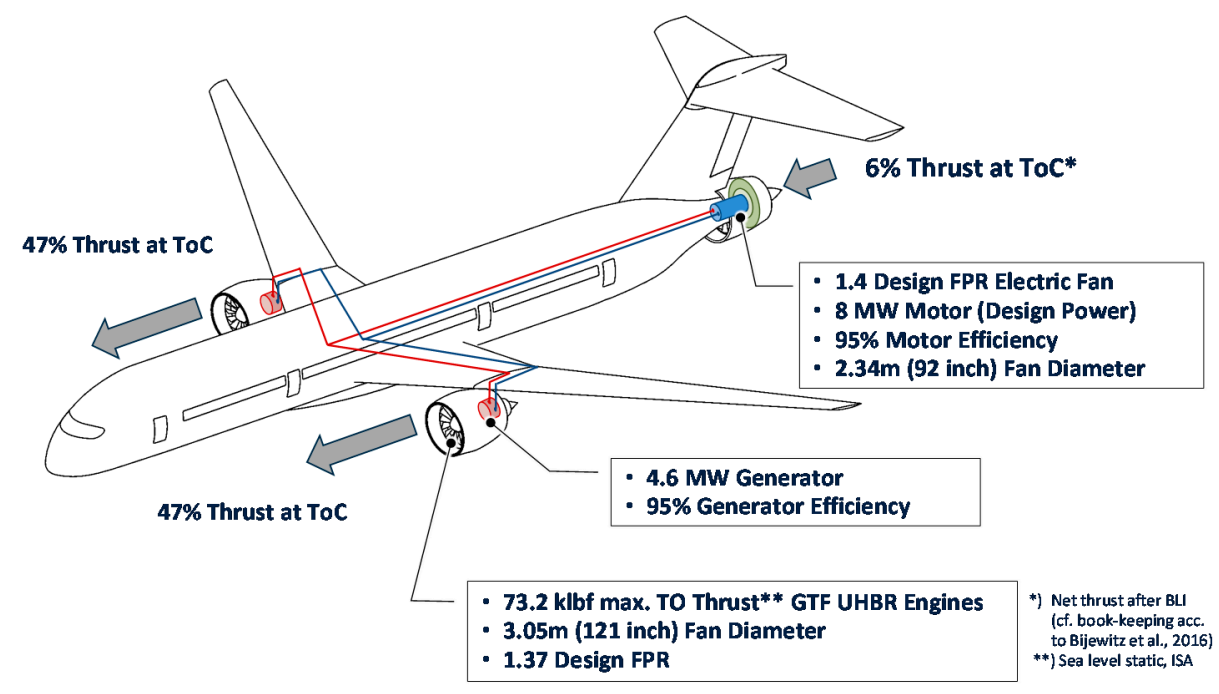

Figure 4. Main design features of the CENTRELINE initial propulsive fuselage target design (adapted from [43]). 


\section{Fuselage BLI Propulsion Aerodynamics}

Key requisites for a meaningful evaluation of the fuselage BLI technology include a rigorous bookkeeping of the aerodynamic interaction between the BLI propulsion system and the airframe as well as a sufficiently refined aerodynamic shaping of the aircraft. This section discusses the performance bookkeeping standards followed in CENTRELINE and presents key aspects of the aerodynamic design and analysis activities at the overall configuration and the FF level.

\subsection{Performance Bookkeeping and Efficiency Metrics}

The assessment of aircraft concepts with highly integrated propulsion systems, such as the CENTRELINE configuration, requires adherence to rigorous bookkeeping standards and consistent performance assessment metrics. A comprehensive review of existing bookkeeping schemes and their applicability to aircraft concepts with a strong coupling of airframe aerodynamics and propulsion system can be found in [45]. In general, bookkeeping schemes can be classified by the quantity, which is conserved in a specified control volume. Approaches based on momentum conservation allow consistency with force bookkeeping, but are often neglecting the bi-directional effect of airframe aerodynamics and propulsion system performance. Integral energy methods use kinetic energy or exergy conservation. The "Power Balance" method introduced by Drela in 2009 [8], reflects the need for a holistic bookkeeping approach applicable to highly integrated propulsion system concepts. Similar to the "Exergy Balance" method, later developed by Arntz [46], the evaluation of BLI configurations requires the full resolution of the flow field, which is achieved through experimental test or CFD simulations.

Within the CENTRELINE project, two different bookkeeping approaches were employed: The power balance method and an integral momentum conservation approach. The application of the power balance method is very resource demanding, because it requires the full resolution of the flow field. Therefore, it was solely applied to analyze the wind tunnel particle image velocimetry (PIV) measurement results of a single PFC configuration at the end of the project in order to estimate the experimental BLI performance in detail $[47,48]$.

For the aircraft-level sizing studies, an integral momentum conservation approach was deemed to be most practicable together with a distinction between the bare PFC configuration, i.e., the integrated assembly of the fuselage and the fuselage BLI propulsive device, and, all other adjacent aircraft components [45]. The control volume for the bare PFC configuration is pictured in Figure 5. It allows for the rapid evaluation of the bare PFC configuration aerodynamics and performance properties, e.g., based on a 2D axisymmetric shape definition (see Section 2.2).

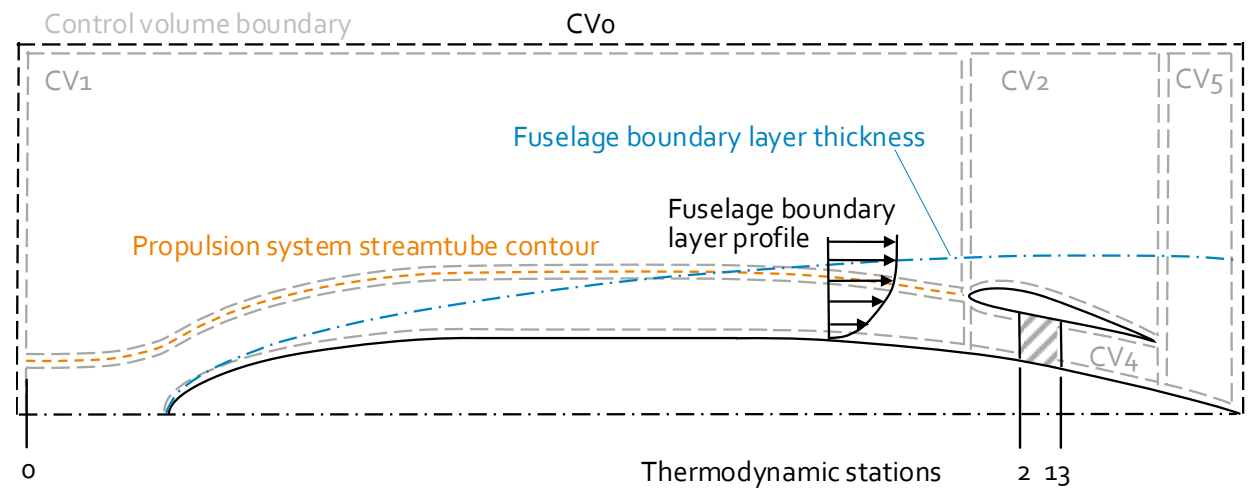

Figure 5. Control volume scheme for bare PFC bookkeeping (adapted from [45]). 
As a key descriptor for the bare PFC configuration, the net propulsive force $N P F_{P F C \text {, bare }}$ is introduced, representing the net axial force acting on the bare PFC configuration. It is the result of an integral momentum conservation applied to the depicted control volume

$$
N P F_{P F C, \text { bare }}=F_{F F, \text { disc }}+F_{F u s}+F_{A f t b o d y}+F_{F F, N a c}+F_{F F, D u c t}=F_{F F, \text { Disc }}+F_{P F C, \text { bare }}
$$

$F_{F F, D i s c}$ represents the axial force produced by the FF (between the thermodynamic stations 2 and 13). $F_{F u s}$ is the total aerodynamic force of the fuselage up to the BLI propulsion system air intake, $F_{\text {Aftbody }}$ is the total force on the (fuselage) aft-body behind the BLI propulsor nozzle exit, $F_{F F, N a c}$ is the total force of the FF nacelle external surface area, and, $F_{F F, D u c t}$ represents the total force due to the FF duct internal flow. $F_{P F C \text {,bare }}$ is the sum of all surface forces acting on the bare fuselage-propulsor configuration. All total force components include both, viscous as well as surface pressure related axial forces [45].

The total aircraft drag force $D_{t o t}$, i.e., the sum of all forces acting on the individual component surfaces, plus possible interference drag e.g., between the bare PFC and adjacent airframe components $D_{\text {int }}$, miscellaneous drag items such as due to protuberances and leakages $D_{\text {misc }}$. With potential flow buoyancy terms of the individual components assumed to be zero for the closed aircraft body, the $D_{\text {tot }}$ for the PFC aircraft becomes

$$
D_{P F C, \text { tot }}=F_{P F C, \text { bare }}+F_{P F C, \text { res }}+D_{P F C, \text { int }}+D_{P F C, \text { misc }}=F_{P F C, \text { bare }}+D_{P F C, \text { res }}
$$

where $F_{P F C \text {,res }}$ represents the sum of aerodynamic forces acting on the surfaces of all aircraft component forces other than the bare PFC configuration, i.e., including the wing and empennage, any required fairings, as well as, the underwing podded nacelles and pylons. For convenience, the sum of $F_{P F C, r e s}, D_{P F C \text {,int, }}$ and $D_{P F C \text {, misc }}$ may be written as $D_{P F C, r e s}$. It should be noted, that the total drag of a non-BLI reference aircraft $D_{\text {Ref,tot }}$ is directly

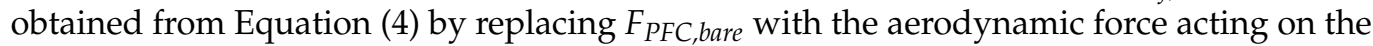
reference aircraft fuselage $F_{\text {Ref,fus }}$, and, evaluating all other aerodynamic forces and drag numbers specifically for the reference aircraft.

Assuming steady level flight, the overall propulsion net thrust requirements $F_{N}$ equal the aircraft total drag force. With the bare PFC net propulsive force defined in Equation (1), the overall net thrust requirement for the non-BLI main power plants of the PFC aircraft yields

$$
F_{N, P F C, \text { main }}=D_{P F C, \text { res }}-N P F_{P F C, \text { bare }}
$$

An overview of relevant figures of merit for the performance assessment of wakefilling propulsion system concepts—such as the CENTRELINE PFC configuration-is provided by Habermann et al. [45]. As a means of aerodynamic inter-comparison of alternative PFC designs, the bare PFC efficiency factor $f_{\eta, P F C, \text { bare }}$ is particularly relevant. It relates the net useful propulsive power of the bare PFC configuration, i.e., the product of

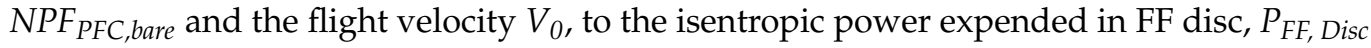

$$
f_{\eta, P F C, \text { bare }}=\frac{N P F_{P F C, \text { bare }} \cdot V_{0}}{P_{F F, \text { disc }}} \quad \forall P_{\text {disc }, F F}>0
$$

For PFC aircraft design optimality considerations and performance assessment purposes against the conventional reference aircraft, integral mission figures of merits are used (see Section 7). This includes the design mission block fuel as well as the corresponding $\mathrm{CO}_{2}$ reduction potential calculated based on jet fuel-specific emission factor of $3.150 \mathrm{~kg}$ $\mathrm{CO}_{2} / \mathrm{kg}$ fuel postulated in [49]. For the assessment of PFC point performance against the non-wake-filling reference, the power saving coefficient, (PSC), originally introduced by [4], is applied

$$
P S C=\frac{P_{\text {Ref }}-P_{P F C}}{P_{\text {Ref }}}
$$

where $P_{\text {Ref }}$ refers to the power required to operate the aircraft in the conventional, nonwake-filling case, and $P_{P F C}$ represents the power requirement of the PFC configuration. 
A detailed discussion of the PSC application to PFC aircraft performance evaluation is presented by [50]. An analytical formulation of the PSC coefficient for PFC aircraft in cruise is provided in Section 7.1.

\subsection{Bare PFC 2D Aerodynamic Design Optimization}

To find a feasible and well-refined aerodynamic design for the PFC, at first the aerodynamic design space for cruise conditions needs to be thoroughly explored. In order to accomplish this, a responsive and suitably accurate aerodynamic analysis method needs to be adopted. All key relevant parameters that influence the aerodynamic performance of the PFC need to be investigated. In order to maximize the gain of knowledge and to reduce the complexity at the early stage of the project, an optimization of the bare PFC configuration based on axisymmetric paradigms was focused on. The optimized axisymmetric aero-shaping formed the basis for the final three-dimensional design of the PFC.

\subsubsection{Aerodynamic Design Space}

The aerodynamic design space of the PFC is comprised of geometric and operational parameters. Examples of the former include the fuselage slenderness ratio, FF nacelle incidence angle and aft-body contraction ratio. Examples of operational parameters are the cruise flight level, flight Mach number and fan pressure ratio (FPR) of the FF. The PFC will be optimized for a given design cruise mission and benchmarked against a R2035 reference aircraft for the same mission. Nevertheless, it is also worthwhile to investigate the sensitivity of the PFC to the flight conditions (see Section 7.1).

The initial phase of the design phase consisted of design modifications of an initial aerodynamic model based on engineering judgement. Even though the initial design was improved significantly, the complex aerodynamic interactions halted further improvements. The last design revision based on iterative design is called "Rev05".

To explore the design space in a more systematic manner, a fully parametric model was developed capturing the axisymmetric shape of the bare PFC configuration. Using a combination of Non-Uniform Rational B-splines (NURBS) [51] and Bezier-Parsec [52], the parametric model describes the PFC geometry based on actual design parameters instead of free-floating control points: The aft fuselage geometry ahead of the aft propulsor was defined in terms of curvature and contraction ratio. The contour of the FF annular ducting was determined by cross-section area ratios as functions of the FF disc area. The nacelle contour was described through Bezier-Parsec parameterization. The boat tail shape follows from the overall fuselage length and the axial FF location. First order continuity between the various segments ensure smooth curvature transitions. Constraints were added, for example to limit the overall fuselage length and avoid very short or slender boat tail designs. Furthermore, it was ensured that the usable floor for each design was the same. In total 23 variables were used to describe the geometry, together with the following operating conditions: Mach number, altitude/flight level (FL), FPR [53].

\subsubsection{Numerical Methods}

To analyze the large variety of PFC designs, an aerodynamic solver is required which is able to capture even subtle differences in the design and at the same time have low or moderate computational demand to avoid bottlenecks in the assessment. In CENTRELINE, it was decided to use axisymmetric 2D Reynolds-averaged Navier-Stokes (RANS) CFD simulations, which are able to capture the mean flow characteristics and boundary layer development over the fuselage with appropriate accuracy. The axisymmetric 2D grids were sufficiently small to be able to run on a standard engineering workstation. In most cases, the generation of the grid consumed the majority of time required to obtain a CFD solution. In order to drastically reduce the person effort of geometry meshing, an automated mesh routine was developed. Using an open-source MATLAB-toolbox [54], a MATLAB-based framework was developed that executes all steps from the initial design vector to geometry-creation and meshing to post-processing of the results [53]. 
The structured hexahedral mesh was constructed using ICEM ${ }^{\circledR}$ by Ansys Inc. (Canonsburg, Pennsylvania, United States). In order to fully resolve the boundary layer up to the wall, it was ensured that the mesh satisfies the requirement $\mathrm{y}^{+}<1$. To model turbulence, the $k-w$ shear stress transport (SST) model [55] was selected. The air was modeled as an ideal compressible gas with Sutherland's three-coefficient law. A pressure-coupled solver was employed to accelerate convergence of the simulation. The domain boundary was modeled using a pressure far field boundary condition. The simulations were performed in Fluent ${ }^{\circledR} 18.2$ by Ansys Inc. (Canonsburg, Pennsylvania, United States).

To model the effect of the FF on the fluid, an actuator disc model was used based on source terms of momentum and energy. The source terms appear directly in the righthand side of the momentum and energy equations. A dedicated volume in the mesh was constructed, representing the boxed-volume of the FF. Note that only axial momentum is added and no swirl is added to the flow. Since the fluid is modeled to be compressible, energy is added to the fluid based on the local work of the momentum source in axial direction. Verification and validation of the actuator disc model is discussed in brief in [50].

The volumetric integration of the momentum source term directly yields the force of the actuator disc provided to the fluid. As such, traditional drag numbers by integration of the wall shear force and pressure wall-normal component, can still be used to assess the drag force of the PFC. The latter is beneficial, as it is a very straightforward and unambiguous method for the bookkeeping of the aerodynamic forces.

\subsubsection{Optimization Results}

Finding the optimum bare fuselage design requires a systematic survey of the aerodynamic design space, sweeping as much of the available design space as possible. To do so, designed experiments based on a partially stratified sampling method [56] was selected to cover the aerodynamic design space. The average computation time for the simulation of a single sample, including pre- and post-processing, was approximately $10 \mathrm{~min}$, on a state-of-the-art personal computer. In total, more than 9000 samples of the design space were evaluated. Of this initial number of samples, approximately one-third of the simulations converged and were used for further analysis. A 1D sensitivity study was carried out to evaluate sensitivities of each design parameter [53]. It was found that the following parameters, beside the operational parameters, drive the aerodynamic performance of the PFC the most:

- $\quad$ FF duct height $\left(\mathrm{r}_{\text {tip }}-\mathrm{r}_{\text {hub }}\right)$

- $\quad$ FF nozzle exit to fan face area ratio $\left(\mathrm{A}_{18} / \mathrm{A}_{12}\right)$

- FF hub-to-tip ratio ( $\left.\mathrm{r}_{\text {hub }} / \mathrm{r}_{\text {tip }}\right)$

- $\quad F F$ relative axial position along the fuselage $\left(\mathrm{x}_{\mathrm{FF}} / \mathrm{L}_{\mathrm{fus}}\right)$

Using the above principal design parameters, a surrogate model based on the technique presented by [57] was fitted to the results. From the pool of evaluated designs, the most promising design was selected for further optimization. Using a gradient-based solver from the MATLAB ${ }^{\circledR}$ Optimization Toolbox by The Mathworks Inc. (Natick, Massachusetts, United States), the design was optimized. As a second step, the design was further refined by including the knowledge of the sensitivity study for the parameters not included in the surrogate model. Verification in CFD confirmed that the new design "Rev06" was improved significantly over the previous design iterations. The evolution of the axisymmetric bare PFC performance is shown in Figure 6. Note that the aerodynamic performance is expressed as the ratio between the product of NPF with flight velocity and the ideal (isentropic) shaft power of the FF, $P_{F F, \text { disc }}$. 


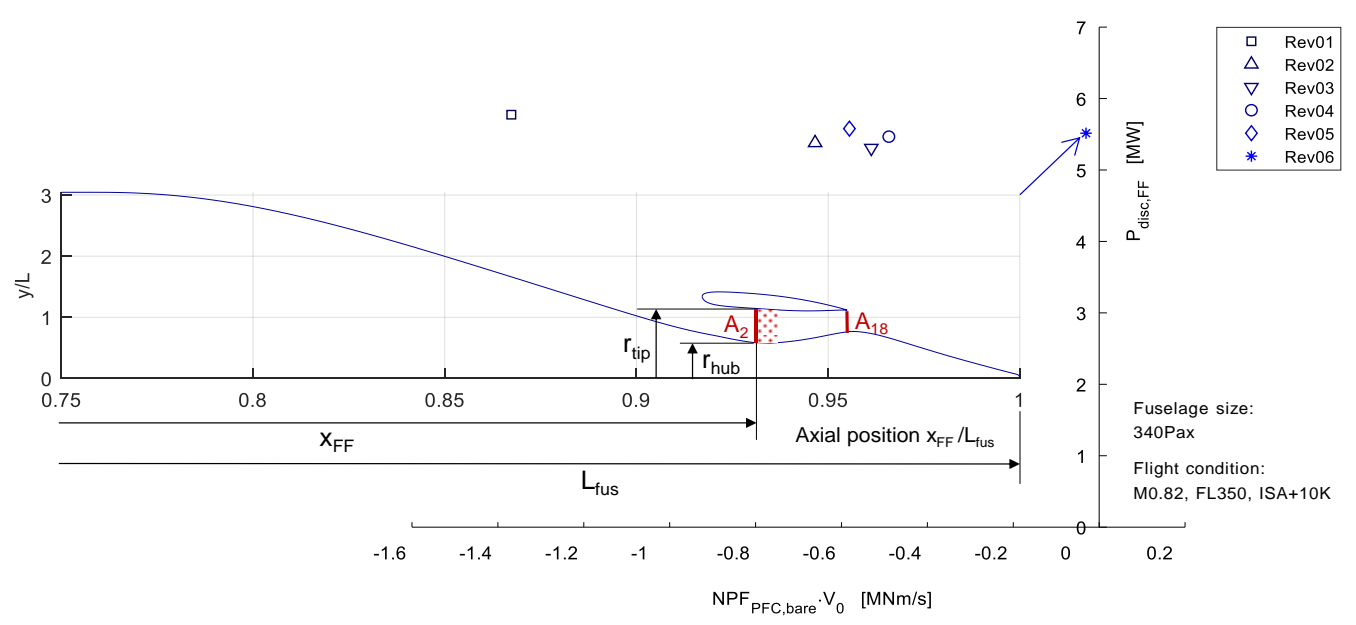

Figure 6. Evolution of the aerodynamic performance of the bare PFC fuselage (adapted from [50]).

To align the optimized design with the target values of the pre-design studies [43], the Rev06 optimization was modified to meet the following additional equality constraints:

- $\quad$ FPR equal to 1.40

- Fuselage diameter constrained to $6.09 \mathrm{~m}$

- Hub-to-tip ratio equal to 0.51

Based on the obtained "Rev07" design, which represents the final axisymmetric bare fuselage design, three case studies were performed and simulated based on various targets of $P_{F F, \text { disc }}$. An overview of the variants of the Rev07 with different FF shaft power requirements is presented in Figure 7.

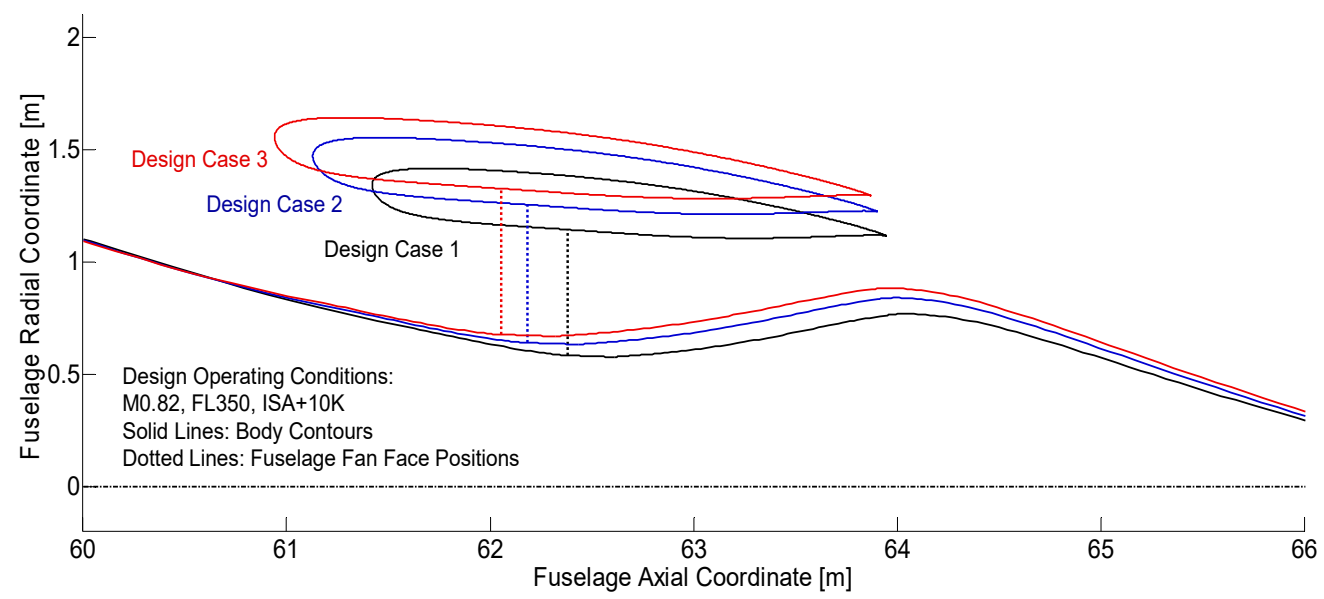

Figure 7. Changes in FF geometry of the Rev07 PFC design for different target FF shaft power.

An overview of the corresponding aerodynamic performance for each Rev07 design case study is presented in Table 2 .

As can be observed from Table 2, the NPF force for the bare PFC becomes positive if the duct height of the FF is increased beyond a certain threshold. For a given FPR, the force exerted by the FF on the fluid is directly proportional to the area of the disc, which scales quadratically with the blade radius. Despite an increase of drag for the bare PFC for case 2 and 3, the BLI efficiency factor is increased for the design cases with a higher FF duct height. Note that the additional benefit for an increased FF duct height is decreasing, as the amount of additional momentum deficit that is ingested is diminishing towards higher duct heights of the FF (see also Section 7.1). 
Table 2. Overview of the main aerodynamic performance parameters for three different case studies based on the Rev07 axisymmetric bare PFC design.

\begin{tabular}{ccccc}
\hline Parameter & Unit & Design Case 1 & Design Case 2 & Design Case 3 \\
\hline$F_{P F C, \text { bare }}$ & $\mathrm{kN}$ & 33.17 & 35.52 & 36.84 \\
$F_{F F, \text { disc }}$ & $\mathrm{kN}$ & 32.44 & 39.32 & 44.02 \\
$N P F_{P F C, \text { bare }}$ & $\mathrm{kN}$ & -0.73 & 3.80 & 7.18 \\
$P_{F F, \text { disc }}$ & $\mathrm{MW}$ & 5.53 & 6.80 & 7.76 \\
$f_{\eta, P F C, \text { bare }}$ & - & -0.033 & 0.139 & 0.229 \\
\hline
\end{tabular}

\subsection{PFC Aircraft 3D Aero-Numerical Analysis}

Having obtained a feasible and much improved axisymmetric bare PFC design, a three-dimensional model of the PFC is constructed to analyze the aerodynamics of the PFC in more detail. The aim of the 3D CFD simulations is twofold, namely to obtain more detailed inflow conditions for the further development of the FF and to verify the main aerodynamic design of the PFC. In order to understand the effect of an increased level of model complexity on the aerodynamics of the PFC, a step-by-step approach was followed starting from the 3D simulation of the bare PFC configuration while successively adding the directly adjacent aircraft components, namely the wing including fuselage belly fairing and the vertical tail. The geometry of the full PFC aircraft model, which was aerodynamically studied is shown in Figure 8.

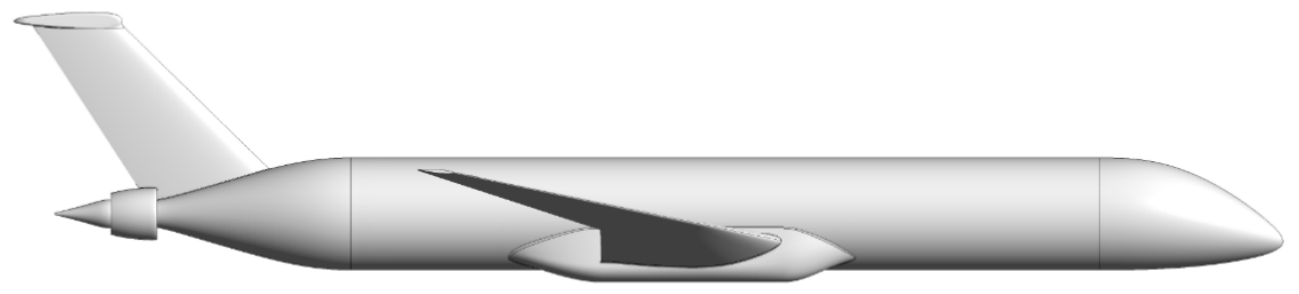

Figure 8. Side-view of the aerodynamic model of the PFC, including wing and vertical tail.

Note that the podded under-the-wing engines and horizontal tail have not been included in the aerodynamic model to reduce the complexity and size of the numerical grid. A symmetry boundary condition was applied to half the computational domain. The numerical setup has been kept as similar as possible to the bare axisymmetric CFD, as discussed in the previous section.

Since the increased model complexity is less suited for a structured hexahedral mesh, an unstructured tetrahedral mesh has been applied with mesh inflation layers to capture the boundary layer in an accurate manner. In total 30 inflation layers were applied, using an exponential growth law with $r=1.15$. It was ensured that $y^{+}<1$. Two bodies of influence were added on the wing and the fuselage to refine the volume mesh along the bodies and near-wake. The grid size for the half-model of the PFC, as shown in Figure 8, exceeded 120 million elements.

Before proceeding with the $3 \mathrm{D}$ analysis of the PFC, the $2 \mathrm{D}$ axisymmetric results where compared with the 3D simulation of the bare axisymmetric PFC. It was found that the difference in drag was in the order of 3\% due to numerical differences. Considering that a systematic mesh dependency study for the 3D mesh has not been part of this work, the difference is considered to be within the acceptable error margin. 


\subsubsection{Effect of Wing and Empennage}

To investigate the effect of the wings and vertical tail on the inflow conditions to the FF, the wings and vertical tail are added step-by-step. To assess the inflow conditions, a total pressure coefficient is defined as

$$
P C=\frac{p_{A I P}-\overline{p_{A I P}}}{\overline{p_{A I P}}}
$$

where $p_{A I P}$ is the local total pressure and $\overline{p_{A I P}}$ the mean total pressure across a specified area. The inflow conditions are measured at the aerodynamic interface plane $(A I P)$, which is located at $60 \%$ of the inlet to the FF inside the FF duct. The results for the effect of wing and empennage are shown in Figure 9.

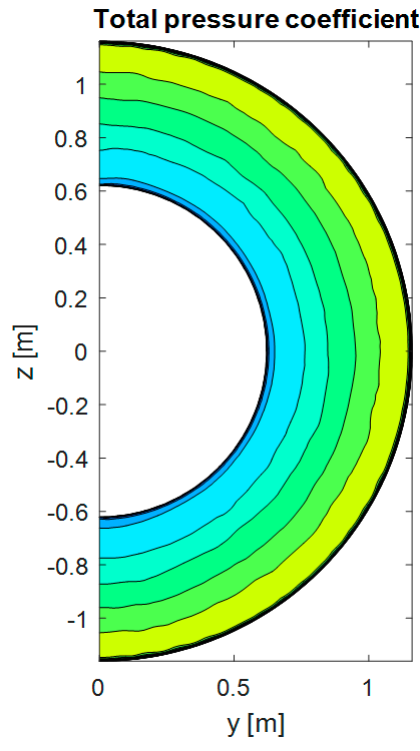

(a)

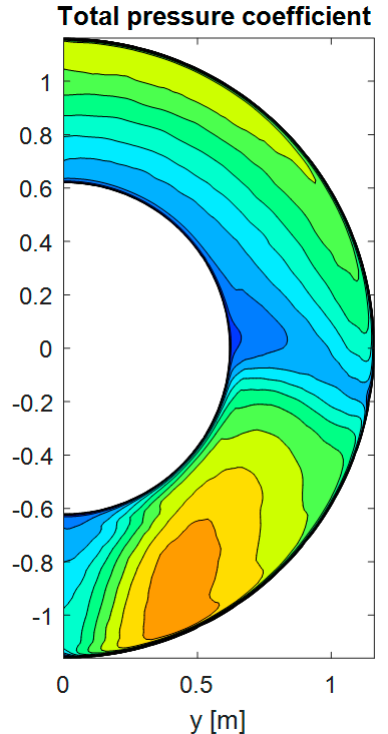

(b)

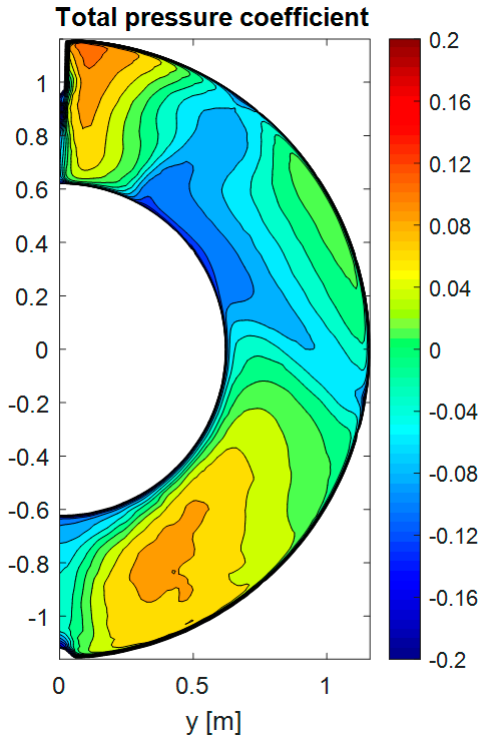

(c)

Figure 9. Contours of total pressure coefficient at the AIP. (a) bare PFC configuration, (b) bare PFC configuration + wing and (c) bare PFC configuration + wing + vertical tail (Source: [58]).

As can be observed, the inflow for the bare fuselage is relatively smooth, with the largest variation in total pressure coefficient near the hub. However, the addition of the wing appears to have a significant impact on the inflow conditions. In the lower half of the disc, there is a zone of significantly higher total pressure. The boundary layer along the fuselage hub, marked by lower levels of total pressure coefficient, is washed upwards. After adding the vertical tail, another zone of higher total pressure can be found on the upper side of the disc. Note that the AIP is intersected by the vertical tail.

Analysis of the external flow field revealed that there is flow separation on the lower side of the belly fairing. The separated flow forms a trailing vortex, which impinges on the nacelle of the FF. The core of the vortex is not ingested by the FF, however air is drawn in from the outer layers of the boundary layer and the freestream. As such, there is an inflow of air of higher total pressure to the duct of the FF. Other than causing a significant disturbance to the FF, the flow separation at the belly fairing is a source of additional drag. The belly fairing design has not been part of the aerodynamic shape refinement, hence it is expected that a redesigned belly fairing should reduce the disturbance to the FF considerably. Similarly, it was found that the zone of higher total pressure coefficient at the top of the AIP is caused by a vortex as well, stemming from the fuselage-tail junction. The latter is much more difficult to avoid; however, the horse-shoe vortex could maybe be reduced with additional fairing design [59]. 


\subsubsection{Effect of Fuselage Upsweep}

Although the axisymmetric aft fuselage is beneficial from an aerodynamic standpoint, it does limit the tail strike angle during take-off rotation of the airplane. To avoid excessive landing gear lengths, the introduction of an aft-fuselage upsweep was investigated. The upsweep was defined by a vertical offset of the FF hub by $600 \mathrm{~mm}$. The fuselage contour was adapted to avoid severe flow separation, however, no iterative design changes have been made to fine-tune the aft-fuselage contour. As can be seen from Figure 10, the inflow pattern to the FF is similar, even though a more pronounced up-wash along the fuselage hub can be noted. Furthermore, it can be noted that the effect of the horse-shoe vortex is more pronounced as the contraction of the aft fuselage is less on the upper side for the PFC with aft-fuselage upsweep. Compared to the axisymmetric PFC aircraft, the fuselage upsweep increased the overall drag by $0.7 \%$. Improvements to the design, such as a refined aft-fuselage shaping and adaption of the nacelle for non-axisymmetric flow could reduce the drag penalty. Detailed discussion of the performed 3D aero-numerical analyses is provided by van Sluis and Della Corte [58].

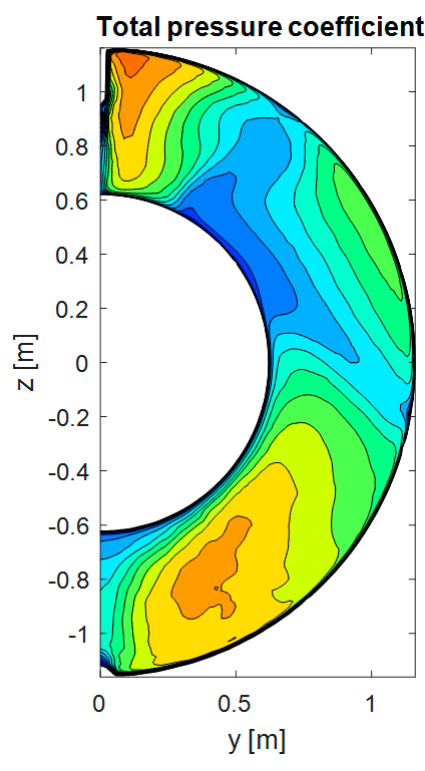

(a)

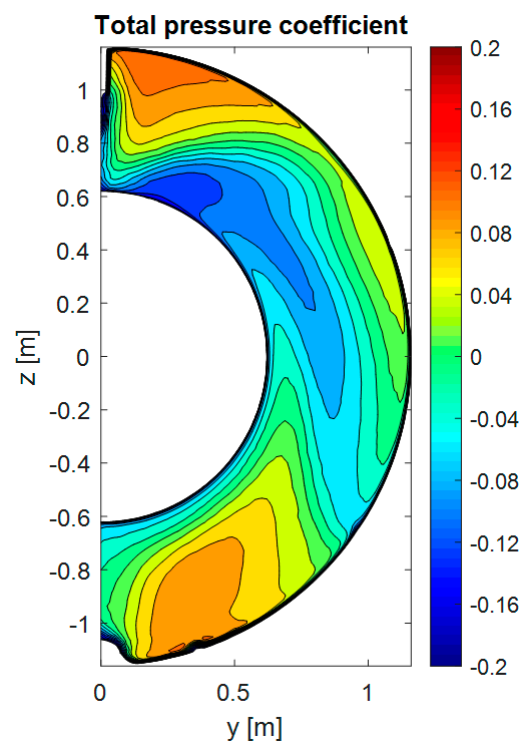

(b)

Figure 10. Contours of total pressure coefficient at the AIP. (a) PFC with axisymmetric aft fuselage, (b) PFC with aft-fuselage upsweep (Source: [58]).

\subsection{Fuselage Fan Aerodynamic Design and Performance}

The BLI fan at the fuselage aft-section has been designed and analyzed using 3D CFD. The solver used is the GPU-accelerated CFD code Turbostream [60]. It is a 3D, unsteady, RANS solver running on structured multi-block meshes. The one-equation Spalart-Allmaras turbulence model [61] was used for all simulations along with adaptive wall functions and $\mathrm{y}^{+}$of approximately 5 on all solid walls. The inlet and outlet boundaries were located one fan diameter away from the fan to allow the free interaction between the fan and the flow.

During the design phase, the flow at the inlet of the fan was assumed axisymmetric. Radially non-uniform profiles of stagnation pressure were extracted at the propulsor AIP for different operating points [58]. These correspond to continuous hub-low stagnation pressure distortion profiles. An example of the distortion profile found during cruise has been previously shown in Figure 9a. These profiles have been prescribed as inlet boundary conditions. An additional clean uniform inlet boundary condition was used to replicate the conditions at which a conventional podded fan would operate. 
Two separate transonic fan stages have been designed and analyzed for the basic operating conditions listed in Table 3. The first fan stage, called Fan A, was designed for clean uniform flow at cruise aerodynamic design point (ADP) conditions. The second one, Fan B, was designed to match the severe continuous hub-low BLI inflow.

Table 3. Aerodynamic design point parameters of CENTRELINE FF.

\begin{tabular}{ccc}
\hline Parameter & Unit & Value \\
\hline Flight altitude & $\mathrm{ft}$ & 35,000 \\
Flight Mach number & - & 0.82 \\
Flow coefficient & - & 0.69 \\
Stage loading coefficient & - & 0.45 \\
Stage pressure ratio & - & 1.4 \\
Rotor inlet tip Mach number & - & 1.24 \\
Rotor inlet hub-to-tip-ratio & - & 0.51 \\
Running tip clearance (\% span) & $\%$ & 0.2 \\
Number of rotor/stator blades & - & $20 / 43$ \\
\hline
\end{tabular}

The main characteristics of Fan A are: midspan loaded work distribution, alignment of the leading edge with the flow for minimum pressure loss and controlled solidity distribution to minimize Lieblein's diffusion factor. More information on the design of Fan A can be found in [62]. Fan A has been tested under uniform and distorted inflow conditions to assess the effect of BLI and to derive the design changes required for an aft-section fan.

For a fixed mass flow, the deficit of axial velocity associated to hub-low distortion is balanced by an increase in axial velocity in the upper part of the span shown in Figure 11a. The decrease in velocity has a twofold effect: an increase of the local incidence into the rotor blade as visualized in Figure $11 \mathrm{~b}$ and a rise of the local work load as indicated in Figure 11c. The opposite trends are found in the upper part of the span where there is an excess of mass flow. The overall effect of BLI distortion on the performance of the fan is driven by the upper part of the blade. Consequently, a consistent drop in work input is shown in Figure 12a for the $100 \%$ corrected speed line. The continuous operation of the blade at off-design results in an efficiency degradation displayed in Figure 12c. The combination of reduced work input and efficiency ultimately results in a reduction in stage pressure ratio shown in Figure 12b and thrust produced. Lastly, the flow capacity of the fan is reduced and the stability margin slightly increased.
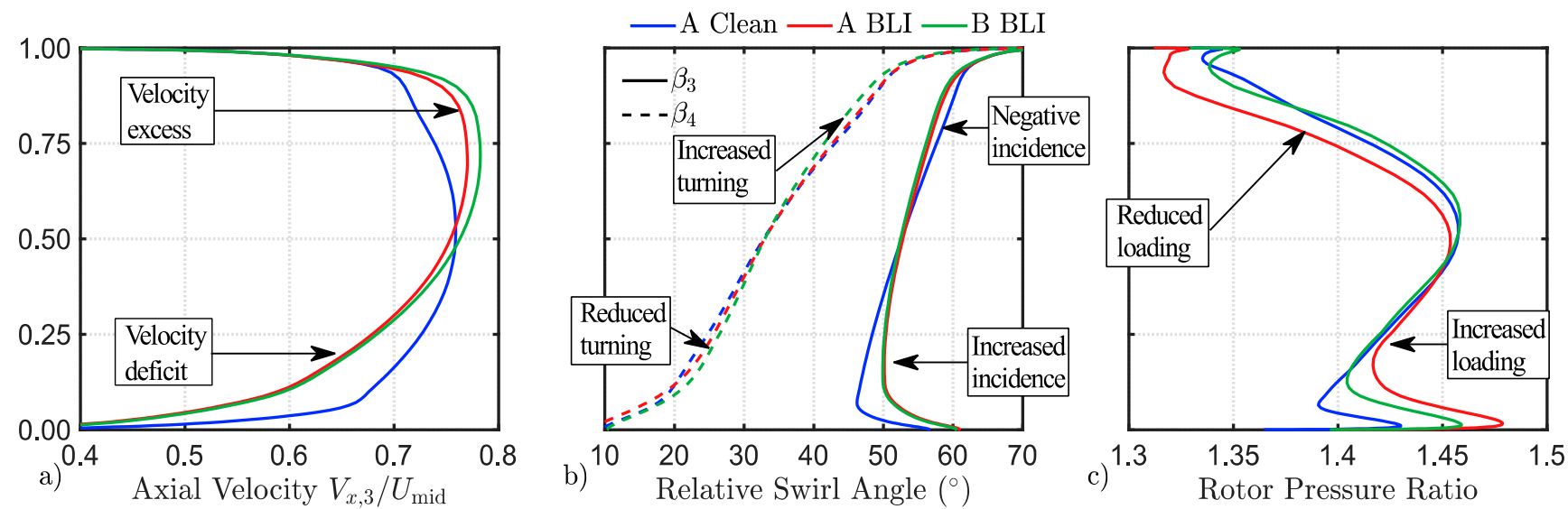

Figure 11. Spanwise distributions at the ADP of: (a) axial velocity, (b) relative swirl angle, (c) rotor pressure ratio. 

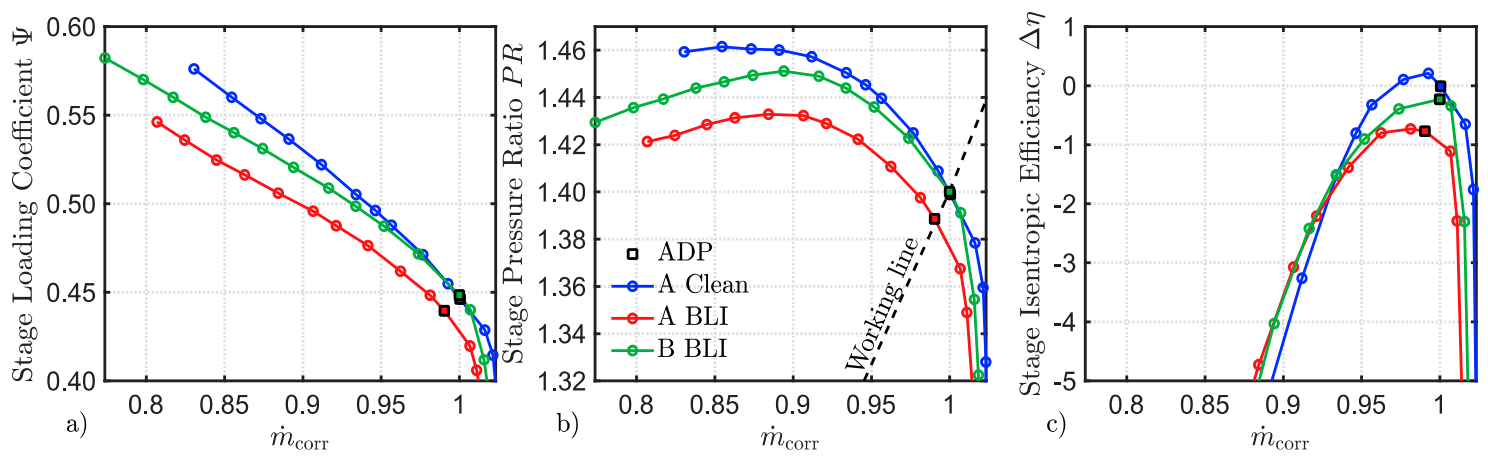

Figure 12. Effect of fuselage BLI on Fan A and Fan B at $100 \%$ corrected speed and cruise conditions: (a) stage loading coefficient, (b) stage pressure ratio, (c) stage isentropic efficiency (\%).

To recover the performance lost due to BLI, a second fan stage, denominated Fan B, has been designed. The leading edge of the blade has been aligned with the flow for minimum pressure loss up to $75 \%$ span. Above $75 \%$ span the sections have been progressively restaggered to operate at negative incidence. This improves the operability of the blade in non-axisymmetric inflow. The magnitude of the negative restagger has been limited to minimize choking losses and maintain the flow capacity. The radial work distribution has been modified to restore the intended loading (cf. Figure 11c). Blade turning has been decreased near the hub and increased in the upper part of the blade as can be seen from Figure 11b. No changes to the solidity distribution were required to maintain the diffusion in optimum values. Note that low levels of rotor hub loading reduce the turning required by stator, maximizing the stage efficiency. The resulting design fulfils the performance requirements at the aerodynamic design point as shown in Figure 12 with a minimal reduction in efficiency and choking margin. Away from the design point, the work input drops. However, a significant rise in stable operating range can be observed.

Figure 13 presents the CFD-based fan map for cruise of Fan A and Fan B. Near ADP, Fan A with clean inflow and Fan B BLI inflow exhibit the same performance. However, away from ADP a drop in work input and efficiency (and consequently pressure ratio) is observed for Fan B. This is caused by the non-linear change in distortion profile with corrected mass flow. Despite the drop in pressure ratio generated, the stability margin of Fan B is greatly improved across the map. Potentially, improving its operability at off-design non-axisymmetric inflows.

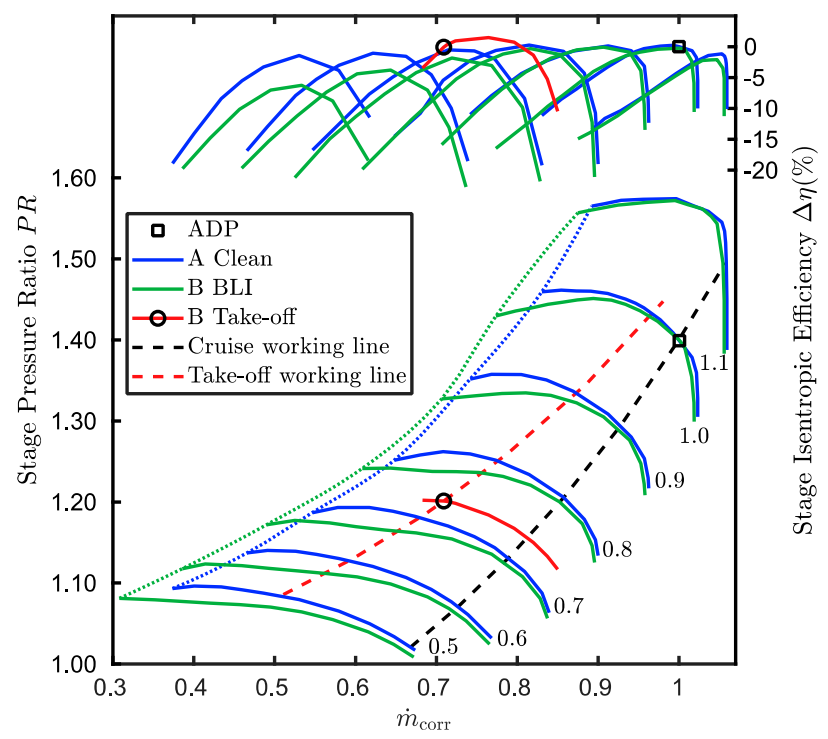

Figure 13. Comparison of cruise maps for Fan A and Fan B. 
The performance of Fan B at take-off has been superimposed in Figure 13. This constitutes the most critical operating condition for the aft-section fan. As reported in [62] in detail, the level of distortion found during take-off is much lower than at cruise. Therefore, the distortion effectively becomes a pseudo tip-low distortion. The fan is driven by an electric motor; the maximum torque delivered by the motor limits (cf. also Section 7.3) the attainable pressure ratio of the fan. For this specific case, the fan is expected to operate only up to a corrected speed of approximately $72 \%$, i.e., stage pressure ratio of 1.2 (cf. also Section 7.3). Additionally, the reduced ram-pressure during take-off moves the working line towards the stability margin, operating at reduced flow coefficient and increased incidence levels across the span. The design features of Fan B alleviate the high levels of incidence at the tip, ensuring stable operation [62].

\section{Aerodynamic Validation Testing}

The core of the conceptual proof for fuselage wake-filling propulsion integration in CENTRELINE is constituted by two experimental test campaigns aiming at obtaining a fundamental understanding of governing flow physics of both, the overall aircraft configuration and the fuselage BLI propulsor. For the overall configuration aero-validation testing, a wind tunnel model was developed to be tested in the low-speed test facilities at Delft University of Technology. The modular nature of the model allowed for an incremental analysis of the configurational effects on the PFC flow field, and more specifically, the FF inflow conditions. In order to verify the FF aerodynamics, the low-speed BLI fan rig facility in the Whittle Laboratory at the University of Cambridge was employed and modified in order to closely replicate the CENTRELINE PFC configuration.

\subsection{Overall Configuration Wind Tunnel Testing}

The experimental studies of the overall PFC aircraft were carried out at the Low Turbulence Tunnel facility of Delft University of Technology. This atmospheric closed-loop tunnel features a closed octagonal $1.8 \mathrm{~m} \times 1.25 \mathrm{~m}$ test-section. The turbulence intensity is below $0.03 \%$ at a freestream velocity $V_{0}$ between $20 \mathrm{~m} / \mathrm{s}$ and $40 \mathrm{~m} / \mathrm{s}$ [63].

The goal of the wind-tunnel experiments was twofold: (1) investigating the effect of fuselage-BLI on the aircraft aerodynamic performance; and (2) understanding the governing aerodynamic interactions between the airframe and the BLI propulsor. The whole experimental campaign was designed with an incremental approach. Firstly, the 2D bare PFC shown in Figure 14 a was tested in simulated cruise conditions $\left(\alpha=\beta=0^{\circ}\right)$ and without the influence of secondary elements, such as wing and tail surfaces. In this setup, the fuselage is directly connected to the external balance and the support structures covered with two symmetric fairings. Secondly, the 3D PFC aircraft including wing and vertical tail depicted in Figure $14 \mathrm{~b}$ was tested to study the PFC performance in representative conditions in on- and off-design phases.

Both setups featured an axisymmetric fuselage (fineness ratio $L_{f u s} / 2 r_{f u s}=11.1$ ) with a shape representative of the CENTRELINE PFC design Rev03 [50]. The fuselage aftsection was equipped with an integrated shrouded fan model. The 12-bladed fan stage was specifically designed to operate at the same conditions, defined by the flow and pressure rise coefficients, as the full-scale BLI fan [64]. The rotor was driven by an electric motor and the speed setting was directly controlled to match the required set point $( \pm 0.5 \mathrm{~Hz})$. The shrouded fan could also be removed to obtain the performance of the unpowered PFC configuration.

A whole range of measurement techniques were employed to characterize the aerodynamic performance of the PFC configuration: (1) six-axis external balance measurements of the aerodynamic forces and moments; (2) total pressure measurements in the airframe viscous layers and far wake; (3) stereoscopic PIV measurements to quantify the 3D velocity field in various survey planes. During all experiments, turbulent transition was ensured on all the model surfaces with the use of turbolator strips. Key measurement results obtained from the performed test campaigns are characterised in the following. 


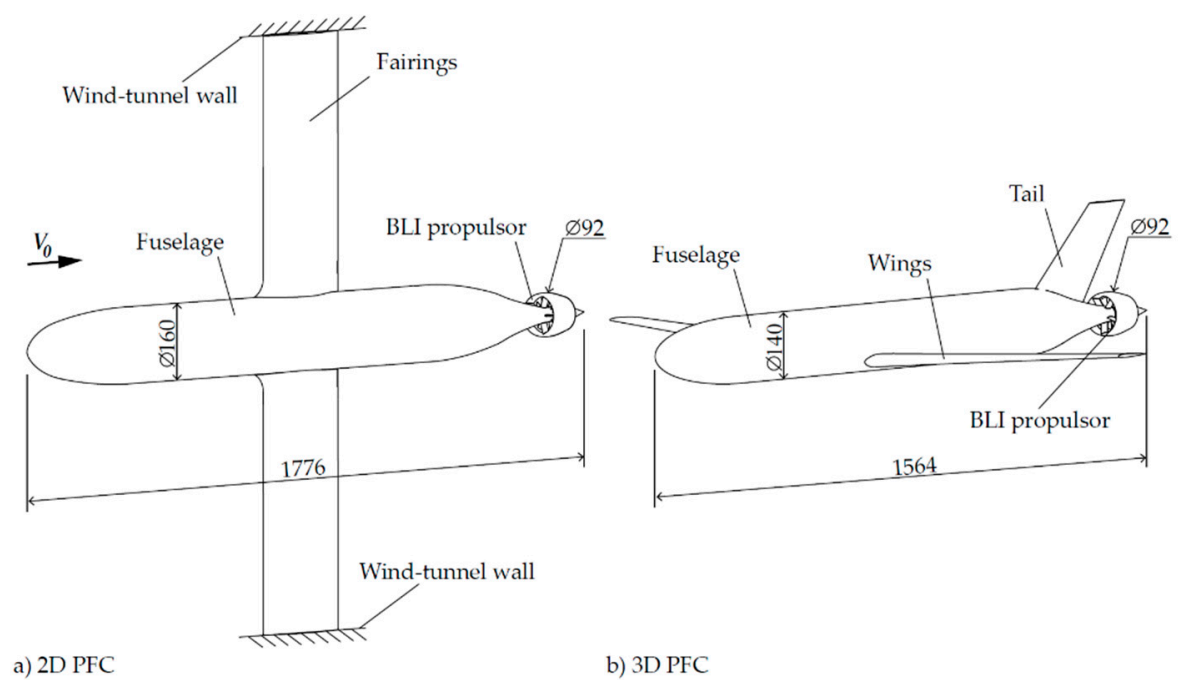

Figure 14. Schematics of the wind-tunnel models setup. Dimensions in $\mathrm{mm}$.

\subsubsection{Time-Averaged Flow Field}

The velocity field was measured around the fuselage aft section for the 2D PFC setup according to Figure 14a through stereoscopic PIV. The time-averaged velocity magnitude field for the unpowered and powered PFC are reported in Figure 15a,b, respectively. The powered case is at axial equilibrium condition, $N P F=0$, where $N P F$ is the net axial force acting on the fuselage-fan assembly. Figure 15a shows the boundary layer development around the fuselage aft-cone. At the fan location $\left(x / L_{f u s}=0.94\right)$ a boundary layer thickness $\delta=0.8 r_{f u s}$ was measured, resulting in approximately $60 \%$ of the boundary layer flow ingested by the fan. In the powered PFC case of Figure 15b, the effect of the fan is twofold: first, it accelerates the boundary layer flow upstream of the inlet, especially in the lowest momentum region close to the fuselage wall; second, the fan slipstream develops and mixes with the outer part of the fuselage boundary layer creating a turbulent shear layer. Moreover, at the trailing edge of the fuselage, a region of turbulent separation is found.

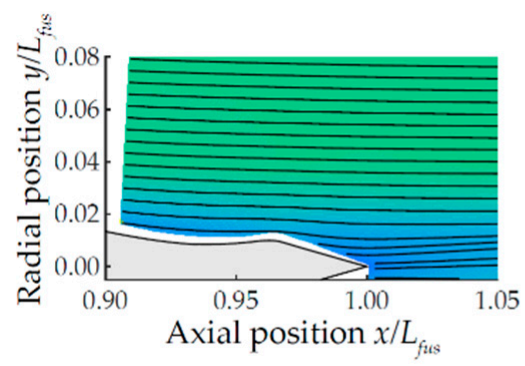

a) Unpowered PFC

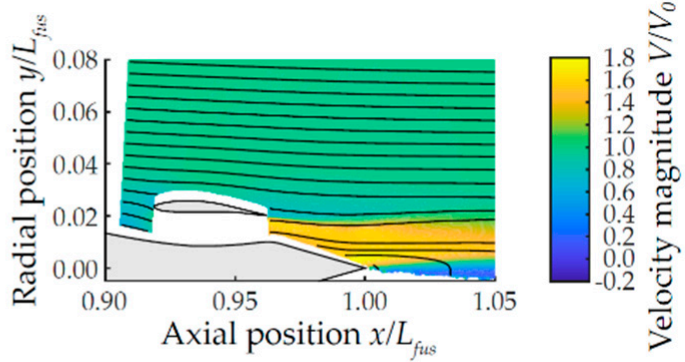

b) Powered PFC $(N P F=0)$

Figure 15. Time-averaged velocity field around the PFC aft-fuselage section of the 2D-PFC setup. Stereo-PIV measurements taken at $V_{0}=20 \mathrm{~m} / \mathrm{s}$ and NPF $=0$.

\subsubsection{Fuselage Fan Inflow Field}

When integrated in the overall PFC aircraft configuration, the fuselage inlet flow field is not only dominated by the fuselage boundary layer, but it is also influenced by the flow around other aircraft elements, such as wing and tail surfaces. The resulting inlet distortion can potentially affect the fan aero-acoustic and aero-mechanical behavior and hence it needs to be known at all the relevant flight phases. The total pressure distribution at the fan inflow for cruise and off-design conditions was measured for the 3D-PFC setup. The results are reported in Figure 16. 


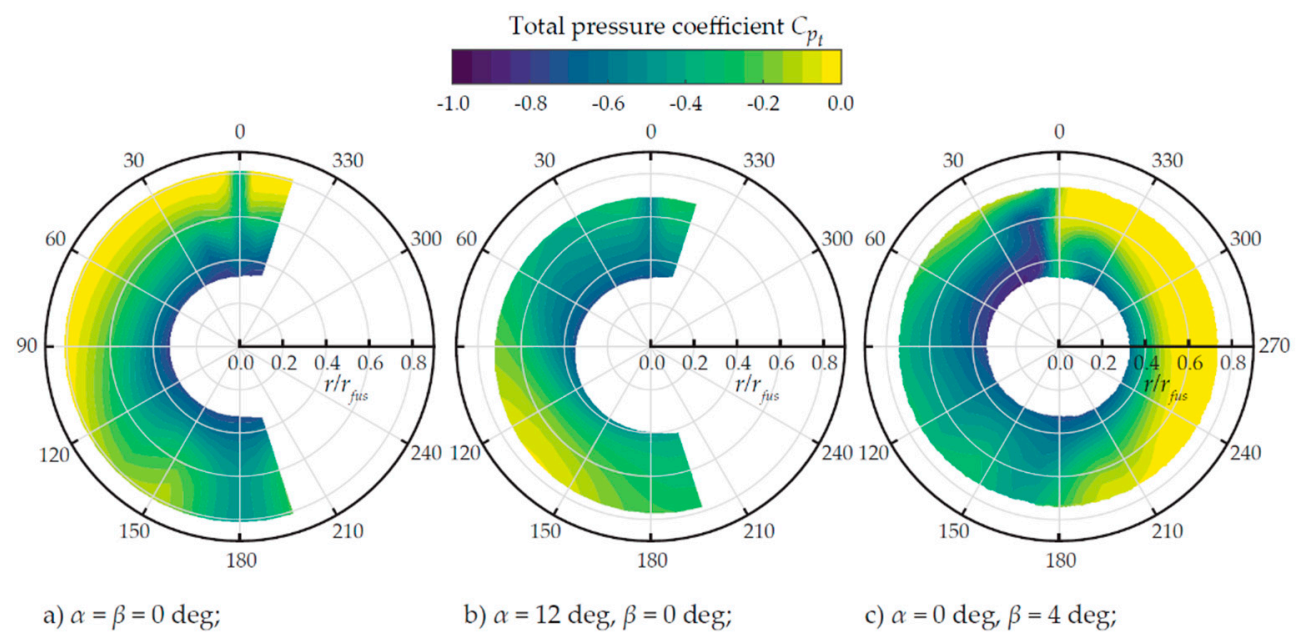

Figure 16. Total pressure field upstream of the FF air intake $\left(x / L_{f u s}=0.89\right)$ in cruise and off-design conditions. Measurements taken on the 3D PFC setup at $V_{0}=40 \mathrm{~m} / \mathrm{s}$.

In zero incidence conditions (at $\alpha=\beta=0^{\circ}$, Figure 16a), the main inlet distortion is due to the fuselage boundary layer which produces radial total pressure gradients. The vertical tail plane (centred at an azimuthal angle $\theta=0^{\circ}$ ) introduces two main distortions in the flow: first, the viscous wake of the tail, with a narrow extension $\left(\Delta \theta \approx \pm 5^{\circ}\right)$ and constant with $r$; second, the junction flow at the tail-fuselage intersection, with a larger distortion $\left(\Delta \theta \approx \pm 30^{\circ}\right)$. Despite a direct quantitative comparison cannot be drawn, the measured distortion patterns in Figure 16a reflect the full-scale high-speed predictions from the CFD simulations (cf. Figure 9c) in the good qualitative manner. This includes the radial distortion due to the fuselage boundary layer as well as relatively sharp vertical tail wake. Stronger differences between the experimental and numerical domains is found in the bottom section of the contours, due to the flow around the fuselage-wing junction fairing, as already discussed in Section 2.3.1.

At $\alpha=12^{\circ}$, representative of take-off rotation conditions, the increased incidence angle results in the onset of a crossflow around the fuselage section as can be observed from Figure 16b. The vertical tail introduces a low $p_{t}$ disturbance for $-5^{\circ}<\theta<5^{\circ}$ which is due to the viscous wake. Unlike the $\alpha=0^{\circ}$ case (cf. Figure 16a), the junction flow distortion is not clearly visible anymore close to the airframe.

Finally, at $\beta=4^{\circ}$ shown in Figure 16c, a strong distortion is introduced by the vertical tail in the sector $-30^{\circ}<\theta<30^{\circ}$. A low $p_{t}$ region is found on the leeward side (suction side of the vertical tail) presumably due to trailing edge separation or corner flow separation. On the windward side (pressure side of the vertical tail), the imprint of a horseshoe vortex can be identified, as a result of the junction flow developing at the tail-fuselage intersection. Furthermore, strong pressure gradients are found in the azimuthal direction around $\theta=0^{\circ}$.

All the measurements were taken at low speed, resulting in a Mach number in the range 0.06 to 0.12 , and a Reynolds number of $0.5 \times 10^{6}$ based on the wing mean aerodynamic chord length. This clearly has an influence on the applicability of the presented results to the full-scale PFC. Even though the fan diameter was scaled to match the fuselage boundary layer at the model scale, other effects due to compressibility and different Reynolds number were not present in the measurements. For example, possible shockwaves at the shroud or tail surfaces could affect the full-scale PFC (see [58] for further analysis in high-speed conditions). More results of the presented wind-tunnel campaigns and detailed data analysis can be found in [48].

\subsection{Fuselage Fan Aerodynamic Design and Performance}

The aerodynamic behavior of the BLI fan has been tested in an experimental low-speed single-stage fan rig, known as the BLI rig. The facility, located in the Whittle Laboratory at 
the University of Cambridge, was purposely built for the aerodynamic analysis of inlet flow distortion fan interaction. Figure 17 presents the meridional view of the of the BLI fan rig. The annulus geometry replicates the geometry of CENTRELINE's aft-section FF.

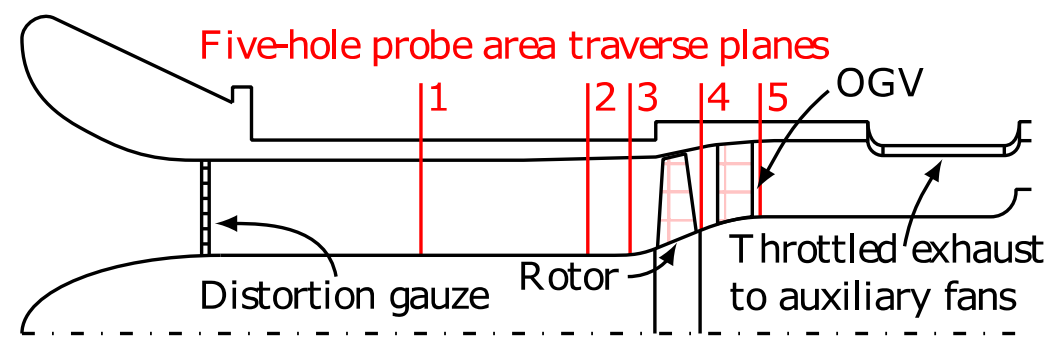

Figure 17. Meridional view of the BLI fan rig.

Two rotor blades designs have been manufactured and tested. The first blade, called Fan A, represents a conventional free-vortex fan designed for clean uniform inflow. The effect of a severe and continuous hub-low radial distortion has been investigated on this conventional blade. A series of design steps have been taken to match this blade to the BLI inflow. The resulting blade shares most of the design features of the transonic BLI optimized Fan B presented in Section 2.4. These are: leading edge aligned with the flow for minimum loss, mid-span loaded work distribution, controlled diffusion factor and increased operability of the tip section. The resulting blade design, called Fan B has been subsequently tested under axisymmetric and non-axisymmetric distorted inflows. The low-speed nature of the rig does not allow compressibility effects to be replicated. However, velocity triangles representative of the full-scale transonic FF have been obtained by matching the full scale flow coefficient and stage loading coefficient (cf. Table 3).

Detailed pressure measurements have been taken at five axial locations with a fivehole pneumatic probe area traverse system as indicated in Figure 17. The five-hole probe measures the time-average values of stagnation pressure, static pressure, swirl angle, and radial angle. Based on these flow properties and the incompressibility of the rig, the complete flowfield has been reconstructed. Further details of the experimental setup can be found in [64].

Experimental tests have been performed for clean and distorted inlet conditions. The baseline distortion chosen for the study is a scaled version of the axisymmetric but radially non-uniform hub-low stagnation pressure distortion calculated in Section 2.3 and used in Section 2.4 for the aerodynamic design point. In a subsequent study a full-annulus non-axisymmetric distortion representative of the CENTRELINE configuration comprising fuselage, wings, and vertical tail plane (cf. also Section 2.3) has been tested for Fan B.

To generate the target inlet velocity profiles, flow conditioning gauzes have been installed at the intake of the rig. The gauzes comprise thousands of small vanes with precisely controlled geometry and are additively manufactured. For the axisymmetric inflow (clean and radial stagnation pressure distortion) the gauzes were designed using the method proposed by Taylor [65]. The method makes use of CFD simulations in an iterative manner to obtain the shape of the vanes that compose the gauze. For the non-axisymmetric inflow, the method reported in [65] has been upgraded to replicate non-uniform distributions of stagnation pressure and swirl distortions. Figure 18 presents the flowfield measured downstream of three different gauzes. Axisymmetric clean and hub-low axial velocity measurements are shown in Figure 18a,b whilst a highly complex distortion pattern (stagnation pressure + swirl) associated to the operation of the aft-section fan with the full aircraft configuration is presented in Figure 18c. 


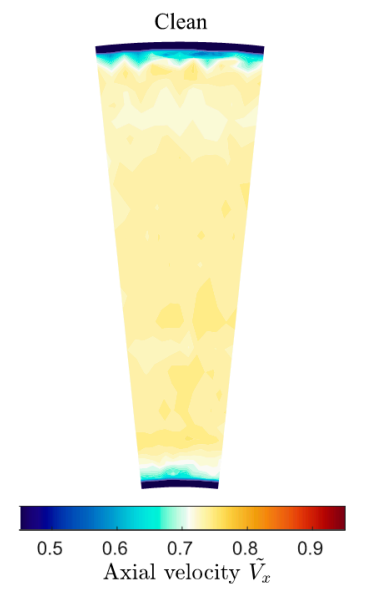

a)

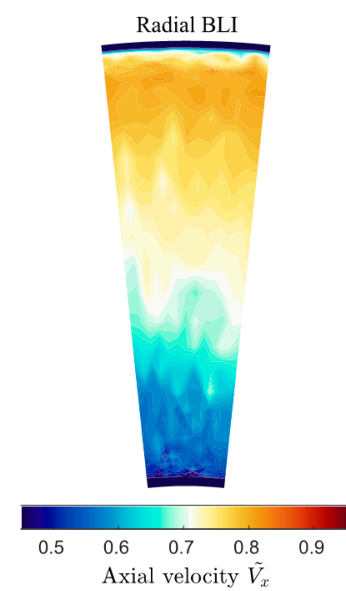

b)

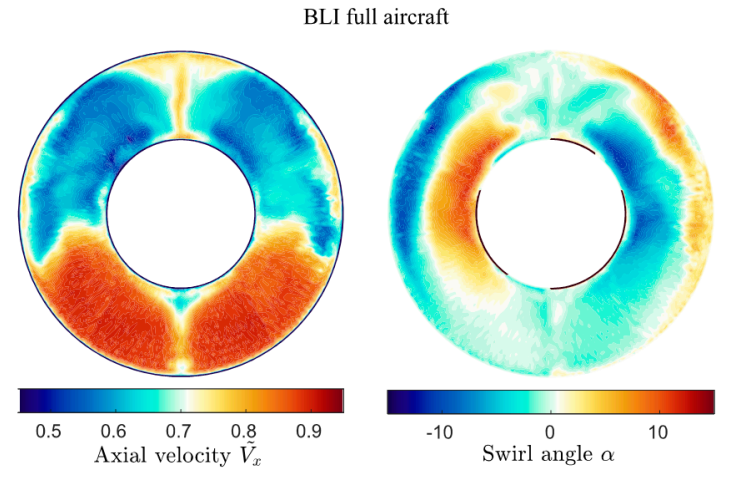

c)

Figure 18. Measured inlet inflow behind the distortion gauzes: (a) Clean, (b) hub-low distortion, (c) full-aircraft configuration.

The low-speed nature of the rig does not allow to capture compressibility effect. However, most of the physics associated to the operation of the fan in a distorted inflow are still captured. To illustrate this, Figure 18 presented the measured spanwise distributions of axial velocity, relative swirl angle and angular momentum. Note that angular momentum is equivalent to work load for a purely axial inflow. The effect of the severe hub-low stagnation pressure distortion on Fan A is consistent to the one found for its transonic version in Figure 19. High incidence and increased work load are found near the hub whilst negative incidence and reduced loading are observed in the upper part of the span. The overall effect on both cases is a reduction in stage loading coefficient of the same magnitude. Additionally, the performance lost due to BLI is recovered applying the same design philosophy for the low- and high-speed versions of Fan B: tailored alignment of leading edge and controlled work and diffusion distributions. With exception of shock related losses, the low-speed rig is able to capture the physics of fan-distortion interaction. Making low-speed fan testing a quick and economical tool to validate the performance of numerically derived fan designs.

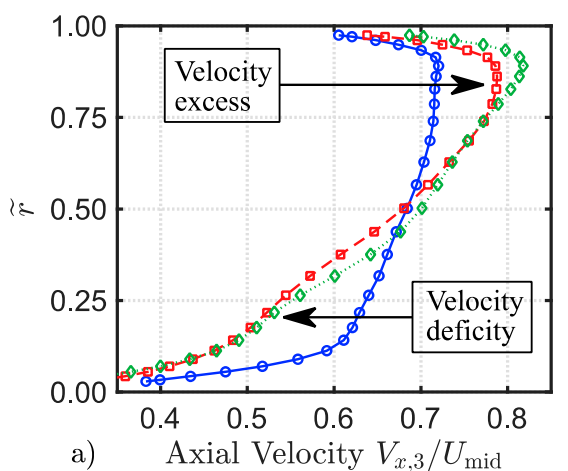

a) Axial Velocity $V_{x, 3} / U_{\text {mid }}$

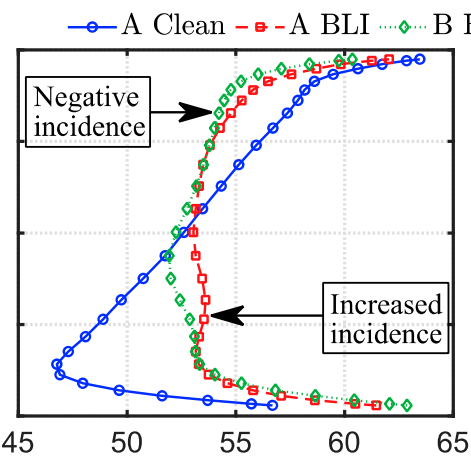

b) Relative Swirl Angle $\alpha_{\text {rel,3 }}$

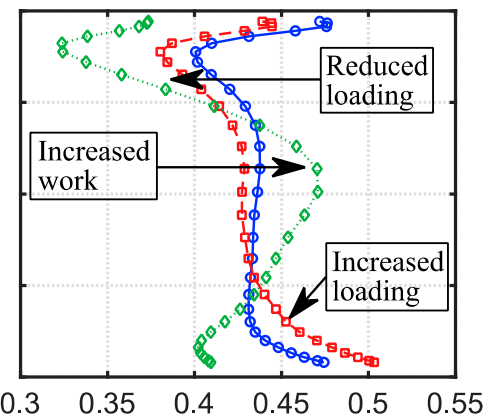

c) Angular momentum $\left(r V_{\theta}\right)_{4} /\left(r V_{\theta}\right)_{\text {mid }}$

Figure 19. Measured spanwise distributions at the ADP of: (a) axial velocity, (b) relative swirl angle, (c) angular momentum.

\section{Fuselage Propulsive Device Design and Structural Integration}

This section is dedicated to the conceptual design integration of the fuselage BLI propulsive device. This covers parametric sizing and performance modeling of the FF module including key components of is mechanical design, as well as the aero-structural design integration at the aft-fuselage. Beside the fuselage nacelle integration, the structural 
design and analysis part also includes the key airframe components directly affected by the FF installation.

\subsection{Fuselage Fan Conceptual Design Synthesis}

The CENTRELINE FF propulsion system consists of a single-rotating ducted fan driven by an electric motor in a direct drive arrangement. The fan rotor design features fixed-pitch blades. The fan rotor blading and outlet guide vane geometry refers to the Fan $\mathrm{B}$ design described in Section 2.4. The fan ducting features a fixed nozzle. The developed design and performance models, however, feature immediate capability to appropriately emulate a nozzle variability device if required for operational flexibility during more detailed aircraft-integrated design optimization (cf. [42]). Nacelle mechanical complexity and structural mass is kept to a minimum as the fan cowling is not equipped with a dedicated thrust-reversing device. Instead, thrust reverse functionality-in case required from the overall aircraft design perspective- is intended to be realized through reverse operation of the electrically driven fan. The FF outer casing includes a rotor containment sized for the kinetic energy of a fan blade-off. The transfer of the aerodynamic, inertial and gyroscopic loads across the FF rotor plane is realized by the structural load path routed through the FF rotor hub. Supported by FEM (finite element method) structural analyses reported in $[66,67]$, this design solution was down-selected from a number of options conceived and evaluated as part of the preliminary design work in the project (cf. $[42,43])$. This solution allows for the least number of structural items in the fuselage inflow streamtube and a complete structural decoupling from loads introduced by the empennage. For the FF bearing, electromagnetic bearing options such as proposed by Steiner et al. [5] were initially evaluated, but discarded for complexity reasons based on the trade-off between performance and overall system complexity. The design of the fan rotor bearing system is a rather conventional one, featuring a floating cylindrical roller bearing in the front. The rear bearing is a fixed ball bearing, designed to take the FF rotor thrust loads. The flanging of key component groups is tailored to enable orderly assembly and disassembly of the FF power plant system. Down-selected from a number of alternative concepts, a compactly folded forward mounting approach was identified as the best and balanced design solution for the electric drive motor attachment to the fan rotor. In Figure 20, a representation of the geometric arrangement of the FF rotor system including electric drive motor, bearings, and internal support structure is presented for the CENTRELINE Rev07 design case 1 . The annotated figure also displays the integration of the auxiliary power unit (APU) in the fuselage aft-cone, as well as the forward and rearward attachment points for the structural load path across the FF rotor plane.

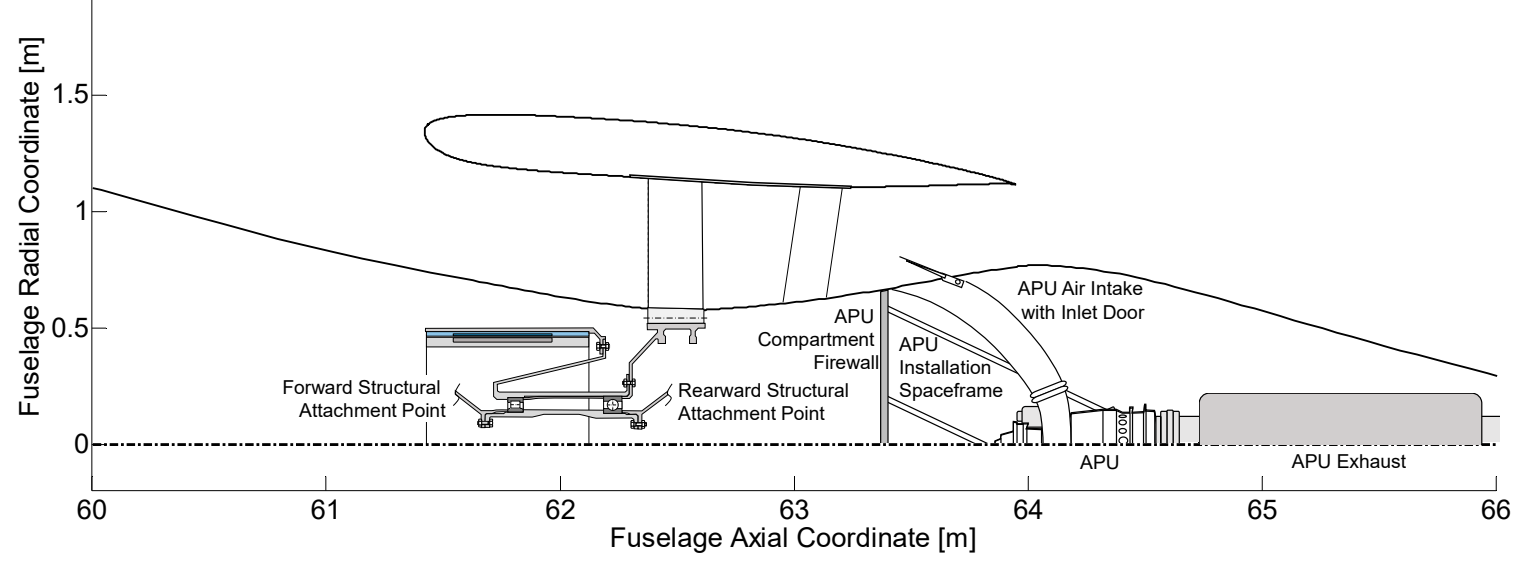

Figure 20. Concept sketch of the aft-fuselage power plant integration.

In order to ensure robustness against uncontained FF disk structural failure, the components of the FF power plant and all adjacent systems require positioning such 
that disk burst corridors do not interfere with critical functions of the vertical tail. A visualization of systems integration at the PFC aft-fuselage with annotation of spread angles as recommended in AMC 20.128A [68] for the shedding of fan blade fragments is provided in [69].

\subsubsection{Flow Path Sizing and Performance Synthesis}

The design and performance synthesis for the FF propulsive device was performed using the APSS framework (cf. also Section 1.4). During flow path sizing, the turbo component cross-sectional areas directly result from mass flow continuity, the local gas properties and prescribed axial design Mach numbers. Similarly, the nozzle exit area results from mass flow continuity and the nozzle exit velocity subject to the prevailing nozzle pressure ratio. A set of typical heuristics along with appropriate iteration strategies is included for cycle design and performance prediction according to [42,70,71]. For the FF propulsion system sizing, specific functional sensitivities were implemented as basic design laws including the mapping of fan tip speed as a function of design fan pressure ratio, nozzle thrust and discharge coefficients as functions of nozzle pressure ratio, as well as fan design efficiency as a function of corrected mass flow and mean stage loading. Flow path sizing was conducted for design cruise conditions with maximum climb power settings for the FF.

For FF operational performance simulation, the Fan B cruise map shown in Figure 13 was used. In order to be consistent with the map scaling standards in APSS, before adoption, the FF map was Reynolds-number scaled to ISA SL conditions. The mass flow and efficiency scaling was performed based on the Reynolds number index (cf. [72]). While a precise representation of FF performance behavior with full reflection of the varying fan inflow conditions-e.g., in cruise and take-off-would require an array of classic component maps (cf. [62]), even with the simplification of the single component map the APSS off-design performance results were found to be in good agreement with the values predicted by TU Delft's CFD simulations in cruise and take-off conditions. As expected, the operating line during take-off was situated at higher pressure levels and lower corrected mass flows, meaning reduced stability margins when compared to cruise conditions. With take-off stability margin still over-predicted due to the use of cruise component map, through a re-staggering of the fan blade tips acceptable stability margins in take-off were shown to be achievable for the CENTRELINE FF by Castillo Pardo and Hall [62]. Based on a preliminary assessment, sufficient stability margin in take-off was obtained at the loss of approximately $0.2 \%$ of isentropic efficiency at the aerodynamic design point [62].

As a pivotal point for the aircraft-level design studies, a FF polytropic design efficiency of $93.4 \%$ was chosen which corresponds to a $1 \%$ reduction in polytropic stage efficiency relative to the underwing podded reference engine fans. Taking into account the aerodynamic design efficiency penalties discussed in Section 2.4, this selected baseline design efficiency appears appropriately conservative. In order to account for 3D duct design and typical installations inside the fan cowling duct, the duct pressure losses predicted by the 2D CFD simulations were increased to yield pressure ratios similar to classic fan bypass ducts. A summary of key design parameters for the FF propulsive device is presented in Table 4.

For the actual fan sizing the reduced maximum flow capacity associated with the aerodynamic design of a BLI fan was taken in account. The design axial fan rotor inlet Mach number is 0.60 , meaning a reduction of approximately $12 \%$ relative to the value assumed for the main engines fan operating without BLI effects. The reduced axial Mach number at the fan rotor inlet yields an increased fan face area, and thus, larger tip diameter in the order of $3 \%$ relative to CFD optimized Rev07 geometry cases, when a constant hub contour is retained. This modification was deemed to be achievable featuring a net neutral impact on the sum of surface pressure forces acting inside the fuselage nacelle and the fan disc [58]. The resultant reduced fan cowling profiles thickness of approximately $8 \%$ (cf. also Table 4) was assessed to remain acceptable for a proper nacelle aerodynamic and aero-structural design. The axial Mach numbers at the FF intake highlight and AIP were 
directly adopted from the CFD optimized Rev07 design cases 1 to 3 . Assuming a limited upstream effect of the increased flow diffusion in front of the FF face at the given fan design pressure ratio of 1.40 , the corresponding impact on the freestream total pressure recovery ratio ahead of the FF face was considered negligible. When operated at a FPR of 1.2 in take-off (cf. Section 2.4), the shaft power absorbed by the FF is increased by approximately $30 \%$ at a simultaneously reduced shaft rotational speed by $20 \%$, relative to the flow path sizing conditions summarized in Table 4 above. In combination, this means an elevation of shaft torque by approximately $63 \%$.

Table 4. Summary of results for actual FF flow path sizing (M0.82, FL350, ISA + 10K).

\begin{tabular}{|c|c|c|c|c|}
\hline Parameter & Unit & Design Case 1 & Design Case 2 & Design Case 3 \\
\hline $\begin{array}{l}\text { Fan isentropic shaft } \\
\text { power }\left(\mathrm{P}_{\mathrm{FF}, \text { Shaft }}\right)\end{array}$ & MW & 5.530 & 6.800 & 7.760 \\
\hline $\begin{array}{l}\text { Fan pressure ratio } \\
\qquad\left(\mathrm{p}_{13} / \mathrm{p}_{2}\right)\end{array}$ & - & 1.40 & 1.40 & 1.40 \\
\hline $\begin{array}{l}\text { Fan mass flow rate }\left(\mathrm{W}_{2}\right) \\
\text { Freestream total }\end{array}$ & $\mathrm{kg} / \mathrm{s}$ & 212.6 & 261.4 & 298.3 \\
\hline $\begin{array}{l}\text { pressure recovery ratio } \\
\qquad\left(\mathrm{p}_{2} / \mathrm{p}_{0}\right)\end{array}$ & - & 0.831 & 0.841 & 0.848 \\
\hline $\begin{array}{l}\text { Nozzle pressure ratio } \\
\left(\mathrm{p}_{18} / \mathrm{p}_{\mathrm{s}, \mathrm{amb}}\right)\end{array}$ & - & 1.795 & 1.817 & 1.832 \\
\hline Gross thrust & $\mathrm{kN}$ & 62.59 & 77.70 & 89.23 \\
\hline $\begin{array}{l}\text { Fan rotor inlet tip } \\
\text { diameter }\left(\mathrm{D}_{\mathrm{FF}}\right)\end{array}$ & $\mathrm{m}$ & 2.349 & 2.585 & 2.745 \\
\hline $\begin{array}{l}\text { Hub/tip ratio at rotor } \\
\text { inlet }\end{array}$ & - & 0.497 & 0.495 & 0.493 \\
\hline Rotational speed & $1 / \min$ & 2730 & 2481 & 2336 \\
\hline $\begin{array}{l}\text { Bearing system inner } \\
\text { diameter }\end{array}$ & {$[\mathrm{mm}]$} & 338 & 367 & 389 \\
\hline $\begin{array}{l}\text { Cowling thickness at } \\
\text { fan face }\end{array}$ & $\mathrm{m}$ & 0.208 & 0.224 & 0.230 \\
\hline Cowling length & $\mathrm{m}$ & 2.531 & 2.776 & 2.935 \\
\hline
\end{tabular}

\subsubsection{Mechanical Component Sizing and Mass Prediction}

With the flow path hub and tip diameters determined through the flow path sizing, the more detailed parametric mapping of the FF flow path geometry was performed based on the methods described in [70]. For the prediction of the FF module weight, the masses of the fan key component group were mapped individually. These included the fan rotor blading, the outlet guide vanes, the rotor disk, the fan bearing, as well as the fan shaft and rotating bearing support structure. The rotor blading and outlet guide vane (OGV) masses are determined based on a simplified blade/vane geometry, i.e., cuboid bodies with prescribed aspect ratios and relative thickness distributions in the radial direction. The number of blades and vanes per row is controlled by a prescribed solidity value. The resultant total displacement volume per row was then scaled with a representative material density in order to obtain the total blading/vane mass. For the present study all input parameters for the blading and vane geometric properties were calibrated to the Fan B aero-shaping discussed in Section 2.4. For the rotor disk sizing, the disk design tool of GasTurb $^{\circledR}$ Details 6 [73] was used. FF rotor bearing sizing was performed based on a method by [74] as discussed in [75]. In order to predict the required bearing size and corresponding mass, the method uses a correlation between the dynamic load rating and the bearing skin surface area, which was derived from existing SKF ball bearings [75]. The required bearing dynamic load ratings were calculated from the actual bearing load cases due to the fuselage rotating mass components under CS-25 regulation [76] and prescribed target service hours. The inner diameters of the bearing system obtained for a typical velocity index of $1.2 \times 10^{6} \mathrm{~mm} / \mathrm{min}$ are listed in Table 4 above. For the fan rotor casing including blade containment, a simplified geometric description including axial length 
determination based on a constant spread was used. Containment thickness was derived from [77] as a function of blade kinetic energy. The individual components included in the mass budget of FF module are highlighted in Figure 21.

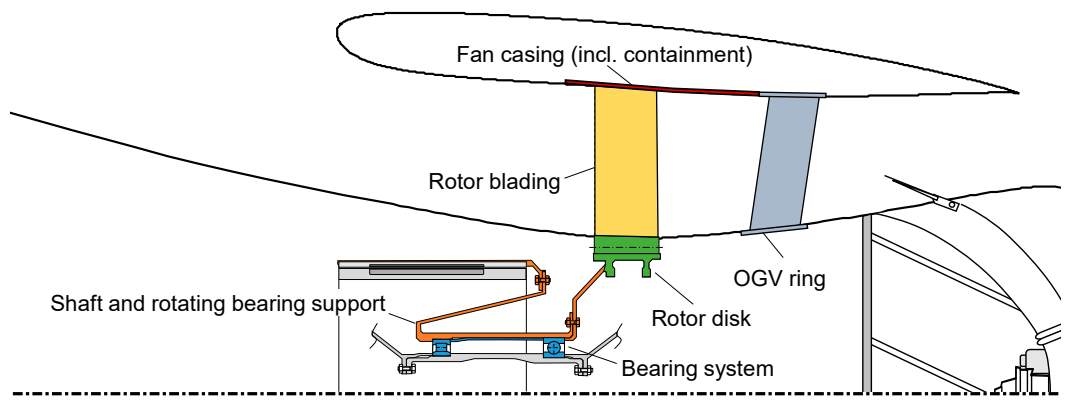

Figure 21. Visualization of control volume for FF module mass budget, individual component groups highlighted in color.

A synopsis of the individual component masses predicted for the FF modules for the Rev 07 design cases is provided in Table 5. The prediction of nacelle structural masses for the Rev 07 design cases involves the FF cowlings as well as all structural elements of the aft-fuselage section. Beside the outer shell structure this also includes the internal load beam routed through the inner diameter of the FF bearing system and the APU firewall and is discussed in the next section.

Table 5. FF component masses predicted for the CENTRELINE Rev 07 design cases.

\begin{tabular}{cccc}
\hline Mass Terms (kg) & Design Case 1 & Design Case 2 & Design Case 3 \\
\hline Fan rotor blading & 136 & 183 & 221 \\
Rotating mass & 306 & 411 & 490 \\
w/o blading & 164 & 206 & 235 \\
Stationary masses & 606 & 800 & 946 \\
(OGV + fan casing) & & & \\
Fan module total & &
\end{tabular}

As can be noted in Table 5, the FF module masses appear to be lower than expected for conventional fans featuring identical diameters. This is the consequent result of two important effects: Firstly, the hub-to-tip ratios of the CENTRELINE FF are considerably higher than for conventional fans (cf. Table 4). Secondly, in contrast to conventional fan face maximum mechanical speeds during maximum take-off conditions, the FFs maximum speed is at flow path sizing conditions, i.e., top of climb. As a result of these two effects, the $\mathrm{AN}^{2}$ metric (cf. e.g., [70]) for the CENTRELINE FF design is approximately $35 \%$ reduced compared to typical conventional fans.

\subsection{Fuselage Fan Aero-Structural Integration}

The aero-structural design concept, analysis and sizing activities in CENTRELINE covered the most relevant airframe components for the investigated PFC aircraft layout. While a focus was placed on the structural integration of the fuselage aft-section including the FF propulsive device, also the entire fuselage structure was conceptually elaborated and sized as well as key components of the wing structure. In the following, important aspects of the developed structural design solutions will be introduced. The FEM simulation-based design and sizing strategy for relevant load cases according to CS-25 regulations [76] will be discussed and main results will be presented including structural mass prediction for the addressed airframe components. 


\subsubsection{Description of Structural Design and Integration Solutions}

The aft-fuselage section including the FF nacelle and supporting structure was the central subject of the structural design work. Starting from a pool of candidate concepts considered as part of the pre-design phase in the first half of the project (cf. [66]), a suitable structural layout was elaborated for the principal conceptual integration of the FF propulsive device as presented in Figure 21. The overall structural concept is based on a ubiquitous use of carbon fibre reinforced polymer (CFRP) material.

The FF cowling is structurally decoupled from the vertical fin in order to avoid the complex aero-elastic interactions between the empennage, the nacelle and the FF rotor. As a result, all loads generated by the $\mathrm{FF}$, as well as the aerodynamic, inertial and gyroscopic forces acting on and inside the rear of the fuselage and FF nacelle are transferred in a single structural path through the FF rotor hub (cf. Figure 21). Important boundary conditions for the design of the load carrying structure were imposed by the Rev07 optimized aerodynamic shaping, as well as by a defined arrangement and positioning of the main internal components, including the FF electric drive motor, the rotor and stator and the aircraft APU. The geometric space available for the internal load-carrying structure was particularly limited by the bore diameters of the FF bearing system (cf. Table 4). A basic visualization of the final aft-fuselage aero-structural integration is provided in Figure 22.

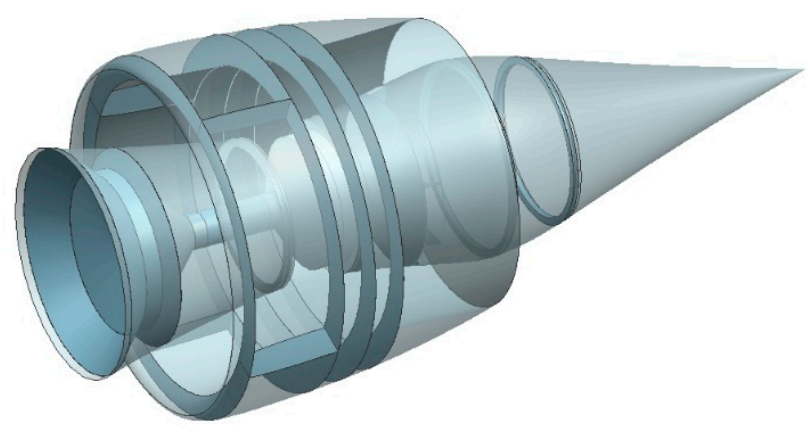

Figure 22. Basic visualization of CENTRELINE aft-fuselage aero-structural integration concept.

The most loaded structural element is the front fixing frame, which transfers the loads to the main structure of the aircraft. This main frame is conically shaped and reinforced to provide the required strength and rigidity. Both, on the rear part of the fuselage and the nacelle, a monocoque structure is used for the transfer of loads through the outer shell. In addition to its load carrying outer shell, the fuselage aft-section is equipped with smaller forming frames, two main fixing frames and a fire wall providing the structural attachments for the space frame holding the APU. The FF OGVs are used as a multifunctional element. Beside the aerodynamic purpose, the OGVs serve as the sole structural connecting element between the FF cowling and rear-section of the fuselage. The load transfer across the FF rotor is implemented through the hollow cylindrical beam connecting the aft-fuselage installation to the front fixing frame. Important aspects for the aero-structual integration of the PFC aft-fuselage are described in [67].

Beyond the FF installation structure, a concept for the entire fuselage main structure was developed. For both aircraft, the PFC and the R2035, the fuselage is made of a hybrid structure utilizing sections with a geodetic layout combined with conventional structure sections. In the cylindrical parts-except for the fuselage-wing junction section-a geodetic structure is adopted, while in the remaining parts a conventional structure is considered more well-suited for manufacturing purposes. As in the case of the PFC aircraft a T-tail empennage arrangement was selected, additional frames are added to its local fuselage structure in order to strengthen the vertical tail attachment area. A PFC aircraft side view featuring basic visualization of the main elements of the fuselage structural layout is provided in Figure 23. Not shown in the figure, are the window and door cut-outs, which however have been taken into account during the structural analysis. 


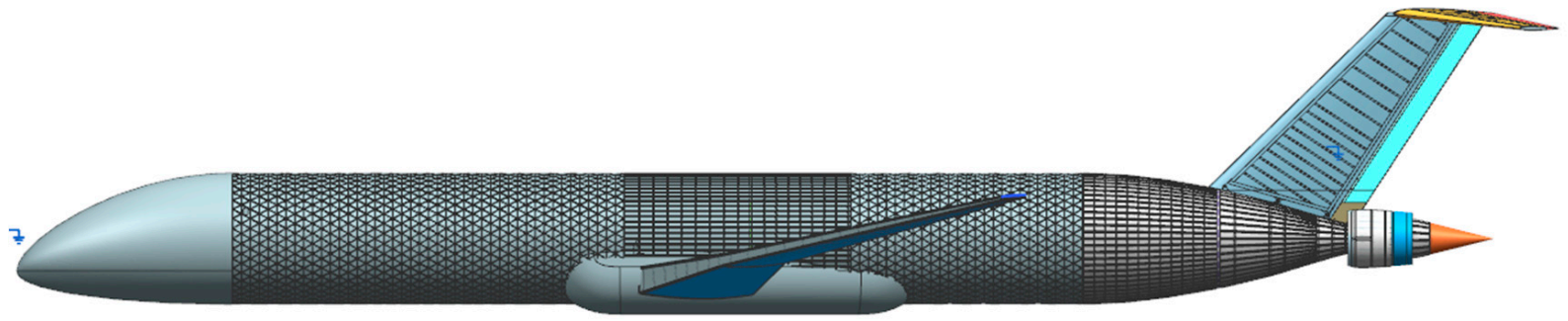

Figure 23. PFC aircraft side view including basic visualization of the main elements of the fuselage structural design concept.

As part of the structural design activities, a concept of the primary load-carrying structure of the PFC aircraft wing was prepared. Accordingly, the wing consists of the skin, two spars (main and auxiliary), ribs, and stringers. The wing skin is divided into zones with different fabric layouts adapted to the loads. The centre wing box features innovative design approach based topologically optimized zones featuring laminates with different layouts, individually adjusted to the local load distribution, allowing for a significant mass reduction while maintaining appropriate mechanical properties of the individual parts [78] The fuselage and wing structural concepts and their analyses are described in more detail in $[79,80]$.

\subsubsection{FEM-Based Structural Sizing Method}

For the effective sizing of the structural concepts described above, 3D Computer Aided Design (CAD) models of the CENTRELINE aircraft geometries were developed and analyzed through FEM using the Siemens $N X^{\circledR}$ software by Siemens PLM Software Inc. (Plano, Texas, United States). Based on the defined external geometry, the internal load-carrying structure of the aircraft was built, which was later converted to a 2D surface model as shown in Figure 24 and subjected to FEM analysis afterwards. The strength analysis was repeated iteratively until the specified requirements were met in terms of strength, stiffness, and weight.

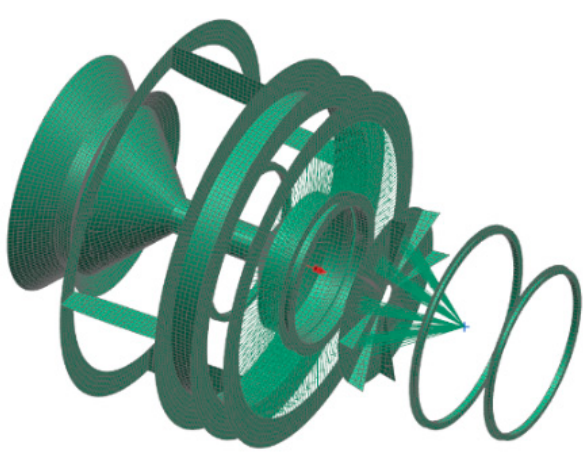

(a)

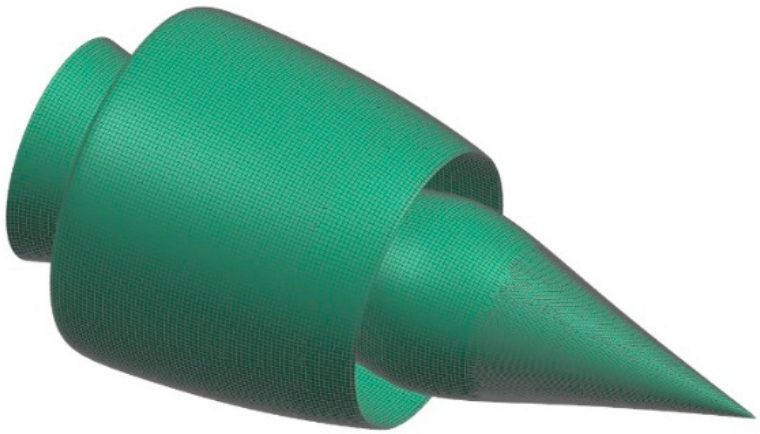

(b)

Figure 24. Finite element mesh for (a) internal structure and (b) skin of the aft-fuselage section.

For the PFC nacelle and aft-fuselage integration, the main sources of loads affecting the load-carrying structure include inertial loads coming from the structural weights, torque due to the FF rotor drive, aerodynamics loads on the nacelle surface and gyroscopic loads due to the FF and APU rotating parts. Considering the unconventional placement of the BLI propulsor as well as the nature of the operation of the entire assembly, the CS-25 regulations [76] were analyzed. Table 6 summarizes the load cases identified and used during the FEM structural analysis. 
Table 6. Fuselage fan integration structural load cases according to CS-25 (cf. [76]).

\begin{tabular}{ccc}
\hline Case Number & Case Description & Regulation Chapter \\
\hline 1 & Emergency landing & CS 25.561 \\
2 & Side load & CS 25.363 \\
3 & Engine and APU loads & CS 25.361 \\
4 & Gyroscopic loads & CS 25.331 \\
5 & APU acceleration & CS 25.361 \\
6 & APU gyroscopic loads & CS 25.371 \\
\hline
\end{tabular}

The overall fuselage structure must be able to withstand a variety of load limitations acting individually and in combination. Rationally analysing the regulations, nine critical load cases were selected and presented in Table 7. Cases of hard landing were not explicitly analyzed, as this would require a detailed design of the undercarriage attachment structure. However, the obtained results can be considered valid since the undercarriage attachment structure was included in another component of the used mass estimation method.

Table 7. Fuselage fan integration structural load cases based on CS-25 (cf. [76]).

\begin{tabular}{cc}
\hline Case Number & Description of Loads \\
\hline 1 & $1 \mathrm{~g}+$ cabin pressurization \\
2 & $-1 \mathrm{~g}$ manoeuvre + cabin pressurization \\
3 & $2.5 \mathrm{~g}$ manoeuvre + cabin pressurization \\
4 & $2.5 \mathrm{~g}$ manoeuvre \\
5 & 1.33 times cabin pressurization (over \\
6 & pressurization) \\
7 & $1 \mathrm{~g}+$ elevator deflection downward \\
8 & $1 \mathrm{~g}+$ elevator deflection upward \\
9 & Lateral gust + cabin pressurization \\
\hline
\end{tabular}

The PFC structural analysis and sizing was performed for all Rev07 design cases as introduced in Section 2.2. In each of the three cases, the load-carrying structure was adapted to the different external geometries (see Figure 7) and internal component masses (e.g., Table 5). The iterative structural refinement process was applied in every case until all structural requirements-such as predefined minimum strength, stiffness, and buckling resistance-were reached.

\subsubsection{Key Structural Design Results}

A structural displacement map for the aft-fuselage installation according to Rev07 design case 2 under CS 25.561 loads is presented in Figure 25. Assuming a fixated front frame, the maximum vertical displacement at the fuselage aft-tip remains within approximately $57 \mathrm{~mm}$

The buckling analysis performed for the final sizing of the Rev07 design case 2 structural design showed the onset of local wrinkling at loads more than $60 \%$ above the ultimate loads, indicating sufficient structural safety and buckling resistance. The FEM structural analyses, furthermore, confirmed the load carrying capability of the FF OGVs as intended by the structural design concept.

Beside the principal proof of the PFC aero-structural feasibility, the purpose of the structural design activities in the project was to deliver weight predictions for key aircraft components suitable for the integrated aircraft design sizing and performance evaluation. With the primary load carrying structure of the fuselage designed and sized based on the previously described FEM-analysis based approach, other structural mass components including the fuselage pressure bulkheads, cabin floor supports, doors, windows cargo hold structures, wheel bays, wing carry-through structural elements, as well as the attachment structures for the wing, tail, and landing gear were estimated using semi-empirical 
methods as described in $[79,80]$. Table 8 provides a synopsis of the fuselage integration and overall fuselage structural weights determined for the R2035 aircraft as well as the three Rev07 design cases for the PFC aircraft. Following a family design strategy, all structural components have been sized for the largest member of each aircraft family.

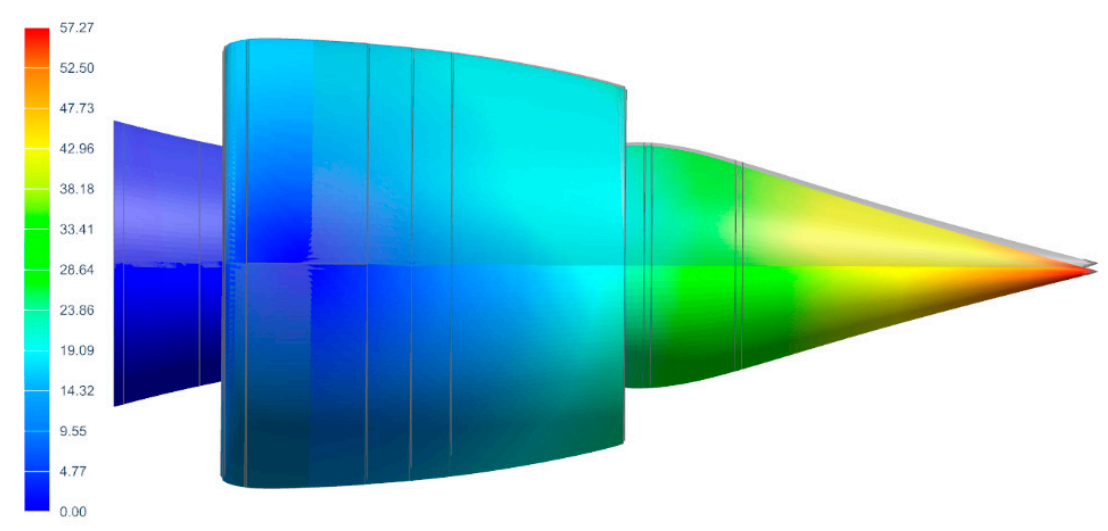

Figure 25. Displacement map for aft-fuselage nacelle and integration structure of PFC Rev07 design case 2 under CS 25.561 loads. Color legend shows vertical displacement in mm.

Table 8. Overview of fuselage and FF integration structural weight results.

\begin{tabular}{ccccc}
\hline Component & R2035 & $\begin{array}{c}\text { PFC (Rev07 } \\
\text { Case 1) }\end{array}$ & $\begin{array}{c}\text { PFC (Rev07 } \\
\text { Case 2) }\end{array}$ & $\begin{array}{c}\text { PFC (Rev07 } \\
\text { Case 3) }\end{array}$ \\
\hline $\begin{array}{c}\text { Aft-fuselage } \\
\text { integration }(\mathrm{kg})\end{array}$ & $\mathrm{n} / \mathrm{a}$ & 490 & 646 & 775 \\
Main fuselage $(\mathrm{kg})$ & 22,286 & 22,742 & 22,889 & 23,027 \\
\hline
\end{tabular}

\section{Turbo-Electric Fuselage Fan Power Supply}

In this section, the pre-design of the turbo-electric drive train system is introduced and explained. The turbo-electric drive train is the system transmitting the mechanical power from the podded engines to the FF in the aft fuselage section. The discussion includes the overall system architectural layout, the design integration of the main power plants, the involved electric machinery and system thermal management aspects.

\subsection{Transmission System Architectural Definition}

The CENTRELINE PFC aircraft features a partial turbo-electric propulsion system, in which the majority of the core engine excess power used to drive the under-wing main fans. The fraction of power required to drive the BLI FF is transmitted electrically, through power conversion by electric generators installed on the main engines and the FF electric drive motor. Due to the low energy density, batteries as used in partial serial-electric power train arrangements have not been considered for the CENTRELINE systems layout.

The electric components in the system must be sized for the maximum mechanical power, which occurs on ground at high power levels. The fuselage power scheduling for the various phase of the mission is determined by the overall aircraft sizing and performance synthesis (cf. also Section 6.2). As a result, the actual power profile differs from conventional fans throughout the mission. This translates into a variable power split between the podded engines and the FF. Compared to a fixed power split the adjustment to the FF power to the current mission segment allows to avoid excessively high sizing power requirements for the electric components to cover the take-off performance.

The turbo-electric drive train can be realized by different electric architectures. The most relevant configurations are the direct current (DC) architecture, where the mechanical power extracted from the engines is converted by a generator and subsequently rectified to DC electric power. The rectification allows to decouple the rotational speeds of the engine 
generators and the FF. On the other hand, power electronic devices are required to rectify and invert the electric power, which results in additional losses and component masses. Moreover, the system must be controlled actively, which increases the development effort and adds failure cases to the propulsion system.

An alternative solution would be an alternating current $(\mathrm{AC})$ architecture, where the extracted mechanical power is converted to electric power, but it is not rectified afterwards. The AC electric power is supplied to the FF drive motor, where it is directly converted back to mechanical power. This architecture would not decouple the rotational speeds of the engine generators and the FF. From a functional point of view, this transmission can be compared to a gearbox with a fixed ratio. AC transmission systems are used in hybridelectric ships to maximize efficiency as the power electronic devices are disconnected from the system and the diesel engine drives the propellers "directly". With an AC transmission, a variable power split between the engines and the FF can only be realized with a variable pitch mechanism in the FF. The advantages are the higher efficiency and no need for active control, which increases the system efficiency and does not require an active input. The downsides of this system are the higher cable masses and the danger of desynchronization of the electric machines. The cables of the AC transmission must be sized to transport the reactive power, which results in higher cable masses and higher losses. As there is no active control of the system, the electric machines can transmit a limited torque, which must no be exceeded to prevent desynchronization. The desynchronization of such a propulsion system is considered catastrophic for the aircraft as the mechanical forces will destroy the electric machines and lead to significant structural damage.

A DC transmission has been selected for the PFC aircraft to enable the variable power split without using a variable pitch fan and to avoid any desynchronization problems typically related to AC transmission systems. The rated DC link voltage is derived from commercially available semiconductor switches, possible inverter topologies and a voltage derating due to increased cosmic radiation at cruise altitude. Since the cosmic radiation intensity at a flight altitude of approximately $12 \mathrm{~km}$, or FL390, increases by a factor of 300 compared to sea level, the voltage rating of the semiconductor switches is reduced to $55 \%$. A positive effect of reducing the voltage rating is the significantly reduced failure rate of the semiconductor switches. The considered voltage ratings of commercially available switches are $900 \mathrm{~V}, 1200 \mathrm{~V}, 1700 \mathrm{~V}, 3300 \mathrm{~V}$, and $6500 \mathrm{~V}$. Switches with lower voltages are available, but the derating and the power level do not favor switches with lower voltage ratings. Finally, two-level, three-level, and five-level converter topologies are considered for this application. The combination of the three factors results in the possible DC link voltages listed in Table 9 below.

Table 9. Suitable DC link voltages including de-rating (Source: [81]).

\begin{tabular}{cccc}
\hline Voltage Rating (V) & Two-Level Converter & $\begin{array}{c}\text { Three-Level } \\
\text { Converter }\end{array}$ & Five-Level Converter \\
\hline 6500 & 3575 & 7150 & 14,300 \\
3300 & 1815 & 3630 & 7260 \\
1700 & 935 & 1870 & 3740 \\
1200 & 660 & 1320 & 2640 \\
900 & 495 & 990 & 1980 \\
\hline
\end{tabular}

Suitable values for the DC link voltage are highlighted in green. Lower values lead to high currents and high cable masses. Higher voltages will increase the insulation effort and affect the cooling performance of the motor and the power electronics. As a reference, a five-level inverter with $1200 \mathrm{~V}$ switches is considered, which results in a DC link voltage of $2640 \mathrm{~V}$ has been selected based on a system-level sensitivity analysis including the electric component weights and efficiency effects.

To complete the propulsion system architecture pre-design, a basic safety assessment is conducted. The results show that the expected failure rates for the electric component do 
not match the level, which is expected to be required by a long-range aircraft with ETOPS (Extended-range Twin-engine Operation(al) Performance Standards) rating. To reduce the failure rate for the loss of the turbo-electric drive train, the DC transmission lines from the engine generator to the FF drive motor are split into multiple parallel transmission lines, which are considered to operate independently. Like this, the loss of the entire transmission system is very unlikely, however, increasing the number of components reduces the system availability as the chance of a component failure increases. In a trade-off, the number of parallel transmission lanes is selected to four. This design allows to reduce the failure rate of a partial loss of power of less than $75 \%$ to less than $1 \times 10^{-9} 1 / \mathrm{h}$. Figure 26 shows the resulting propulsion system architecture. The two podded engines on the left and the turbo-electric drive train with four transmission lanes for each generator are depicted on the right.

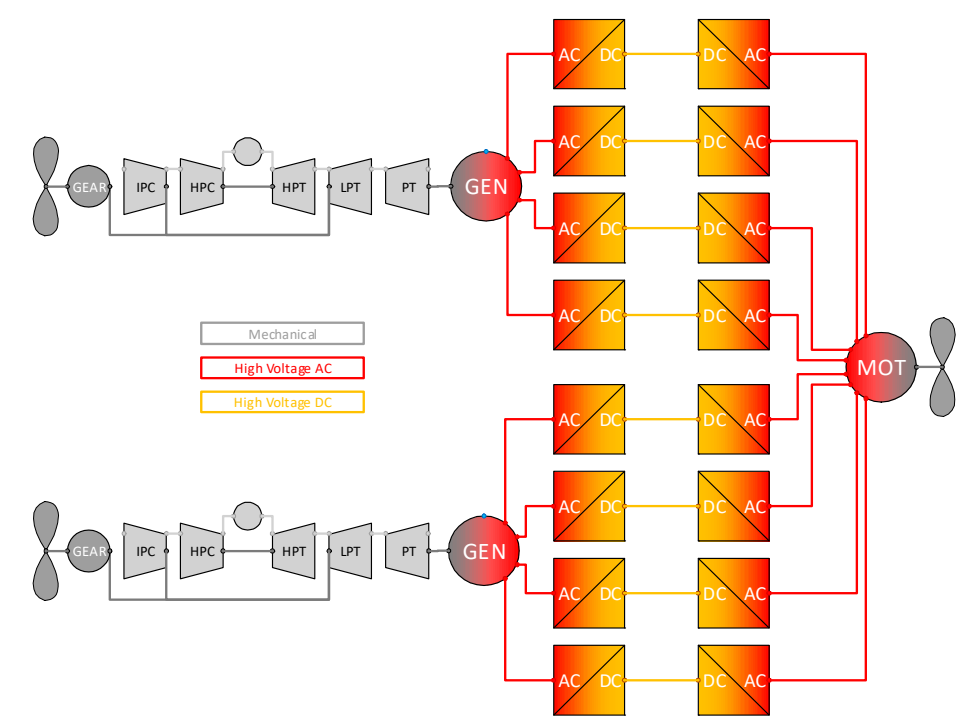

Figure 26. Overall propulsion system architecture (Source [81]).

\subsection{Electric Machinery Pre-Design}

The design of electric machines is driven by the maximum rotational speed and the level and duration of the required maximum torque. The maximum rotational speed and the maximum torque levels do not necessarily appear at the same time. Hence, all major mission points must be considered to size the electric machines and their power electronic devices correctly. The FF performance requirements stipulated by the CENTRELINE initial PFC aircraft target design (cf. Section 1.4) include maximum rotational speed to appear at flow path sizing conditions at Top of $\mathrm{Climb}(\mathrm{ToC})$, while maximum torque is occurring during take-off as outlined in Section 4.1.1. As a result, the motor needs to be designed for a mechanical power level going clearly beyond the maximum rated power during operation. Consequently, the fuselage drive motor resulting from the requirements according to initial PFC aircraft target design (Figure 4) would be able to deliver 11.5 MW but is operated at a maximum power of $8 \mathrm{MW}$ during take-off. In constrast, the relevant rotational speeds for the TEPT generators allow for a more straight-forward sizing in take-off.

The basic machinery type selected for the TEPT electric motor and generator applications in CENTRELINE is a permanent magnet radial flux electric machine. While the FF drive motor is an out-runner machine to maximize power density, the gas turbine integrated generators are in-runner machines in order to better to shield the magnets on the rotor from the high ambient temperatures.

For the electric machine computation, the commercial software package SPEED ${ }^{\circledR}$, PC-BCD 12.04 version 12.04 .010 by CD-adapco ${ }^{\circledR}$ (Melville, New York, United States) was used. The basic scheme followed for the electric machine design and sizing is visualised in Figure 27. As can be seen in the figure, the system sizing and performance requirements, 
including the required torque and rotational speeds during key mission phases, are used to scale an ab-initio machine with approximate radius, length, current, slot and yoke width, etc. under the constrains of physical limits, e.g., the maximum current density in copper under the certain cooling conditions. The obtained geometric and electromagnetic characteristics of the machine are translated to SPEED ${ }^{\circledR}$-specific input settings in order to compute the machine performance properties. If the prescribed machine design is identified as valid based on the performance calculated by SPEED ${ }^{\circledR}$, the underlying machine model is used as an initial point to optimize the exact geometry of the slots, teeth, magnet volume in an iterative way. Machine mass is calculated from the 2D geometry with the 3D components such as the winding heads included based on the winding scheme. The best machine configuration in terms of power to weight with a minimum required efficiency is saved as a SPEED ${ }^{\circledR}$ design.

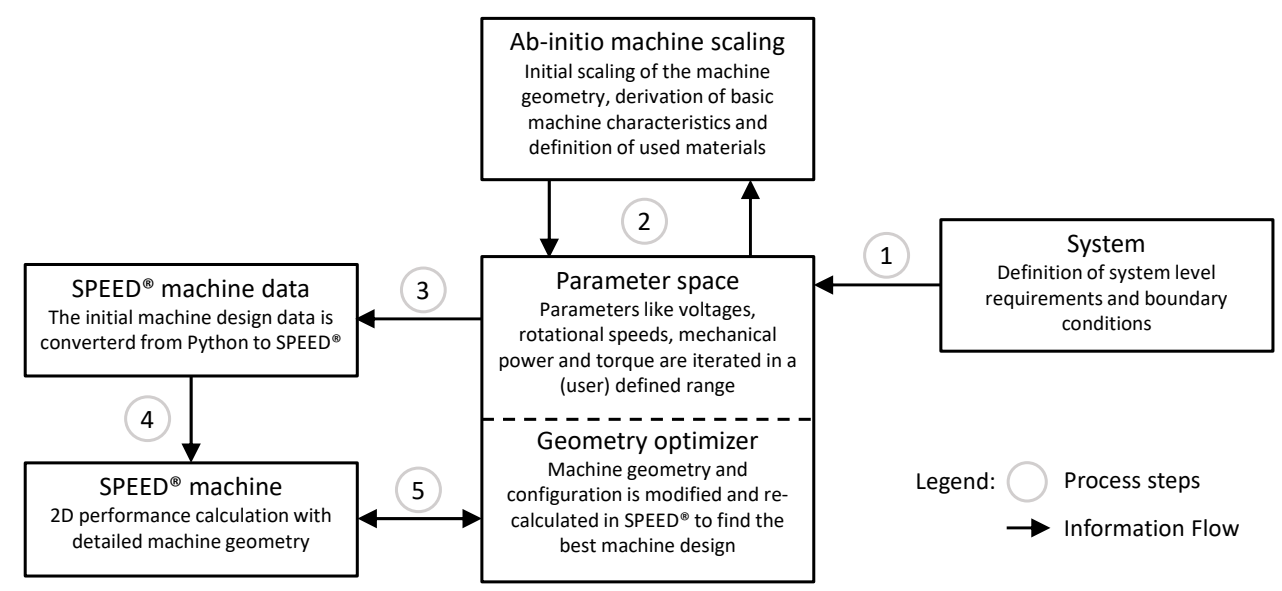

Figure 27. Basic electric machine design scheme.

In CENTRELINE, this machine scaling and optimization procedure was implemented to run automatically for every unique set of input requirements [81]. In order to support the aircraft-level systems design activities in a parametric manner, the procedure was employed for the FF electric drive motor and the main power plant integrated generators using systematic variations of maximum rotational speed, torque, DC voltage level and electric frequency. Beside the obtained mass, geometric and efficiency properties, also the resulting external driving and cooling parameters required to operate the electric machinery, such as the current and voltage per phase provided by the inverter or the cooling power by the heat exchanger, were provided back to the system [81].

The design calculation for the inverters was done for two-level, three-level, and fivelevel topologies and individually for each machine design. The result of these design calculations were the masses of all involved parts. Connection and mounting devices were not considered in this pre-design phase since they depend strongly on the detailed mechanical design. It is highlighted that the mass obtained from this calculation reflects only a net mass of the 'active' parts of the inverter. By incorporating all other parts in order to obtain the inverter gross mass, the net mass needs to by multiplied by a factor between 1.5 to 2 . The mass values for power switches, their drivers and the DC-link capacitors were calculated by the help of an in-house database with collected state of the art devices. If a certain device was not explicitly found in the database, required key properties were derived by interpolation and curve fitting approached from similar devices of the same voltage class.

The cooling device scales with the power electronic base plate area. The housing was scaled with the volume of all above mentioned parts. After the parts were designed, the conducting and the switching losses and hence the efficiency was evaluated. This was realized by a numeric electrical simulation with a PLECS ${ }^{\circledR}\left(\right.$ PLECS $^{\circledR}$ is a registered 
trademark of Plexim GmbH, Zurich, Switzerland) model [81]. Table 10 summarizes the sizing results for the detailed settings of the initial PFC aircraft design provided by the initial PFC target design in the project (cf. [43]). For the aircraft-level investigations, the evaluation of electric component sizing and performance was incorporated using response surface models based on the produced parametric data for each component (see also Section 6.1).

Table 10. Component mass breakdown for the turbo-electric power train (Sources: [82,83]).

\begin{tabular}{cccc}
\hline Component & Unit & Engine Generator & Fuselage Fan Motor \\
\hline Converter & $\mathrm{kg}$ & 152 & 182 \\
Converter cooling & $\mathrm{kg}$ & 71 & 80 \\
system & $\mathrm{kg}$ & 30 & 100 \\
AC cables $(5 \mathrm{~m})$ & $\mathrm{kg}$ & 434 & 905 \\
Electric machine & $\mathrm{kg}$ & 165 & 280 \\
Electric machine & $\mathrm{kg}$ & 852 & 1475 \\
cooling system & Total mass & & \\
\hline
\end{tabular}

Not included in Table 10 is the mass of the DC cabling required for the TEPT, which was assessed to be $690 \mathrm{~kg}$. A parametric analysis of the DC cable sizing is provided in [81]. The TEPT component efficiencies for the performance requirements at the beginning of cruise are listed in Table 11.

Table 11. Component efficiencies of the turbo-electric power train in cruise (Source: [84]).

\begin{tabular}{ccc}
\hline Component & Unit & Value \\
\hline Generator & $\%$ & 96.5 \\
Rectifier & $\%$ & 98.5 \\
Inverter & $\%$ & 99.0 \\
Motor & $\%$ & 96.5 \\
Total system efficiency & $\%$ & 90.8 \\
\hline
\end{tabular}

\subsection{Component Cooling and System Waste Heat Management}

One key issue of electric propulsion systems is the thermal management. In aircraft, the only way to reject waste heat is to transfer the heat to the ambient air. The advantage of classic gas turbine engines is that most of the waste heat is generated at a high temperature level and ejected via the hot exhaust gas flow. Electric machines and power electronics operate at much lower operating temperatures, which increases the effort to cool the components, as the available temperature difference to the ambient air is much smaller. Moreover, the losses are generated in solid material and not in a gas flow that is intrinsically released to ambient air. This implies that the heat must be transferred to the ambient air via multiple transfer mechanisms, which include thermal resistances and reduce the cooling performance compared to gas turbine engines. Moreover, designing an electric machine for maximum power density means that the amount of material is minimized. This also minimises the volume losses are generated within, and, the areas available for the external heat rejection. Hence, an electric machine with high power density requires a high cooling effort and smart cooling methods.

The electric machines designed for this project operate at high current density so that direct air cooling is not possible. Hence, a fluid cooling system is required to extract the waste heat from the electric machines. The generator, which is integrated downstream of the engine LPT requires a complex cooling system to sustain the high ambient temperatures. The casing is cooled with an internal jacket cooling and the permanent magnets on the rotor are cooled with oil running on the inner shaft wall. The fuselage drive motor requires a direct cooling of the stator windings.

The significant amount of electric machinery waste heat contained in the cooling fluid needs to be rejected to the ambient air at a minimised drag penalty. Beyond the classic 
approach of heat rejection via ducted radiators, the utilization of existing aircraft surfaces as an interface to the external heat sink was explored in CENTRELINE. Therefore, the on-board fuel was used to transfer the heat from the fluid cooling circuits of the electric machines to the lower wing surface, in order to be cooled down by the forced convection on the outer wing surface during as the aircraft is in motion. A preliminary estimation of fuel temperatures at the end of diversion, i.e., the most critical conditions during the design mission, showed that for the present case the fuel temperature can be kept well below the ignition temperature limit even with low fuel quantities remaining in the tank [84]. This result is in good agreement with independent studies of fuel sink systems and electric waste heat rejection through existing aircraft surfaces published in the very recent past $[85,86]$.

The power electronic devices are designed for a low current density on the switches, which enables air cooling and increases efficiency. This comes at the price of many semiconductor switches and a high component price. Moreover, the additional drag from cooling fins must be considered and traded carefully against oil cooling of the power electronic devices. The converters of the engine generator are located at the inner wall of the engine nacelle to enable air cooling, like the cooling of the gearbox oil. The advantage of this location is that an air flow is available as soon as the engine (and the generator) are rotating. The drawback is the high sensitivity of the engine specific fuel consumption on pressure losses in the bypass section. The power electronics for the FF motor may be oil cooled and the heat may be transferred to fuel circulation system built-in for the aircraft's trim tank capability. For anti-icing purposes, incurring electric waste heat may be directly rejected though the aircraft external surface areas near the leading edge of the FF cowling and the fuselage section in front of the BLI propulsive device, whenever required.

\subsection{Main Power Plant System Design Integration and Performance}

Similar to the R2035 power plants, the basic architecture of the PFC main engines is based on a two-spool, boosted, GTF layout featuring a short duct separate flow nacelle. However, aside from the residual net thrust requirements (cf. Section 2.1), the main power plant systems of the turbo-electric PFC aircraft also need to deliver the power required for the FF electric drive. These power offtakes exceed the level of typically considered customer offtakes, even if all electric subsystems are considered. Together with the overall design power offtake level comes the operational requirement of relative independence between the thrust produced by the main propulsion system nozzles and the shaft power extracted by the generator. More specifically, an optimal operation of the PFC aircraft (see also Section 7.3) means the ratio of generator power offtakes to main engine thrust to be relatively low during take-off, however particularly high in cruise.

\subsubsection{Cycle Design and Performance Modeling}

Propulsion system design and performance synthesis in the project was conducted using the APSS framework (cf. Sections 1.4 and 4.1.1). Flow path sizing was performed for ToC conditions at maximum climb (MCL) rating. For the cycle design definition, a set of typical heuristics according to [71] and [70] along with appropriate iteration strategies was adopted along with appropriate iteration strategies. Specifically, fan tip speed was mapped as a function of the design outer FPR based on data given in [71]. Turbo component design efficiencies were modeled with functional sensitivity to component size and Reynolds number effects, the aerodynamic loading conditions and, if applicable, cooling air insertion [42]. For off-design performance, component maps from the GasTurb ${ }^{\mathrm{TM}}$ map collection [87] were employed. Maximum rating settings including maximum allowable temperature levels and component mechanical speeds for take-off and climb were correlated to the turbine cooling air demand based on the multi-point sizing strategy as described by Bijewitz et al. [42]. Lower part power operation was facilitated by handling bleed laws as proposed by Seitz [70]. For the mapping of the PFC-specific power offtakes in design and off-design, a set of relative descriptors was used [42] which—-together with the overall model parameterization-allow for broad ranges of power offtake in a Cartesian input 
space. Specific details for the R2035 and PFC main engine weight estimations used for the aircraft-level design and performance evaluation presented in Section 7 are provided in [69].

\subsubsection{Engine Architectural Integration Options}

The TEPT impact on the PFC main power plants under nominal and abnormal operating conditions needs to be limited by design as much as possible. Therefore, two main propulsion system design options have been investigated within the project combining the considerations of cycle performance, mechanical design and integration aspects, as well as operability in all flight modes.

Figure 28 shows the flow path layout of the two main propulsion system design options, which can be distinguished by the source of the power extraction from a free power turbine (FPT) shaft or from the LPT shaft [88]. Both options have the generator integrated behind the final turbine stage in the hub section. This position, firstly, could satisfy sufficient circumferential speeds and space for the generator design with direct drive; secondly, it is the best position with respect to the weight balance of the propulsion system; thirdly, it enables a disassembly on wing [89].

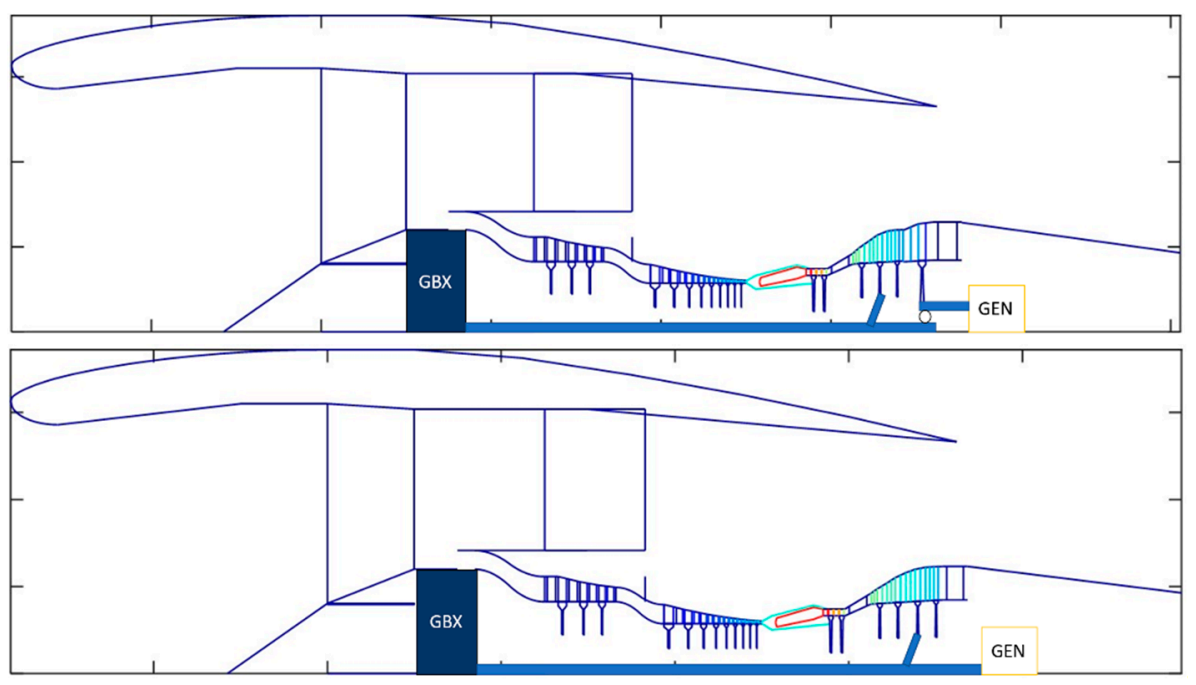

Figure 28. Flow path layout of the main power plant design options, free power turbine power offtake (top) and low-pressure turbine power offtake (bottom).

While the LPT shaft power extraction was considered as a default case since the intitial PFC aircraft target design, the FPT-based architecture was investigated as an alternative in order to explore its potential benefits from the mechanical decoupling of the generator from the main engine core and propulsive device and the intrinsic possibility to select a suitable design rotational speed for the FPT and generator.

The design point performances of both design options are nearly the same: A slightly better TSFC for the configuration with direct LPT power extraction at normal operating points can be attributed to a better performance of the LPT compared to the variable geometry FPT. An efficiency penalty of $0.5 \%$ at design point and a efficiency correlation derived from publicly available resources $[90,91]$ were included for the effects incurring from the FPT variability. The power output of the FPT at a given flight condition is basically controlled by two speeds, the fan speed and its own speed. The former dominates the power output potential at a certain operating condition whilst the latter has a marginal influence mainly given by its effect in the FPT efficiency variation. In order to increase the flexibility of FPT power extraction, a variable turbine nozzle has been considered for the special thrust/power extraction requirements as mentioned above. At a constant main engine thrust setting, a variation of the FPT nozzle area allows to shift powers between the FPT and the LPT without the necessity of the varying the FPT rotational speed. For 
normal operations, such as mid cruise and take-off, an FPT nozzle variation of $\pm 30 \%$ could satisfy the need for flexibility. However, operating points, featuring low main engine thrust settings at simultaneously high generator power offtake requirement such as end of cruise pose signification challenges to the FPT design: Firstly, the FPT efficiency penalty increases considerably when the turbine nozzle area is reduced below $70 \%$ of the design area [88]. Second, with the electric power demand remained constant, the mechanical loading of the FPT disc increases despite the de-throttling of the core engine.

Beside the performance implications, the FPT design would add about $1.5 \%$ more weight to the main propulsion system compared to the LPT design. The additional weight is mainly caused by the variable geometry of the power turbine. The weight estimation is based on the layout given in Figure 28, which has no casing between the LPT and FPT. If a casing must be included, a 3.5\% additional weight is expected. A detailed discussion of the design and operational implications including impacts on turbo component stability margin at relevant operating conditions for both main engine design options is provided by [88].

\subsubsection{Architectural Selection Based on Abnormal Modes}

The final selection of the PFC main propulsion system architecture is dominated by the considerations of abnormal flight conditions. Therefore, cases without nominal TEPT power offtake from the PFC main engine need to be considered. Key abnormal conditions include the shortfall of FF power absorption, as well as a case in which the generator has to be stopped from rotation due to an internal short circuit [89].

For the FPT design variant, both problems are critical, because the FPT would accelerate and exceed safe speed limits as it is coupled aerodynamically to the rest of the core engine. To prevent the FPT from overspeeding, in both cases a number of counter measures are conceivable, including using the TEPT generators for the subsystems power supply, rotating the turbine inlet vanes to a position in order the power delivered by the free power turbine [92], and, bypassing a fraction of the core mass flow around the FPT through bleed valves located between the LPT and the FPT [89].

For the LPT direct drive design, the former case is not considered to be a major problem as the main fan still consumes the majority of the mechanical power generated from the LPT. The latter condition, however, would require a mechanism to disconnect the generator from the LP spool, such as predetermined breaking point in the shaft connecting the LPT and the generator rotor. In case the generator could continue rotating despite a short circuit in one of its winding systems, such as disconnection mechanism would not be required. Corresponding technologies that are currently being investigated are considered to be available for an EIS in 2035 [89].

In conclusion, both architectural options are conceivable; however, under the occurrence of TEPT failure cases, the LPT direct drive design is considered significantly less complex than the FPT variant. Together with its slight weight and performance advantages discussed in the previous section, the LPT direct drive design was selected as the final architecture for the CENTRELINE PFC aircraft.

\section{Multi-Disciplinary Aircraft-Level Design Synthesis}

This section describes the overall aircraft-level design and multi-disciplinary knowledge integration performed in the project. Therefore, the developed collaborative framework and data integration solution are presented, before key aspects of the PFC and R2035 aircraft design and performance synthesis methodology is introduced. To round off, the partial system safety assessment conducted as part of the aircraft design integration activities is discussed.

\subsection{Collaborative Framework and System-Level Knowledge Integration Approach}

The foundation of the aircraft design and performance studies presented in this paper was formed by the multi-disciplinary, multi-partner collaborative research conducted 
within CENTRELINE. This section provides a brief overview of the interfacing and data handling processes established in order to facilitate efficient collaboration between the project partners as well as the consistent propagation of the multi-level, multi-disciplinary design and performance information to the level aircraft sizing and operational assessment.

The knowledge on PFC aircraft design was incrementally refined during the CENTRELINE project involving multiple levels of modeling fidelity. Incremental results from the various detailed design and analysis tasks need to be evaluated at aircraft-level in a continuous manner in order to provide adequate design guidance from an overall system optimality perspective. Therefore, a rapid-responding aircraft-level sizing and optimization setup was required, featuring robust parametric sensitivity for key design parameters from all relevant system components and disciplines; flexibility and extensibility in the parametric interfacing between the various design aspects; and the capability of zooming by a quick inter-changeability of disciplinary models.

Given the nature of this design problem, a fully-coupled multi-disciplinary, multipartner design optimization process featuring the direct execution of the specialized disciplinary models seems widely impractical. Instead, decomposition of the overall system design and optimization problem was performed. The individual disciplinary and component design optimization subtasks were decoupled from the aircraft level, by imposing local objectives and constraints directly derived from the aircraft level design and optimization task. Such an approach, commonly known as the "Bi-Level Integrated System Synthesis (BLISS) technique [93,94], allows the handling of complex design optimization problems based on a relatively small number of top-level variables effectively shared by the various subtasks. For the interfacing between the system-level design optimization and the local design optimization activities, a problem-oriented set of direct exchange of parametric data and tailored surrogate modeling techniques was adopted. Due to their extremely fast response times, surrogate models enable rapid design space exploration and a quick gain of system behavioral knowledge. Surrogate model application intrinsically enforces quality assurance measures such as expert checks prior to the system level integration of subsystem analysis result data (cf. e.g., [70]). Accordingly, the design and performance characteristics of the main power plants systems as well as the BLI FF power plant are integrated using feedforward neural networks (FNN), trained and validated by Latin hypercube sampled (LHS) [95] data as described in [70]. PFC aerodynamic performance properties, structural design characteristics as well as the design and efficiency properties of the turbo-electric power train components were integrated based on custom-developed non-linear regression models. The detailed structural design results in terms of component weights and geometric properties were transferred through customized parametric data fittings. The turbo-electric powertrain design and performance information was incorporated through multi-dimensional data interpolation.

In order to facilitate an efficient, collaborative, distributed, multidisciplinary analysis and design process, a highly effective set of tools, infrastructure and processes is necessary. Therefore, basic requirements, common conventions, processes and infrastructure had been derived already at the beginning of the project, based on the organizational structure and the type of planned activities. The areas of data security, semantically correct data integration, consistency and traceability of results had been identified as of central importance. In result, a secure git server was set up for data exchange between the project partners. Versioning and branching guidelines were developed at the beginning of the project and refined throughout the project in order to facilitate convenient data traceability and consistency. A consistent set of suitable formats for data exchange was defined, in order to support an efficient exchange of data. The developed infrastructure, policies and procedures for the efficient and secure data handling in CENTRELINE is reported by Shamiyeh [96]. The multi-partner, multi-disciplinary workflow is discussed in detail by Troeltsch at al. [97]. A detailed overview and discussion of the system-level knowledge integration for the overall aircraft design including specifications of the individual data and surrogate model parametric characteristics is provided by Habermann et al. [69]. 


\subsection{Aircraft Sizing and Performance Modeling}

The overall sizing process for the R2035 and PFC aircraft families in CENTRELINE was implemented using a customized version of the commercial aircraft preliminary design (APD) software within the modeling environment Pacelab Suite [98]. The APD software offers a set of handbook methods for aircraft conceptual design mostly based on Torenbeek [99]. As a starting point for the present activities, a customized version of the framework featuring comprehensively supplemented methodology based on Bauhaus Luftfahrt (BHL) in-house developed semi-empirical and analytical methods was employed (cf. [70,100-102]). During the CENTRELINE project, the baseline methods were systematically replaced by the surrogate models and datasets produced from the in-depth analyses of the PFC-specific design and performance aspects as described in the previous sections.

The R2035 and PFC aircraft sizing was performed using typical family sizing conditions, i.e., with the three members of the family (shrink, baseline, and stretch) sharing a majority of components. Each of the shared components is sized for the most critical requirement with in the aircraft family. The stretch and shrink members of both families of the aircraft are derived from the baseline variant by adding or removing common barrel sections from the baseline fuselage, respectively. The commonly used empennage accords to the shortest family member (shrink version). The wing, landing gear, main propulsion system, pylons, and other aircraft subsystems are sized for the largest family member (stretch). The geometry of the FF propulsion system is aerodynamically optimized for the baseline aircraft. The sizing of the FF PT is driven by the take-off power requirements of the stretch version. A compact overview of the specific component sizing laws followed for the R2035 and PFC aircraft families is provided in Table 12.

The core of the integrated PFC aircraft performance modeling in CENTRELINE is the point performance evaluation scheme depicted in Figure 29. The total aircraft thrust demand $\mathrm{FN}_{\text {req }}$ is calculated from the aerodynamic performance of the aircraft at a specific point of the flight envelope, for which the operational parameters altitude, ISA temperature deviation and flight Mach number are prescribed. The FPR schedule for the FF (see below) determines the instantaneous FPR for the given operating condition. All parameters serve as an input to the bare PFC aerodynamic model presented in [69], which predicts the NPF and the required ideal FF shaft power as introduced in Section 2.1. The NPF is subtracted from the total net thrust $\mathrm{FN}_{\text {req }}$ in order to calculate the thrust requirement for the main engines, $\mathrm{FN}_{\text {MainPPS }}$ discussed in Section 5.4. The FF performance model (cf. Section 4.1) delivers the actual shaft power required by the FF, $\mathrm{P}_{\text {Shaft }}$ and the corresponding shaft speed $\mathrm{N}_{\text {Shaft }}$ for the operating point. Subsequently, the power requested from the main engine generators is calculated in the FF power train model. With the generator power offtake taken into account, the main power plant model returns the fuel flow $\mathrm{W}_{\text {fuel }}$ for the operating point.

The FF is operated at its design FPR of 1.4 during cruise. In take-off, FPR is limited to 1.2 as a best and balanced trade-off between overall propulsion system performance and the component weights of the turbo-electric FF power train. During climb, FF performance is controlled by a linearized schedule of FPR versus flight altitude. While flow incidence angles relative to the fuselage longitudinal axis are assumed to be small during high-speed operation in clean aerodynamic configuration. Bare PFC performance effects during takeoff rotation and initial climb with high angles of attack are taken into account based on a dedicated 3D CFD simulation at low-altitude and low-speed featuring an incidence angle $10^{\circ}$.

The aircraft design mission simulation includes a step cruise profile with three steps targeting a maximum specific air range for each cruise point. Standard climb is conducted using a 250/300 KCAS schedule. Design ToC is at M0.82, FL350, ISA +10K. For the determination of design loaded fuel, international reserves with $200 \mathrm{nmi}$ diversion, $30 \mathrm{~min}$ hold, $5 \%$ final reserves are considered. 
Table 12. Overview of specific component sizing laws for the R2035 and PFC aircraft families.

\begin{tabular}{|c|c|}
\hline Component & Characterization of Key Sizing Conditions \\
\hline Wing & $\begin{array}{l}\text { Wing span: Variable, with fixed aspect } \\
\text { ratio } A R=12.0 \text {. } \\
\text { Wing loading: Scaled to meet required } \\
\text { landing field length. } \\
\text { - High-lift: } C_{\mathrm{L}, \max } \text { Scaled to meet approach } \\
\text { speed requirements. }\end{array}$ \\
\hline Empennage & $\begin{array}{l}\text { - } \quad \text { Sizing based on tail volume coefficients. } \\
\text { PFC T-tail: 5\% reduced relative to R2035 } \\
\text { with conventional tail. } \\
\text { Potential stability and control } \\
\text { enhancements due the FF cowling } \\
\text { neglected, in the first instance (cf. [69]). }\end{array}$ \\
\hline Fuselage & $\begin{array}{l}\text { - Sizing: Design payload in 2-class, } \\
\text { nine-abreast seating arrangement in } \\
\text { economy class (6.09 m diameter). } \\
\text { Family design via common barrel } \\
\text { sections. Family members share fuselage } \\
\text { nose and tail (incl. FF in PFC case). }\end{array}$ \\
\hline Landing gear & $\begin{array}{l}\text { - Main gear extended length determination } \\
\text { for required tail strike angle. } \\
\text { - Constant load distribution between nose } \\
\text { and main gear. }\end{array}$ \\
\hline Main power plants & $\begin{array}{l}\text { Flow path sizing in order of meeting } \\
\text { take-off field length and time-to-climb to } \\
\text { initial cruise altitude requirements. } \\
\text { Identical cycle design settings at flow } \\
\text { path sizing point (MCL@ToC). }\end{array}$ \\
\hline Fuselage fan * & $\begin{array}{l}\text { - Flow path sizing for design cruise } \\
\text { conditions. } \\
\text { FPR during take-off limited by trade-off } \\
\text { between FF performance and TEPT } \\
\text { weight. }\end{array}$ \\
\hline Turbo-electric power train * & $\begin{array}{l}\text { FF electric drive motor sizing for max. } \\
\text { required torque (take-off) and speed } \\
\text { (top-of-climb). } \\
\text { Power electronics and electric generator } \\
\text { sizing for max. power demand (take-off). }\end{array}$ \\
\hline
\end{tabular}




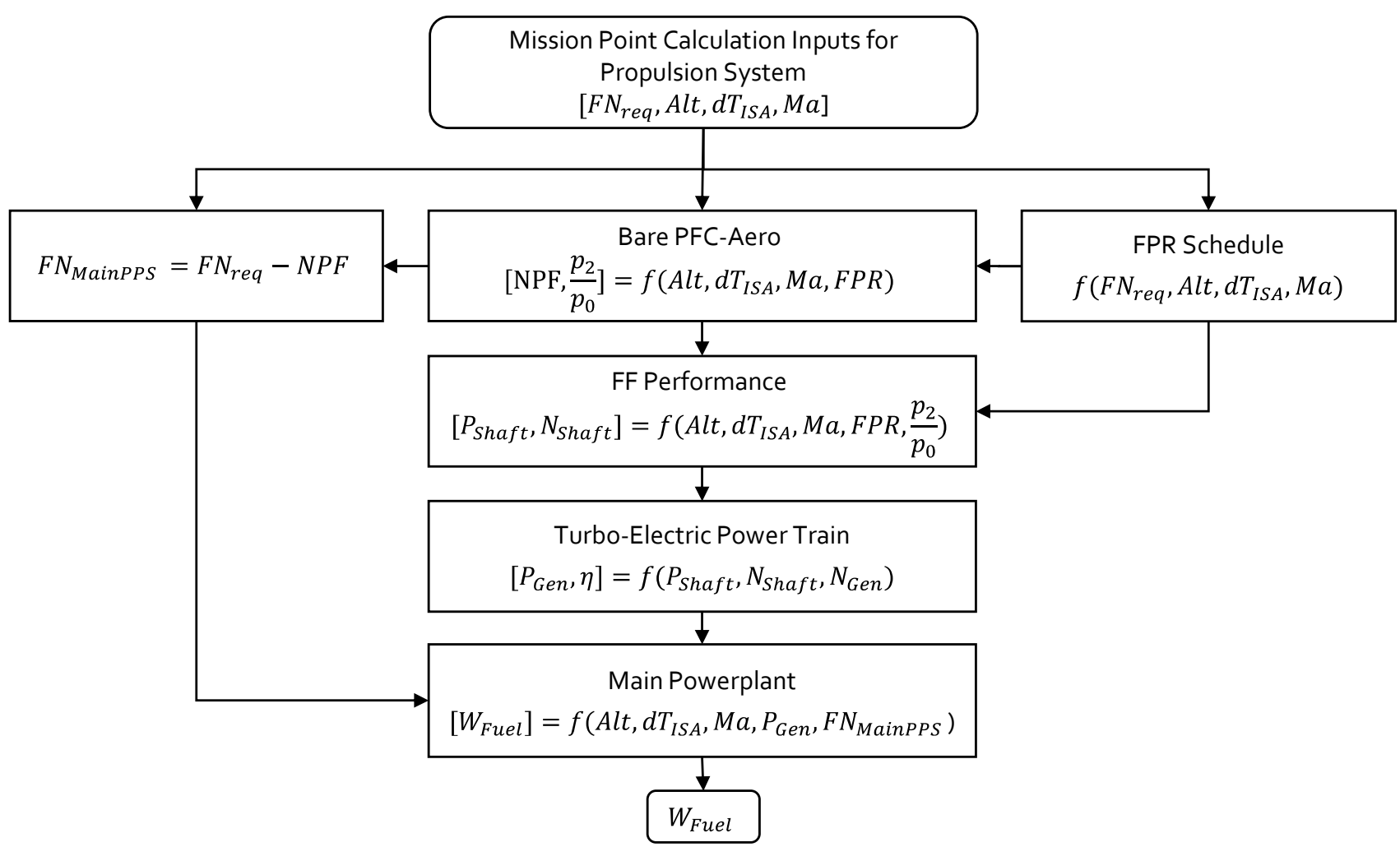

Figure 29. Logic for PFC point performance evaluation within aircraft sizing framework (adapted from [97]).

\subsection{Preliminary System Safety Analysis}

As part of the aircraft-level design integration effort, a partial system safety assessment was performed. The basis for the safety assessment process (SAP) activities was formed by the CS-25 [76], SAE ARP4761 [103], and SAE ARP4754 [104] standards. The execution of the complete SAP as defined in the ARP4761 was out of scope for the CENTRELINE project. However, the large number of conventional components in the overall technology set, allowed the focus of the SAP activities to be placed specifically on the parts directly connected to the technological innovations of the project. In specific, the actions carried out were a partial aircraft and system level function hazard assessment (FHA), a partial aircraft level failure tree analysis (FTA), and partial a preliminary system safety assessment (PSSA) together with its system level FTA.

The first step of the aircraft level FHA was the selection and definition of the relevant aircraft top level functions. From the examples given by SAE ARP4754, only the "Engine Control" was selected to be analyzed in the SAP activities. Subsequently, the aircraft level FHA process was conducted with the steps defined by SAE ARP4754:

1. Identification of related failure condition(s).

2. Identification of the effects of the failure condition(s).

3. Classification of each failure condition based on the identified effects (i.e., catastrophic, hazardous/severe-major, major, minor, or no safety effect) and assignment of the necessary safety objectives, as defined in AC 25.1309-1A and AMJ 25.1309 extended to include the no safety effect classification.

4. Identification of the required system development assurance level.

5. A statement outlining what was considered and which assumptions were made when evaluating each failure condition (e.g., adverse operational or environmental conditions and phase of flight).

The steps in this process were executed and key information connected to the identified failure conditions was collected. Therefore, the template provided by Kritzinger [105] was 
used. From the resulting failure conditions, the hazardous and catastrophic rated conditions as listed in Table 13 were analyzed further for their most critical flight phase.

Table 13. Identified hazardous and catastrophic aircraft level failure conditions specific to the CENTRELINE PFC aircraft.

\begin{tabular}{|c|c|c|c|}
\hline ID & Failure Condition & Phase & Severity \\
\hline 2.1.2.a & $\begin{array}{l}\text { Unannounced partial loss } \\
\text { of ability to provide thrust }\end{array}$ & Take-off & Hazardous \\
\hline 2.1.3.a & $\begin{array}{c}\text { Complete loss of ability to } \\
\text { provide thrust }\end{array}$ & Take-off & Catastrophic \\
\hline 2.1.4.a & $\begin{array}{l}\text { Unforeseen vibration } \\
\text { frequencies and/or } \\
\text { amplitudes }\end{array}$ & Take-off & Hazardous \\
\hline 2.1.5.a & $\begin{array}{l}\text { Ignition of fire in the } \\
\text { electric components of } \\
\text { the FF }\end{array}$ & Take-off & Hazardous \\
\hline 2.1.6.a & $\begin{array}{l}\text { Ingestion of foreign object } \\
\text { or ice in the FF }\end{array}$ & Take-off & Hazardous \\
\hline 2.2.1.a & $\begin{array}{l}\text { Announced loss of } \\
\text { command authority for } \\
\text { thrust control }\end{array}$ & Take-off & Hazardous \\
\hline 2.2.2.a & $\begin{array}{c}\text { Unannounced loss of } \\
\text { command authority for } \\
\text { thrust control }\end{array}$ & Take-off & Catastrophic \\
\hline 2.2.3.a & $\begin{array}{l}\text { Announced erroneous } \\
\text { thrust control }\end{array}$ & Take-off & Hazardous \\
\hline 2.2.4.a & $\begin{array}{c}\text { Unannounced erroneous } \\
\text { thrust control }\end{array}$ & Take-off & Catastrophic \\
\hline
\end{tabular}

Each of these failure conditions was used as a top event in a specific FTA diagram. The top event probability was defined by the allowable quantitative probability in average probability per flight hour of failure occurrence, i.e., $10^{-9}$ for the as catastrophic and $10^{-7}$ for the as hazardous classified failure conditions (cf. CS-25 [76]). The accumulated probability of the events leading to the top event must not exceed the probability of the top event. The probabilities of an AND gate, meaning that both events have to occur for the higher event to occur, are multiplied. The probabilities of an OR gate, meaning that both events have to occur for the higher event to occur, are added. The probabilities of the events leading to the top event were assigned by either known data or experience. As an example, the FTA for the failure condition "Complete loss of ability to provide thrust" is shown in Figure 30.

The bottom events of these aircraft level FTAs were then distributed amongst the partners responsible for the respective systems and the process was repeated at system level, thereby executing the PSSA as a part of a partial system level safety assessment. The system level PSSA was successfully executed for all PFC specific component failure modes and target levels for maximum allowable failure probabilities were determined along the associated functional chains. In no occasion, concerns were raised by the expert partners regarding the criticality of achieving the required levels of failure probabilities for the involved basic events. The component specific safety goal obtained from the SAP provided valuable guidelines in the design decision-making processes in CENTRELINE. 


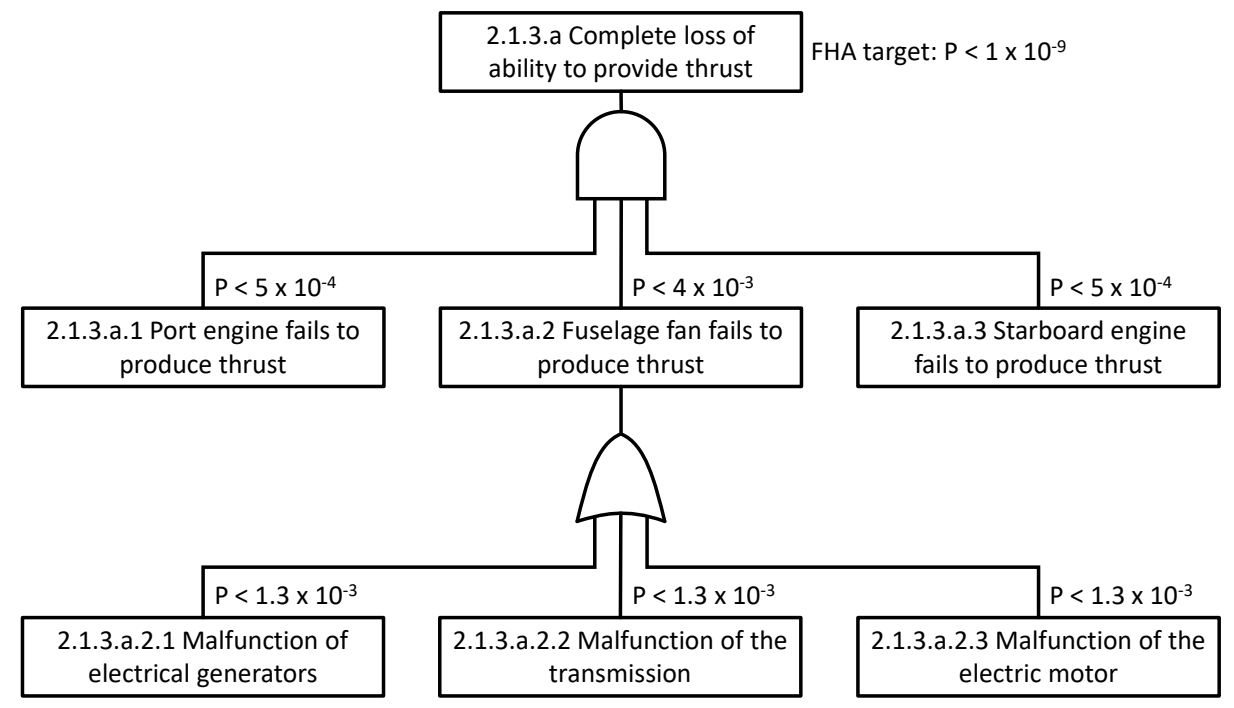

Figure 30. Example FTA for complete loss of ability to provide thrust for the CENTRELINE PFC aircraft.

\section{Aircraft-Level Evaluation Results}

An overview of key results and insights gained from the PFC aircraft design and technology evaluation is provided in the following. This include a brief discussion of fundamental aspects for optimum fuselage BLI aircraft design. A summary of the current maturity of the PFC technology together with an outlook towards further technology development steps is presented. Eventually, the final design and performance benchmarking for the CENTRELINE PFC aircraft is presented and discussed together with the results from the multi-disciplinary technology evaluation including noise, emissions and cost assessments.

\subsection{Fundamentals of Optimum Fuselage BLI Aircraft Design}

Before the integrated CENTRELINE PFC aircraft design results will be presented and benchmarked against the R2035 reference aircraft family, the discussion of a few fundamental aspects on fuselage BLI aircraft design optimality for maximum power savings is warranted. Therefore, a multitude of refined and optimized 2D aero-shapings of the bare PFC configuration as obtained from the EU-funded DisPURSAL and CENTRELINE projects have been analyzed with regard to the $f_{\eta, P F C, \text { bare }}$ metric by Seitz et al. [50]. The aerodynamic data basis of the analysis was formed by 2D-axisymmetric RANS CFD simulations conducted for typical cruise conditions at zero angle of attack. A common heuristic for $f_{\eta, P F C, \text { bare }}$ as a function of $\mathrm{P}_{\text {disc, FF }}$ was derived from the best aero-shaping cases of both projects.

A more generalised version of the heuristic is presented in the following. Therefore, the FF isentropic power values for all given bare PFC configuration cases were non-dimensionalized by reference fuselage drag powers, i.e., the products of reference fuselage drag values $D_{\text {Reffus }}$ and given flight velocities $V_{0}$, yielding the non-dimensional $F F$ isentropic powers $P_{\text {disc, FF,non-dim }}$

$$
P_{\text {disc }, F F, \text { non-dim }}=\frac{P_{\text {disc }, F F}}{D_{\text {Ref }, f u s} \cdot V_{0}}
$$

The correspondingly upgraded BLI efficiency factor analysis chart featuring a nondimensionalized abscissa is presented in Figure 31. 


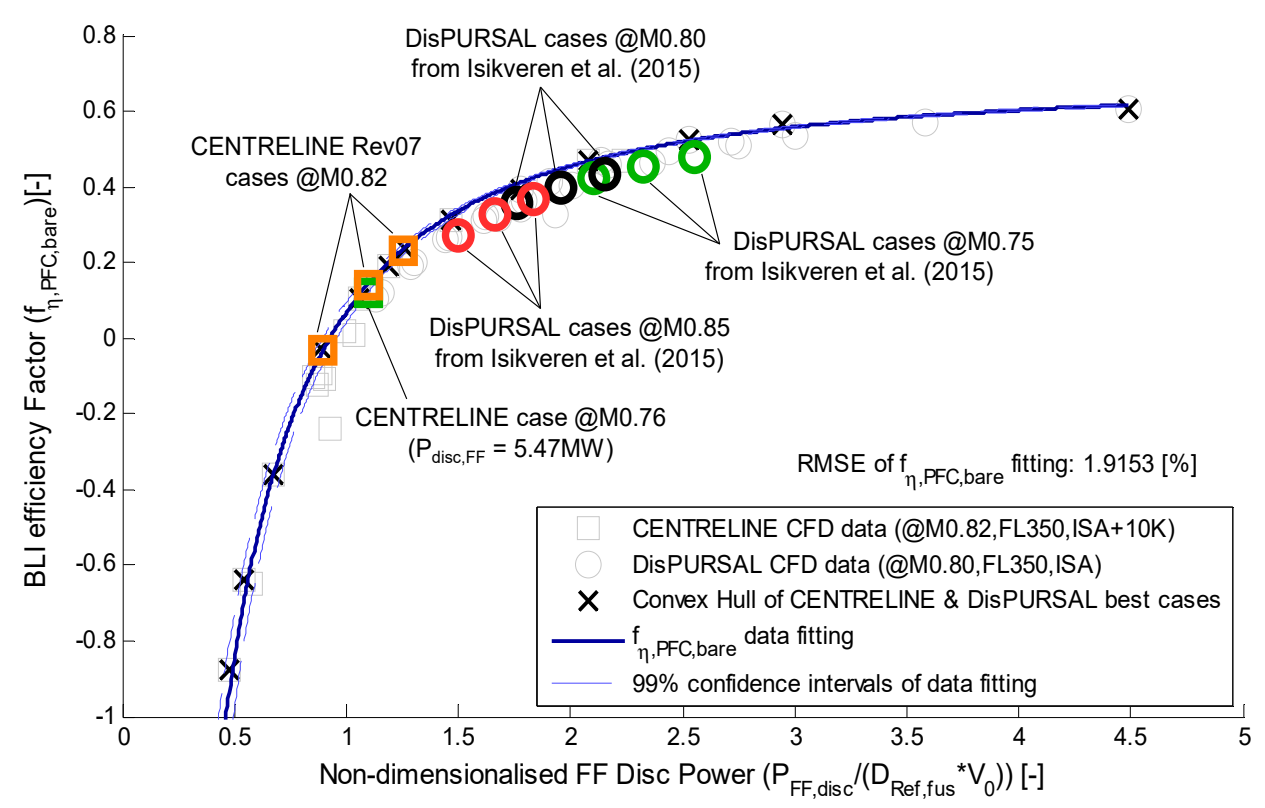

Figure 31. Non-dimensional analysis of BLI efficiency factor for CENTRELINE and DisPURSAL aero-shapings (adapted from [50]).

With the original $f_{\eta, P F C, \text { bare }}$ versus $P_{\text {disc, } F F}$ chart and its validation discussed in detail by Seitz et al. [50], inspection of Figure 31 reveals that the basic shape of the Pareto front formed by the best bare PFC 2D aero-shaping cases is retained. The generalised form of the data-fitting curve for the best designs originally introduced by Seitz et al. [50] yields

$$
f_{\eta, P F C, \text { bare }}=0.6863-0.7321 \cdot\left(P_{\text {disc }, F F, \text { non }-\operatorname{dim}}[M W]+0.1177\right)^{-1.5334}
$$

Beyond the bare PFC designs contained in the original study, in Figure 31 above, a number of additional cases is added. These involve the final PFC 2D aero-shapings of CENTRELINE (Rev07, cf. Table 2) as well as cases for a range of different cruise Mach numbers. Beside a CENTRELINE design featuring a $P_{\text {disc }, F F}$ of $5.47 \mathrm{MW}$ that was optimized for a reduced cruise Mach number of 0.76 , an array of cases from a speed sensitivity performed as part of the DisPURSAL project has been incorporated from [25]. Despite the slight sub-optimality of the addition DisPURSAL cases when compared to the Pareto front of best designs, it is apparent that even for varying cruise speeds between approximately M0.75 and M0.85 the non-dimensional $f_{\eta, P F C, b a r e}$ heuristic is a good indication for 2D bare PFC performance. Accordingly, lower cruise Mach numbers lead to higher $P_{\text {disc,FF,non-dim }}$

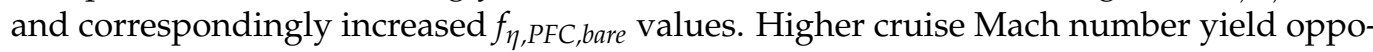
site trends along the heuristic curve. This observation made for the DisPURSAL speed sensitivities is basically confirmed by the M0.76 design case featuring almost identical $P_{F F, \text { disc }}$ as the lowest power case of the Rev07 designs for M0.82. The displacement to higher $f_{\eta, P F C, \text { bare }}$ and $P_{F F, \text { disc,non-dim }}$ directly along the heuristic curve is visible as a first order effect in Figure 31.

For steady level flight, the heuristic provided in Equation (8) can be directly used in order to calculate optimum power saving potentials for PFC aircraft based on the analytical formulation derived by Seitz et al. [50]

$$
P S C=1-\left(\frac{D_{P F C, r e s}}{D_{\text {Ref,tot }}}+\frac{P_{\text {disc, } F F}}{V_{0} \cdot D_{\text {Ref,tot }}} \cdot\left(\frac{\eta_{p d, e f f}}{\eta_{P T, F F} \cdot \eta_{p o l, F F}}-f_{\eta, P F C, \text { bare }}\right)\right)
$$

where $D_{P F C \text {,res }}$ refers to the sum of drag components of the PFC aircraft apart from the bare PFC configuration and $D_{\text {Ref,tot }}$ represents the total drag of the non-BLI reference aircraft at the given operating conditions. The efficiency figure $\eta_{p d, \text { eff }}$ refers to the effective propulsive 
device efficiency for the conventional non-BLI power plants of the PFC and the reference aircraft, describing the ratio of net propulsive power $\left(F N \cdot V_{0}\right)$ to the effective core engine excess power $P_{c o, e f f}$ as defined in Seitz et al. [50]. The aerodynamic efficiency of the fuselage and the transmission efficiency of the FF power train-i.e., the actual FF shaft power related to the power off-take from the main engine turbine-are reflected by $\eta_{p o l, F F}$ and $\eta_{P T, F F}$, respectively. The evaluation of Equation (9) for the CENTRELINE aircraft application scenario based on the bare PFC efficiency heuristic from Equation (8) immediately allows for the identification of maximum power saving potentials and correspondingly optimum FF isentropic powers $P_{F F, d i s c}$ as shown in Figure 32.

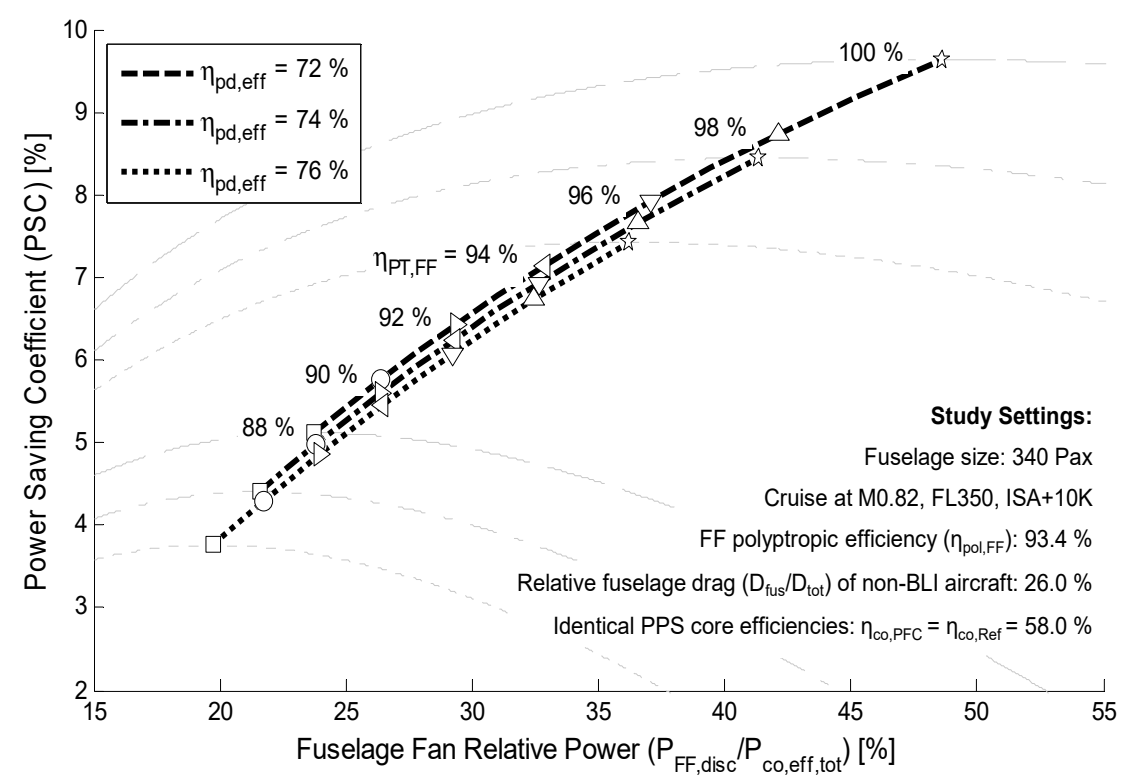

Figure 32. Identification of optimum power savings and corresponding FF cruise power settings for combinations of power train and non-BLI propulsive device efficiencies.

For the CENTRELINE specific settings and $\eta_{\text {pd,eff }}=74 \%$ for the main engines, under ideal power transmission conditions, i.e., $\eta_{P T, F F}=100 \%$, a $P S C$ of approximately $8.5 \%$ might be achieved with a corresponding optimum FF power share $P_{d i s c, F F} / P_{c o, e f f}$ of $41 \%$. For a turbo-electric power transmission as given in Table 11, the obtainable PSC value is $5.3 \%$ as optimum $P_{\text {disc }, F F} / P_{c o, e f f}=25 \%$. A potential mechanical transmission scenario featuring $\eta_{P T, F F}=98 \%$, would yield $P S C=7.7 \%$ for an optimum $P_{\text {disc }, F F} / P_{c o, e f f}$ of $37 \%$. It is obvious that larger transmission losses make a shift of power to the aft-fuselage BLI fan less attractive for maximum vehicular efficiency. The reduction of transmission losses is key to enabling high power saving potentials.

\subsection{Technology Readiness Level Assessment}

The maturation of the PFC technology to TRL 3-i.e., to perform the proof-of-concept for the promising technical approach to fuselage BLI propulsion integration-was one of the prime objectives for the research presented in this paper. In order to evaluate the maturity of the technical results developments, a TRL assessment was conducted for all critical components.

The first part of this section provides a compact overview of key technology component of the CENTRELINE PFC aircraft design and their TRLs at the end of the project. The overview is based on dedicated TRL assessments performed as part of the final deliverables of the individual tasks in CENTRELINE. Table 14 below lists the condensed assessment of the current TRL including component-specific justifications of the claimed TRLs. 
Table 14. Assessment of the current TRL of the PFC critical technologies.

\begin{tabular}{|c|c|c|}
\hline Aspect & TRL & Justification \\
\hline $\begin{array}{l}\text { Overall vehicle aerodynamic } \\
\text { design for fuselage BLI \& } \\
\text { wake-filling }\end{array}$ & $3-4$ & $\begin{array}{l}\text { The CENTRELINE PFC aircraft configuration } \\
\text { was investigated in a laboratory environment } \\
\text { (low-speed wind tunnel) at relevant flow } \\
\text { incidence angles [48]. The low-speed } \\
\text { scale-model experimental results were } \\
\text { extrapolated to full speed and scale based on } \\
\text { extensive CFD numerical analyses [58]. }\end{array}$ \\
\hline $\begin{array}{l}\text { FF aerodynamic design and } \\
\text { performance }\end{array}$ & $3-4$ & $\begin{array}{c}\text { The CENTELINE FF was 3D numerically } \\
\text { designed and tested in a laboratory } \\
\text { environment (low-speed fan rig) at relevant } \\
\text { operating conditions [106]. }\end{array}$ \\
\hline $\begin{array}{l}\text { Aero-structural integration of } \\
\text { FF propulsive device }\end{array}$ & 3 & $\begin{array}{l}\text { Numerical simulation of CS- } 25 \text { load cases } \\
\text { were executed, The primary structures were } \\
\text { sufficiently conservative designed and } \\
\text { analyzed with FEM using the certification } \\
\text { relevant load cases [80]. A partial SAP was } \\
\text { conducted and a sufficiently conservative } \\
\text { design was derived. }\end{array}$ \\
\hline $\begin{array}{l}\text { Turbo-electric power } \\
\text { transmission system }\end{array}$ & 3 & $\begin{array}{l}\text { The architectural definition, component } \\
\text { design the thermal management } \\
\text { specifications for the overall transmission } \\
\text { were performed system under consideration } \\
\text { of realistic system redundancy requirements } \\
\text { and failure modes [81]. }\end{array}$ \\
\hline FF electric drive & 3 & $\begin{array}{l}\text { Advanced numerical methods have been } \\
\text { used for the pre-design of the electric } \\
\text { machines in the drive train. The } \\
\text { electro-magnetic and structural design of the } \\
\text { electric machines was conducted in } \\
\text { compliance with the geometric, structural } \\
\text { and thermal boundary conditions in the } \\
\text { aft-fuselage environment. The applied } \\
\text { technology has been validated by } \\
\text { experiments outside of the CENTRELINE } \\
\text { project }[83,84] \text {. }\end{array}$ \\
\hline Electric generators & 3 & $\begin{array}{l}\text { The electro-magnetic and structural design of } \\
\text { the generator was conducted in compliance } \\
\text { with the geometric, structural and thermal } \\
\text { boundary conditions in the podded engine } \\
\text { environment }[82,89] \text {. }\end{array}$ \\
\hline $\begin{array}{l}\text { Underwing-podded power } \\
\text { plants }\end{array}$ & 3 & $\begin{array}{l}\text { A sufficiently conservative design based on a } \\
\text { comprehensive investigation of the impact of } \\
\text { significant power offtakes on cycle and } \\
\text { engine operating behavior } \\
\text { was conducted [88]. }\end{array}$ \\
\hline Overall aircraft design & 3 & $\begin{array}{l}\text { A sufficiently conservative aircraft sizing } \\
\text { with incorporation of detailed numerical } \\
\text { aerodynamic and key electrical component } \\
\text { data was executed. The baseline aircraft was } \\
\text { integrated in an aircraft family designed by } \\
\text { common industrial practices [69]. }\end{array}$ \\
\hline
\end{tabular}

At the heart of the PFC conceptual proof, the aerodynamic experiments on the overall configuration and the BLI propulsor validated the core technology of the PFC. Therefore, TRL 3 is claimed. However, even though the current research is considered at TRL 3, some aspects of the wind-tunnel and fan rig experiments are approaching TRL 4 . The numerical and analytical methods used to predict the PFC aerodynamic performance were validated against the experimental data. The design of the aero-structural components, 
all key elements of the propulsion system and the overall aircraft design synthesis was performed under realistic operating conditions, compliant with common industrial practice and by the adoption of sufficiently conservative design assumptions.

Further actions for increasing the TRL go from more elaborate numerical analysis and design optimization taking into account more detailed boundary conditions and physical effects, to experiments with increasing approximation of the relevant environmental conditions, leading up to sub and full-scale flight testing. An intermediate step in between experiments in commonly available wind tunnels and a scaled flight demonstrator would be a test campaign in a representative wind tunnel, able to recreate relevant flow conditions with sufficient accuracy. Tests in such facilities (e.g., the European Transonic Windtunnel) are very expensive. An alternative option, either in addition or as a substitute, could be the application of a 'flying wind tunnel'. The European funded demonstrator "Breakthrough Laminar Aircraft Demonstrator in Europe" (BLADE) testbed is an example of this concept [107]. BLADE employs an Airbus A340 [108] refitted with wing tips aiming at the assessment of natural laminar flow on a representative scale. Several configurational options are possible and are shown in Figure 33. The testbed could be fitted with wing-tip devices, representing a fuselage with and without a FF in different integration levels. A measurement of the occurring drag by the necessary compensation of yaw moment, or by a force scale at the junction of the test section, can provide information of the effectiveness of the FF under very representative environmental conditions. In addition, flow conditions could be monitored from the junction fairings, as is done for the BLADE tests. Alternative configurations are shown on the right side of Figure 33, featuring either an attachment on top of the fuselage or the replacement of an engine as is ofter done for engine program tests.

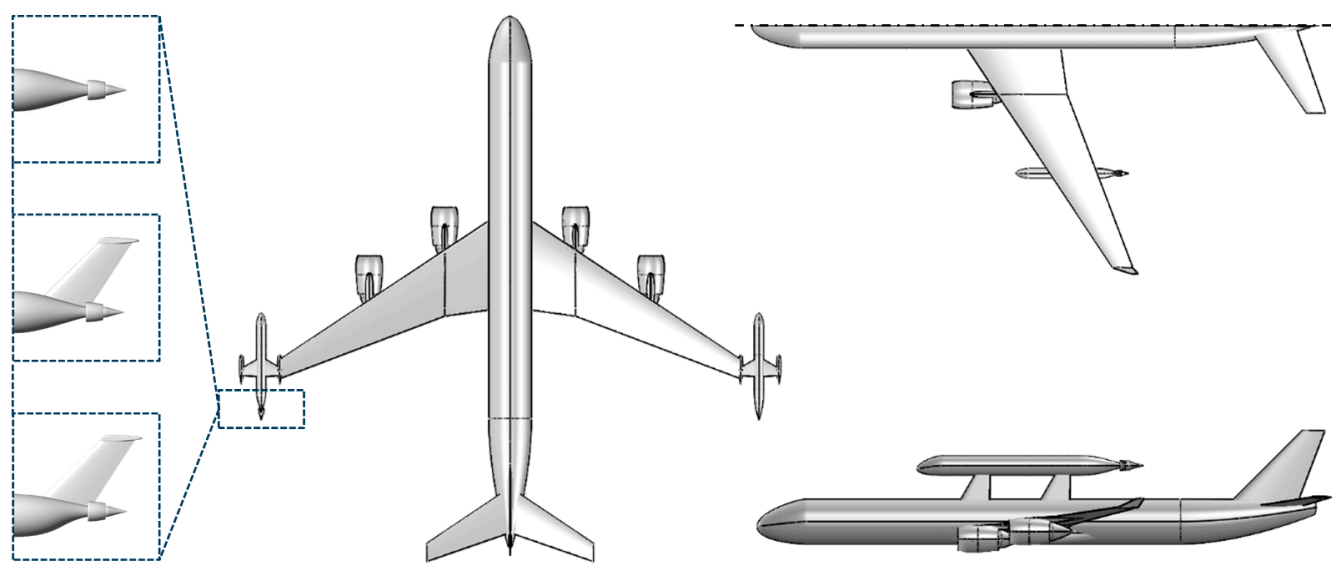

Figure 33. Basic schematic of PFC flying lab similar to the BLADE demonstrator aircraft.

Data acquired with such a testbed would also be applicable to different propulsion train architectures as, e.g., a turbo-mechanical drive train. Naturally, the last stage of the roadmap foresees the integration on a full-scale PFC configuration and consequently the progression of all technology maturities, sufficient to be included in the program of a production aircraft. More detailed discussion documentation of the technology maturation results within the CENTRELINE project as well as a detailed list of the necessary actions to advance the critical PFC technology aspects to target TRL6 is provided [109].

\subsection{Design and Performance Benchmarking}

The aircraft integrated sizing and performance benchmarking of the PFC technology versus the R2035 was performed as a family design exercise as described in Section 6.2. In the following, key characteristics of the final PFC baseline aircraft are presented and compared to the R2035 reference aircraft. Table 15 shows a comparison of important design properties for both aircraft. 
Table 15. Key design characteristics of the PFC and R2035 baseline aircraft.

\begin{tabular}{|c|c|c|c|c|c|}
\hline Category & Parameter & Unit & PFC & R2035 & $\begin{array}{c}\text { Delta } \\
(\%)\end{array}$ \\
\hline \multirow{7}{*}{ General } & PAX (2-class) & - & 340 & 340 & 0.00 \\
\hline & Design range $^{a}$ & nmi & 6500 & 6500 & 0.00 \\
\hline & MTOW $/ \mathrm{S}_{\mathrm{ref}}$ & $\mathrm{kg} / \mathrm{m}^{2}$ & 666 & 679 & -1.91 \\
\hline & SLST/MTOW & - & 0.32 & 0.33 & -3.03 \\
\hline & MLW/MTOW & - & 0.77 & 0.75 & 2.67 \\
\hline & OEW/MTOW & - & 0.55 & 0.53 & 3.77 \\
\hline & Design block $\mathrm{CO}_{2}$ & $\mathrm{t}$ & 196.6 & 206.2 & -4.66 \\
\hline \multirow{4}{*}{ Wing } & Reference area & $\mathrm{m}^{2}$ & 355.3 & 346.4 & 2.57 \\
\hline & Aspect ratio & - & 12.0 & 12.0 & 0.00 \\
\hline & Quarter chord sweep & $\circ$ & 29.7 & 29.7 & 0.00 \\
\hline & Span & $\mathrm{m}$ & 65.8 & 65.0 & 1.23 \\
\hline \multirow{2}{*}{ Fuselage } & Total length & $\mathrm{m}$ & 67.0 & 66.7 & 0.43 \\
\hline & Diameter (centre section) & $\mathrm{m}$ & 6.09 & 6.09 & 0.00 \\
\hline \multirow{11}{*}{$\begin{array}{l}\text { Main power } \\
\text { plants }\end{array}$} & Design net thrust ${ }^{b}$ & $\mathrm{kN}$ & 54.6 & 59.8 & -8.70 \\
\hline & Design specific thrust ${ }^{b}$ & $\mathrm{~m} / \mathrm{s}$ & 86.0 & 86.0 & 0.00 \\
\hline & $\mathrm{OPR}^{\mathrm{b}}$ & - & 61.0 & 61.0 & 0.00 \\
\hline & $\mathrm{T}_{4}^{\mathrm{b}}$ & K & 1780 & 1780 & 0.00 \\
\hline & Relative HPT cooling air & $\%$ & 20.0 & 20.0 & 0.00 \\
\hline & Fan tip diameter & $\mathrm{m}$ & 3.21 & 3.36 & -4.46 \\
\hline & Design bypass ratio $b$ & - & 14.5 & 16.4 & -11.6 \\
\hline & SLS net thrust & $\mathrm{kN}$ & 376.6 & 343.6 & -8.76 \\
\hline & Mid-cruise net thrust ${ }^{c}$ & $\mathrm{kN}$ & 35.5 & 46.7 & -24.0 \\
\hline & Mid-cruise TSFC ${ }^{c}$ & $\mathrm{~g} / \mathrm{kN} / \mathrm{s}$ & 17.4 & 14.0 & +24.3 \\
\hline & Mid-cruise total fuel flow ${ }^{\mathrm{c}}$ & $\mathrm{kg} / \mathrm{s}$ & 1.24 & 1.31 & -5.52 \\
\hline $\begin{array}{l}\text { Main landing } \\
\text { gear }\end{array}$ & Extended length & $\mathrm{m}$ & 5.70 & 4.70 & 21.3 \\
\hline \multirow{5}{*}{$\begin{array}{l}\text { Turbo electric } \\
\text { power train }\end{array}$} & Total efficiency (take-off) & - & 0.914 & $\mathrm{n} / \mathrm{a}$ & $\mathrm{n} / \mathrm{a}$ \\
\hline & Total efficiency (cruise) & - & 0.919 & $\mathrm{n} / \mathrm{a}$ & $\mathrm{n} / \mathrm{a}$ \\
\hline & Total specific power ${ }^{\mathrm{d}}$ & $\mathrm{kW} / \mathrm{kg}$ & 2.10 & $\mathrm{n} / \mathrm{a}$ & $\mathrm{n} / \mathrm{a}$ \\
\hline & $\begin{array}{l}\text { Electric motor sizing power } \\
\text { (output) }\end{array}$ & MW & 10.0 & $\mathrm{n} / \mathrm{a}$ & $\mathrm{n} / \mathrm{a}$ \\
\hline & $\begin{array}{l}\text { Generator sizing power } \\
\text { (output per unit) }\end{array}$ & MW & 3.67 & $\mathrm{n} / \mathrm{a}$ & $\mathrm{n} / \mathrm{a}$ \\
\hline \multirow{6}{*}{ Fuselage fan } & Tip diameter & $\mathrm{m}$ & 2.26 & $\mathrm{n} / \mathrm{a}$ & $\mathrm{n} / \mathrm{a}$ \\
\hline & Rotor blade height & $\mathrm{m}$ & 0.57 & $\mathrm{n} / \mathrm{a}$ & $\mathrm{n} / \mathrm{a}$ \\
\hline & Design isentropic disc power $b$ & MW & 5.00 & $\mathrm{n} / \mathrm{a}$ & $\mathrm{n} / \mathrm{a}$ \\
\hline & Design pressure ratio ${ }^{b}$ & - & 1.40 & $\mathrm{n} / \mathrm{a}$ & $\mathrm{n} / \mathrm{a}$ \\
\hline & Max. take-off shaft power ${ }^{\mathrm{e}}$ & MW & 7.00 & $\mathrm{n} / \mathrm{a}$ & $\mathrm{n} / \mathrm{a}$ \\
\hline & Max. take-off pressure ratio ${ }^{\mathrm{e}}$ & - & 1.20 & $\mathrm{n} / \mathrm{a}$ & $\mathrm{n} / \mathrm{a}$ \\
\hline
\end{tabular}

a LRC (long range cruise), ISA, International allowances, $200 \mathrm{nmi}$ diversion. ${ }^{\mathrm{b}}$ MCL@ToC: FL 350, Ma 0.82, ISA + $10 \mathrm{~K} .{ }^{\mathrm{c}} \mathrm{FL} 370, \mathrm{M} 0.82$, ISA $+10 \mathrm{~K}$ at $50 \%$ design loaded fuel. ${ }^{\mathrm{d}}$ based on the FF design isentropic shaft power. ${ }^{\mathrm{e}} \mathrm{SL}$, $\mathrm{M} 0.23, \mathrm{ISA}+10 \mathrm{~K}$.

As can be seen from Table 15, key aircraft properties of the sized turbo-electric PFC aircraft differ from the R2035: The additionally installed propulsion system components and the associated structural design cascade effects yield an increased operating empty weight $(\mathrm{OEW})$ by $3.8 \%$. Maximum wing loading is reduced by $1.9 \%$ relative to the R2035, as a result of its higher maximum landing weight (MLW) fraction of MTOW. The maximum sea level static thrust (SLST) loading is reduced by $3.0 \%$ due to the PFC-specific thrust lapse characteristics during take-off. The PFC design block $\mathrm{CO}_{2}$ emissions are reduced by $4.7 \%$ relative to the $\mathrm{R} 2035$.

For a fair evaluation of the PFC technology, the wing aspect ratio was kept identical at 12.0 for both aircraft, the PFC and the R2035. It should however be noted, that with the given R2035 wing span of $65.0 \mathrm{~m}$, the PFC wing span exceeds the limit posed by ICAO 
Annex 14 Code E $(52 \mathrm{~m}<\mathrm{b}<65 \mathrm{~m})$ [110] by $0.8 \mathrm{~m}$. Enforcing compliance with the Code E span limit would yield an increase of PFC design block $\mathrm{CO}_{2}$ emissions by $0.6 \%$.

The total transmission efficiency of the turbo-electric FF power train is $91.9 \%$ during cruise. The overall turbo-electric power train specific power is $2.1 \mathrm{~kW} / \mathrm{kg}$ based on the power extraction from the main engines for the FF design isentropic shaft power of 5.0 MW which means a FF rotor tip diameter of $2.26 \mathrm{~m}$. The FF shaft power is limited to $7.0 \mathrm{MW}$, allowing for stable operation of the FF at an FPR of 1.2 in take off but minimizing electric system oversizing, and thus excess weight, with regard to the transmission power needed during cruise. The shape-optimized PFC overall fuselage length exceeds the R2035 fuselage by only $0.3 \mathrm{~m}$. The extended landing gear length of the PFC aircraft is increased by $1.0 \mathrm{~m}$ in order yield the same tail strike angle as the R2035. This additional landing gear length is smaller than half of the FF diameter due to the backwards shift of the aircraft center of gravity for the PFC aircraft and the associated longitudinal positions of the wing and the main landing gear.

The thermodynamic cycle settings for the R2035 power plants at flow path sizing point, namely design specific thrust, $\mathrm{OPR}, \mathrm{T}_{4}$ and relative HPT cooling are selected for minimum R2035 design block fuel (cf. [69]). To allow for a most straight-forward comparison, identical cycle design settings are adopted for the PFC main engines. As a result, both engine types feature the same maximum rated temperature levels for take-off and climb. While the R2035 power plants are sized for the time-to-climb requirement, which is typical for ultra-high BPR engines, the PFC main engine sizing is driven by the take-off field length (TOFL) requirement. This is a direct result of the FF maximum shaft power being limited to approximately 1.3 times the shaft power in cruise or top-of-climb conditions, which reduces the FF share of the total fan power in take-off considerably when compared to typical cruise. As a result, the ratio between take-off and cruise thrust is increased relative to the R2035 aircraft (cf. Table 15). With maximum rating settings identical to the R2035, the allowable TOFL becomes the active sizing constraint for the PFC main power. As a result, the PFC aircraft features a slightly short time-to-climb than the R2035, and, the PFC main engines operate at slightly lower power settings in cruise when compared to the R2035 engines.

Figure 34 presents the three view of the resultant PFC baseline aircraft. Dimensions are given in $\mathrm{mm}$ and rounded to the nearest 5 . The airfoils used for the lifting surfaces are the same as the airfoils used for the R2035 reference aircraft.

Table 16 presents the mass breakdown of the baseline family members of the R2000, R2035, and PFC aircraft family. Additionally, changes of the PFC aircraft compared to the R2035 aircraft are shown. A synopsis of key weight terms for all nine members of the CENTRELINE R2000, R2035, and PFC aircraft families is provided by Habermann et al. [69].

Compared against the R2000, all structural component weights are considerably reduced for the PFC aircraft. Most of the weight reduction is due to the technology advancement assumptions projected for the year 2035. In a direct comparison with the R2035, the PFC fuselage structural weight is increased by $1.8 \%$, due to the additional bending moment introduced by the BLI propulsion system. Endplate and lever arm effects inherent to the T-tail arrangement, offer sizing benefits for the PFC empennage relative to the conventional tail arrangement of the R2035. However, the weight of the VTP is increased over the R2035 due to the necessity to transmit the loads of the HTP through the fin. The HTP area is reduced, resulting in a $4.3 \%$ weight benefit. The increased MTOW and wing size yield a $1.1 \%$ rise in wing structural weight for the PFC. The increased landing gear length required for the PFC aircraft translates to an $11 \%$ increased weight of the undercarriage. The added weight of FF and TEPT constitute $17.62 \%$ of the total aircraft propulsion system weight. Payload, operational items, furnishing, and aircraft systems weights are kept unchanged between the R2035 and the PFC. 


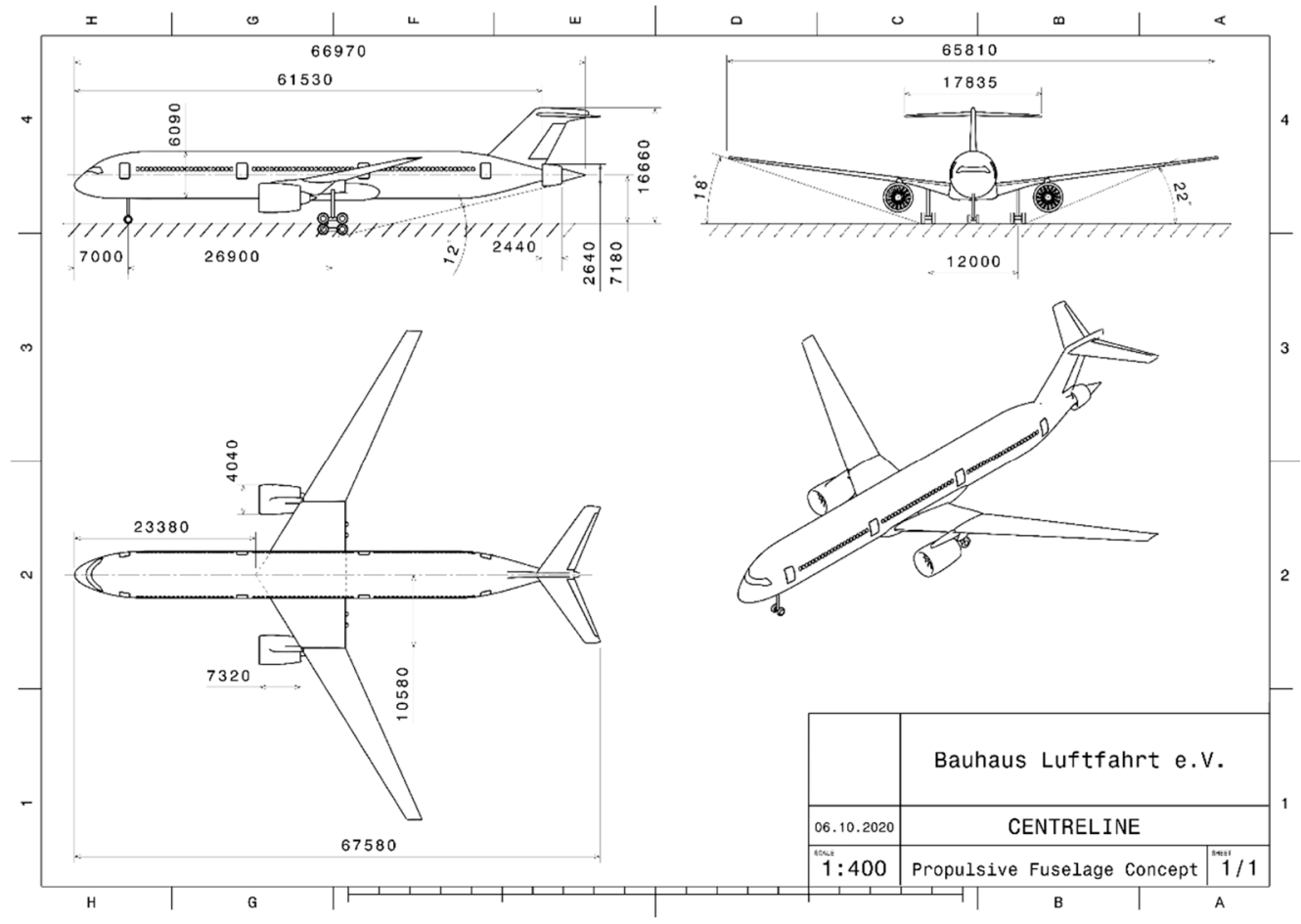

Figure 34. Three-view of the baseline member of the CENTRELINE PFC aircraft family, dimensions in mm.

Table 16. Mass breakdowns of the CENTRELINE R2000, R2035 and PFC baseline aircraft.

\begin{tabular}{|c|c|c|c|c|c|}
\hline Mass Term (kg) & R2000 & R2035 & PFC & PFC vs. R2035 (\%) & PFC vs. R2000 (\%) \\
\hline Structure Total & 97,388 & 76,280 & 78,364 & 2.73 & -19.5 \\
\hline Wing (incl. surface controls) & 46,770 & 37,075 & 37,484 & 1.10 & -19.9 \\
\hline Fuselage & 27,854 & 22,286 & 22,683 & 1.78 & -18.6 \\
\hline Horizontal stabilizer & 3144 & 1835 & 1757 & -4.25 & -44.1 \\
\hline Vertical fin & 2540 & 1936 & 2402 & 24.1 & -5.43 \\
\hline Undercarriage & 12,482 & 10,304 & 11,450 & 11.1 & -8.27 \\
\hline Pylons & 4598 & 2844 & 2588 & -9.00 & -43.7 \\
\hline Propulsion system & 23,167 & 18,637 & 21,253 & 14.0 & -8.26 \\
\hline Main power plants & 23,167 & 18,637 & 17,509 & -6.05 & -24.4 \\
\hline Bare engines & 16,217 & 12,232 & 11,742 & -4.01 & -27.6 \\
\hline Underwing nacelles & 6950 & 6405 & 5767 & -9.96 & -17.0 \\
\hline Fuselage fan propulsive device & $\mathrm{n} / \mathrm{a}$ & $\mathrm{n} / \mathrm{a}$ & 958 & $\mathrm{n} / \mathrm{a}$ & $\mathrm{n} / \mathrm{a}$ \\
\hline Fan module & $\mathrm{n} / \mathrm{a}$ & $\mathrm{n} / \mathrm{a}$ & 427 & $\mathrm{n} / \mathrm{a}$ & $\mathrm{n} / \mathrm{a}$ \\
\hline Nacelle and integration structure & $\mathrm{n} / \mathrm{a}$ & $\mathrm{n} / \mathrm{a}$ & 531 & $\mathrm{n} / \mathrm{a}$ & $\mathrm{n} / \mathrm{a}$ \\
\hline Turbo-electric power train & $\mathrm{n} / \mathrm{a}$ & $\mathrm{n} / \mathrm{a}$ & 2787 & $\mathrm{n} / \mathrm{a}$ & $\mathrm{n} / \mathrm{a}$ \\
\hline Main generators & $\mathrm{n} / \mathrm{a}$ & $\mathrm{n} / \mathrm{a}$ & 618 & $\mathrm{n} / \mathrm{a}$ & $\mathrm{n} / \mathrm{a}$ \\
\hline Fuselage fan drive motor & $\mathrm{n} / \mathrm{a}$ & $\mathrm{n} / \mathrm{a}$ & 700 & $\mathrm{n} / \mathrm{a}$ & $\mathrm{n} / \mathrm{a}$ \\
\hline Cabling & $\mathrm{n} / \mathrm{a}$ & $\mathrm{n} / \mathrm{a}$ & 586 & $\mathrm{n} / \mathrm{a}$ & $\mathrm{n} / \mathrm{a}$ \\
\hline Power electronics & $\mathrm{n} / \mathrm{a}$ & $\mathrm{n} / \mathrm{a}$ & 434 & $\mathrm{n} / \mathrm{a}$ & $\mathrm{n} / \mathrm{a}$ \\
\hline Cooling system & $\mathrm{n} / \mathrm{a}$ & $\mathrm{n} / \mathrm{a}$ & 449 & $\mathrm{n} / \mathrm{a}$ & $\mathrm{n} / \mathrm{a}$ \\
\hline Aircraft systems & 10,151 & 11,803 & 11,802 & -0.01 & 16.3 \\
\hline Operational items & 13,213 & 10,248 & 8354 & -18.5 & -36.8 \\
\hline Furnishing & 8154 & 8354 & 10,248 & 22.7 & 25.7 \\
\hline Operating empty weight & 152,072 & 125,322 & 130,021 & 3.75 & -14.0 \\
\hline Design payload & 32,300 & 34,000 & 34,000 & 0.00 & 5.26 \\
\hline Design reserves fuel & 10,986 & 10,570 & 10,416 & -1.46 & -5.19 \\
\hline Design landing weight & 195,358 & 169,892 & 174,438 & 2.68 & -10.7 \\
\hline Design trip fuel & 97,829 & 65,192 & 62,158 & -4.65 & -36.5 \\
\hline Maximum take-off weight & 293,187 & 235,084 & 236,596 & 0.64 & -19.3 \\
\hline Design block fuel & 97,951 & 65,453 & 62,403 & -4.66 & -36.3 \\
\hline
\end{tabular}


Key characteristics of the PFC baseline aircraft during the cruise phase of the design mission are presented in Figure 35. With a constant flight Mach number and FF FPR in cruise, the three flight level changes are directly visible in the trends of the flight altitude, ideal fuselage shaft power and the main engine fuel flow. The reduction of the shaft power absorbed by the FF is an immediate reflection of the reduction in air density as flight altitude is increased. The main engine fuel flow behavior results from the superposition of continuous loss in aircraft gross weight along the mission the power peaks associated with the en-route step climb maneuvers. The NPF of the bare PFC configuration stays fairly invariant when fuselage FPR is retained constant.

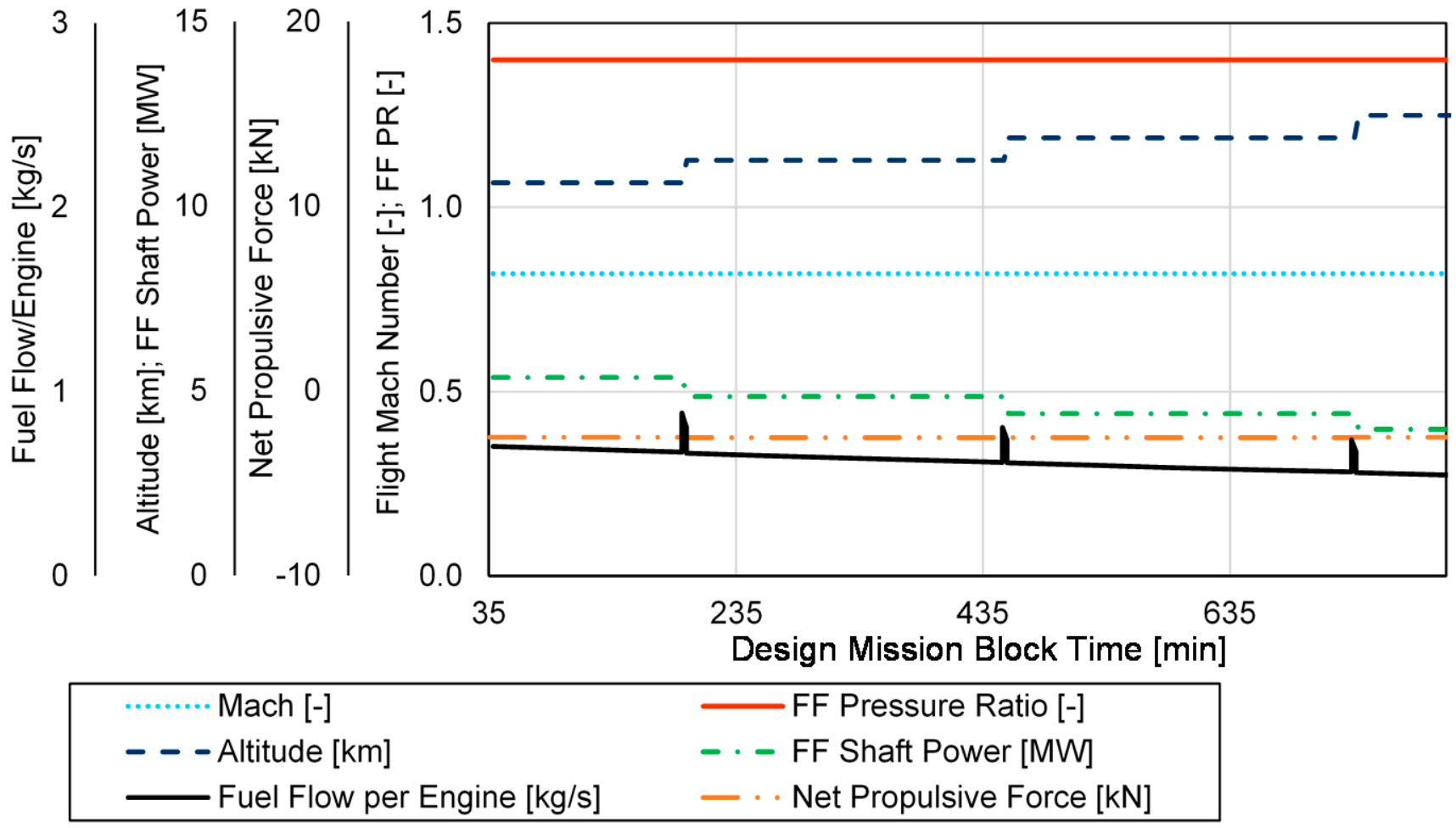

Figure 35. Simulated PFC aircraft specific performance characteristics recorded for the design mission cruise phase (adapted from [69]).

Due to the inherently different wing loadings, the family members feature different optimum initial cruise altitudes as well as individual optimum schedules for flight level changes during cruise. Figure 36 shows the step cruise mission profile of all PFC family members, targeting maximum specific air range for each cruise point. In specific, flight altitude and FF shaft power are plotted, again, with a constant FF PR of 1.40. As expected from the previous figure, the cruise altitude has a direct influence on the required ideal FF design shaft power. Despite the different stepping schedules, the FF power absorption at a given flight level; however, does only differ marginally by the order of $1 \%$ between the different members of the PFC aircraft family. This small difference at identical FPR is rooted in the change in actual fan mass flow due to the slightly different boundary layer profiles depending on the wetted fuselage area ahead of the FF for the individual PFC aircraft family members. In fact, the fuselage mass flow rate, and thus the fan power absorption, is the highest for the shrink family member. More detailed analyses of PFC mission performance characteristics including transversal flight phases are presented in [69]. 


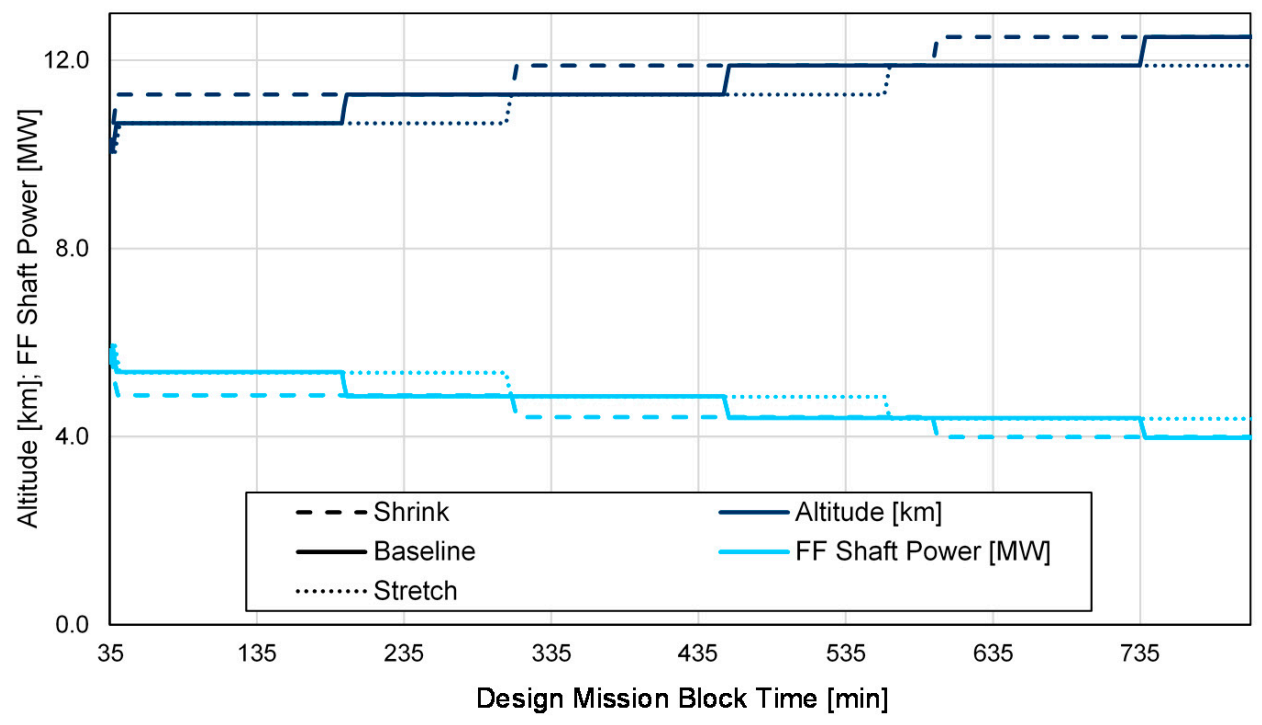

Figure 36. Cruise altitude and FF ideal shaft power profile for the PFC family members at Ma 0.82, ISA $+10 \mathrm{~K}$ (adapted from [69]).

\subsection{Propulsive Fuselage Multi-Disciplinary Evaluation}

To complete the PFC technology assessment, in this section a more detailed analysis of the main design and performance aspects that influence PFC aircraft fuel efficiency is provided together with assessments regarding $\mathrm{NO}_{\mathrm{x}}$ emissions, certification noise, and operating economics.

\subsubsection{Stepwise Analysis of Effects on PFC Fuel Efficiency}

In order to better resolve the key design and performance effects driving the fuel efficiency of the CENTRELINE PFC aircraft relative to the R2035 aircraft, an incremental analysis approach was followed. Therefore, a series of successive modifications to the aircraft platform were defined and evaluated in a stepwise manner using a simplified aircraft sizing and performance evaluation methodology as described in [111]. The individual steps defined for the incremental analysis approach are characterized in Table 17.

Table 17. Individual steps for incremental analysis of effects on PFC fuel efficiency.

Baseline-Idealized PFC design without cascade effects:

- $\quad$ FF cruise polytropic efficiency identical to underwing podded main fans

- Idealised efficiency of FF power train (losses identical to LP spool of main engines)

- Tail configuration identical to reference (conventional tail)

- $\quad$ FF power train specific power identical to main engines

- $\quad$ Adoption of pure optimum 2D-Aero heuristic for bare PFC aerodynamics

- $\quad$ No aircraft design scaling considered aircraft design (cf. Table 14) 
Steps 1 through 8 in the table above represent the scope of design integration results discussed in Section 7.3. In Step 9, the result of a preliminary assessment of the PFC aircraft performance impact due to 3D aerodynamic integration effects in cruise is included. The assessment was performed based the 3D RANS simulation results for an integrated PFC configuration with axisymmetric PFC aft-fuselage section, featuring attached wings, belly fairing, and vertical tail plane as presented by van Sluis and Della Corte [58]. A detailed discussion of the 3D performance assessment is provided by Seitz and Engelmann [111]. Here, the results of nine conceivable scenarios for the PFC 3D aerodynamic performance benchmarking were compared against the corresponding PFC aircraft performance based on the 2D aerodynamic design heuristic (cf. Section 7.1). The identified 3D aerodynamic discounts in terms of PSC ranged between 1.0 and $1.8 \%$, with a nominal scenario considered to the most comprehensive and realistic one out the nine scenarios yielding a PSC penalty of $1.5 \%$. This means an actual all integrated PSC value of $3.6 \%$ [111]. The 3D aerodynamic delta effects were incorporated within PFC aircraft sizing and performance evaluation through a calibration of the BLI efficiency factor heuristic (cf. Equation (8)) via constant offset values for the individual 3D aerodynamic benchmarking scenarios.

Important results gained from the incremental analysis of effects on PFC fuel efficiency are presented in Figure 37. Here, key figures of merit for the PFC resulting aircraft including the PSC metric, OEW, MTOW, and design mission fuel burn relative to the R2035. Also shown in the figure are the FF design isentropic shaft powers, which have been optimized for minimum PFC design mission fuel burn at each of step of the incremental analysis.

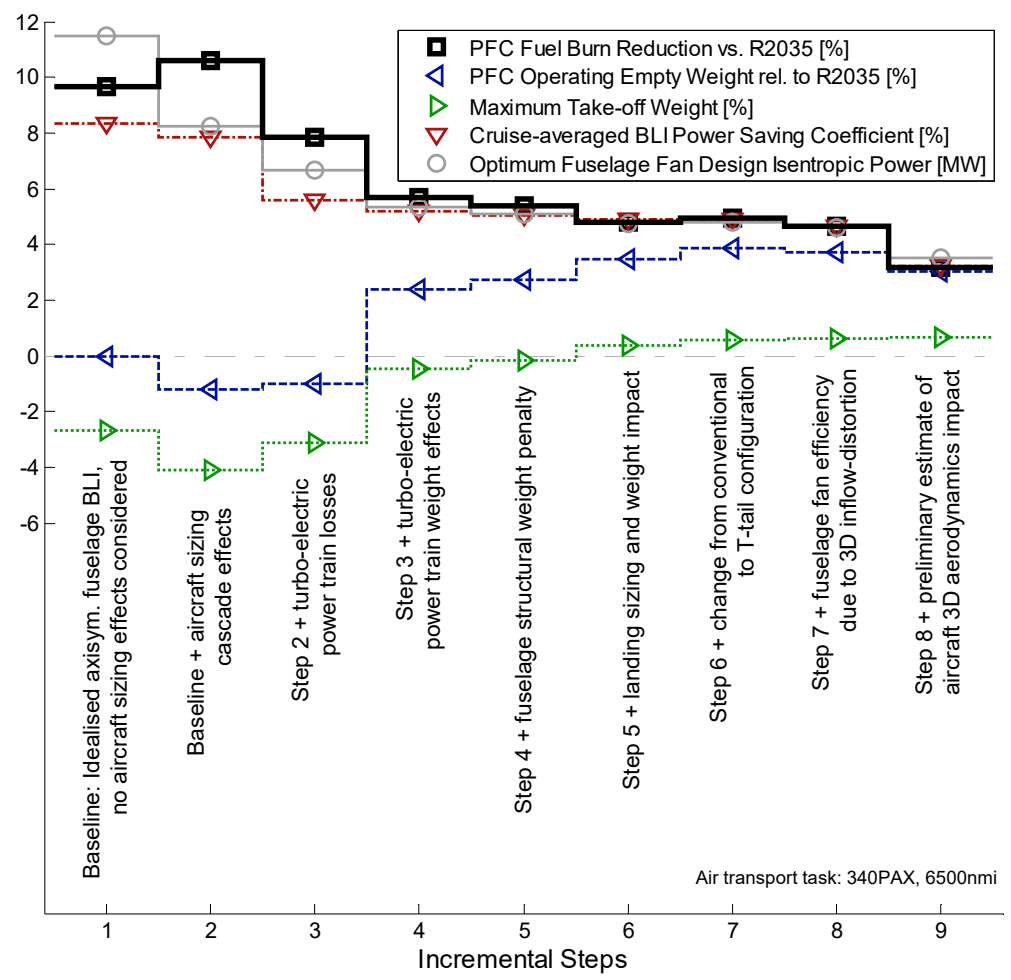

Figure 37. Stack-up of effects analysis on fuel burn reduction of CENTRELINE turbo-electric PFC against R2035 aircraft.

In the idealized analysis case without aircraft weight and sizing effects considered, namely Step 1, the highest power savings are obtained together with the highest FF design power, yielding a cruise-averaged PSC value of $8.6 \%$ and corresponding PFC fuel benefit of $9.9 \%$ for the given design range of $6500 \mathrm{nmi}$. With the unaffected OEW in this case, the PFC MTOW is reduced by $2.7 \%$ relative to the R2035. The $\mathrm{P}_{\text {disc,FF,des }}$ value of $11.9 \mathrm{MW}$ corresponds to a $43 \%$ share of $\mathrm{P}_{\mathrm{co}, \text { eff }}$ for the PFC aircraft. With aircraft scaling effects and 
propulsion system component weight evaluation included in Step 2, the overall aircraft sizing cascade starting from MTOW benefit given by Step 1, yields mass reductions for key airframe structural components, in particular the wing. The additive mass of the fuselage propulsive device is partially set off against a decrease in fuel optimum $P_{\text {disc,FF,des }}$ and a correspondingly reduced power saving potential. The resultant $1.1 \%$ net reduction in OEW and the associated lower aircraft gross weights during cruise is compounded by the fuselage drag share being boosted due to the reduced wing size and induced drag. On top of the pure PSC value, this yields an idealized fuel burn benefit for the CENTRELINE PFC aircraft of $10.7 \%$ relative to the similarly advanced R2035 aircraft without fuselage BLI technology.

The introduction of the transmission losses and the component masses associated with the FF turbo-electric power train in Steps 3 and 4, both, the power saving potentials and PFC OEW are penalized noticeably. In effect, leading to a reduction in PFC fuel benefit of approximately $5 \%$ relative to the idealized case in Step 2 . The particularly strong discount in fuel efficiency due to the transmission losses directly emanates from the reduced PSC. While in this case, aircraft gross weight effects remain mostly compensated by a decreased fuel optimum $P_{\text {disc,FF,des, }}$, the turbo-electric power train weight effect has a major impact with regard to an increased OEW. The airframe structural component mass penalties specific to the PFC, i.e., the reinforced fuselage (Step 5) and the resized landing gear (Step 6), have a combined effect of less than $1 \%$ on the PFC fuel benefit. Under consideration of the empennage sizing implications, the introduction of the T-tail is beneficial for the PFC aircraft (Step 7). This is the case even without a full accounting of the aerodynamic and aero-structural interaction a conventional tail would have with the aft-fuselage BLI propulsive device. The penalty in PFC fuel benefit due to the BLI impact on FF efficiency as introduced in Step 8 is approximately $0.3 \%$, yielding a net PFC fuel burn benefit against the R2035 of $4.7 \%$, which directly corresponds to PFC aircraft design result presented in the previous section of the paper. The PSC discount according the to nominal PFC 3D aerodynamic design and performance scenario translates into a $1.5 \%$ reduction of the PFC fuel benefit, leaving an all-integrated design mission fuel burn improvements of $3.2 \%$ for the CENTRELINE turbo-electric PFC aircraft, relative to the R2035. When assuming the most pessimistic from the conceived scenarios [111], the PFC fuel benefit yields $2.8 \%$, while the most optimistic from the conceived 3D aerodynamic scenarios would show a $3.7 \%$ PFC fuel benefit.

\subsection{2. $\mathrm{NO}_{\mathrm{x}}$ and Noise Assessments}

The environmental impact of the CENTRELINE PFC, as well as that of the two reference aircraft R2000 and R2035, has been evaluated at system level based on the ICAO certification regulations in terms of $\mathrm{NO}_{\mathrm{x}}$ and noise emissions. For the $\mathrm{NO}_{\mathrm{x}}$ emissions assessment, a standard ICAO landing and take-off (LTO) cycle is used with a suitable combustor technology assumed for the corresponding EIS year. For R2000, a correlation developed by AECMA (European Association of Aerospace Industries) which provides a good estimation of the $\mathrm{NO}_{x}$ emissions of large engines around the year 2000 is used [112]. For the advanced R2035 and PFC applications targeting an EIS in 2035, a Lean Direct Injection (LDI) concept is assumed. A correlation found in [113] is adopted. The correlation is based on experimental data with a similar total pressure $\left(p_{3}\right)$ level and marginally lower total temperature $\left(T_{3}\right)$ level as occurring at the HPC exit of R2035 and PFC main engine sea level static take-off operation. For the noise assessment, noise emissions from aircraft and engine components at the ICAO certification points (sideline, cutback, and approach) are calculated from component-based noise source modeling [114]. The total effective perceived noise level (EPNL) is then computed from the perceived noise level accounting for spectral irregularities and duration, as presented in the ICAO Noise Certification Workshop [115].

Results of the $\mathrm{NO}_{x}$ and noise assessments are given in the charts below based on [116]: The LTO $\mathrm{NO}_{\mathrm{x}}$ emissions data presented in Figure 38 are normalized by Trent $772 \mathrm{~B} \mathrm{NO}_{\mathrm{x}}$ 
emissions given in [117]. As can be seen, a $40 \%$ reduction in LTO cycle total $\mathrm{NO}_{\mathrm{x}}$ emissions is predicted for the R2035, and a reduction of $41 \%$ could be expected for the PFC, compared to the R2000 aircraft. This is mainly contributed by the radical improvement of the combustor technology and fuel burn reduction. On the other hand, due to the much higher OPR and turbine entry temperature of the main engine, R2035 and PFC actually have a much higher $\mathrm{EINO}_{\mathrm{x}}$ at high ratings than $\mathrm{R} 2000$.

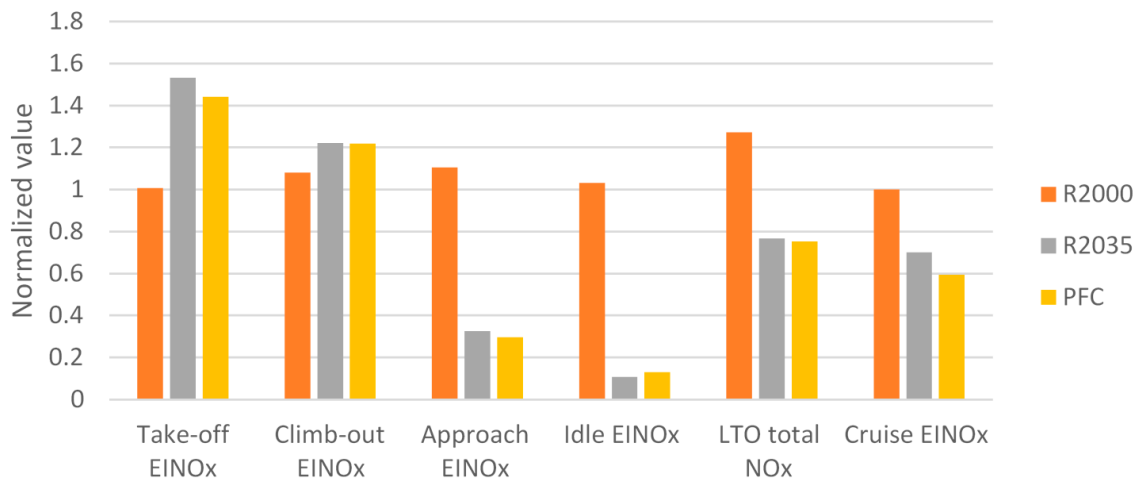

Figure 38. $\mathrm{NO}_{\mathrm{x}}$ emissions assessments results for the CENTRELINE R2000, R2035 \& PFC aircraft.

When comparing the PFC main engines against the R2035 power plants in cruise, the slightly lower part power settings of the PFC main engines (cf. Section 7.3) lead to a reduction in cruise $\mathrm{NO}_{x}$ emissions of $20 \%$ relative the $\mathrm{R} 2035$. Combining the low fuel consumption and low $\mathrm{EINO}_{\mathrm{x}}$ at cruise, which is the mass of $\mathrm{NO}_{\mathrm{x}}$ emitted per unit of mass of fuel burned, the cruise $\mathrm{NO}_{\mathrm{x}}$ emissions of the PFC would be as low as $36 \%$ of R2000.

Looking at the noise footprint shown in Figure 39, a considerably lower EPNL may be expected from the R2035 and PFC aircraft when compared to the R2000. A cumulative reduction of about $12 \mathrm{~dB}$ is observed. The key drivers for the lower noise level are the smaller size of the wing, the low FPR and low specific thrust design main engine fan. Between the R2035 and the PFC, the difference is, however, small. Uncertainty exists due to the FF inlet distortion. Several research activities focusing on BLI effects on noise generation, such as ONERA NOVA concept [34] and NASA D8 [118], have indicated a possible cumulative noise penalty up to $18 \mathrm{~dB}$. Nevertheless, these study objects are different from the CENTRELINE $360^{\circ} \mathrm{BLI}$ concept for which the FF is not the dominating source of noise. Assuming an increase of $10 \mathrm{~dB}$ in sound pressure level at the predicted directivity angle and predicted frequency for the entire reception time, the increase of FF EPNL is 6.98, 6.15, and 1.52 for sideline, cutback, and approach, respectively. Though the estimation is similar to the NASA D8 BLI penalty estimation [118], it increases the total cumulative EPNL by only 0.83 .

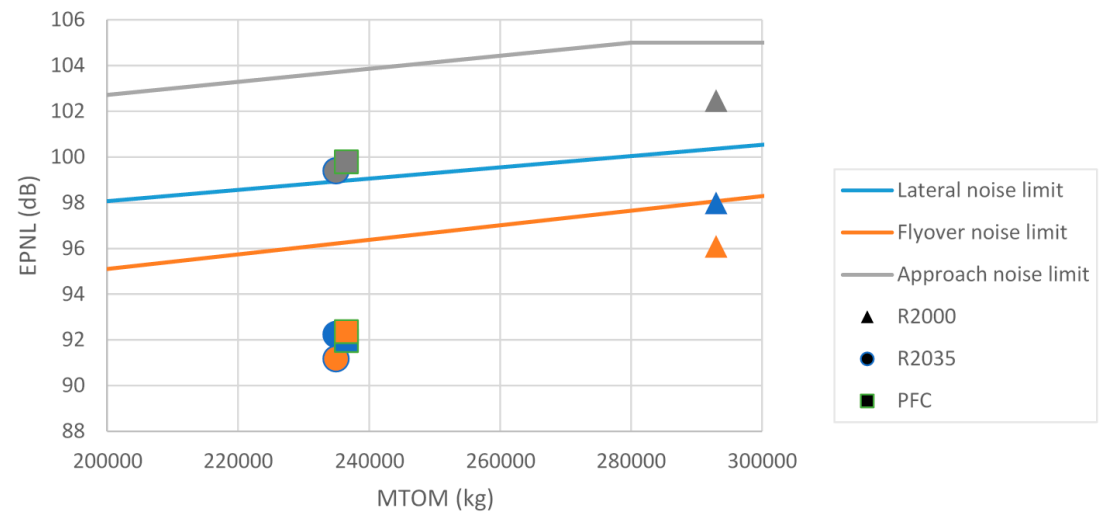

Figure 39. Noise emissions assessments results for the CENTRELINE R2000, R2035 \& PFC aircraft. 


\subsubsection{Cash Operating Costs Estimation}

For the purpose of an initial assessment of the operating economics of the CENTRELINE turbo-electric PFC technology, aircraft Cash Operating Costs (COC) were evaluated using ALiCyA (Aircraft Life Cycle Assessment), Bauhaus Luftfahrt's in-house cost assessment model. Initially based on methods introduced by [119], the model has been methodologically extended and customized (cf. $[120,121])$ and applied to PFC technology already in previous assessments [25].

In order of facilitate a fair comparison between the turbo-electric PFC and R2035 aircraft in CENTRELINE, specific model enhancements were developed to adequately resolve differences between the two configurations. A key aspect in this was the estimation of the direct maintenance costs (DMC) for both aircraft. Based on a reference DMC breakdown according to chapters defined by the Air Transport Association (ATA), individual scaling approaches for the cost of key chapters affected by the CENTRELINE technology were introduced. Moreover, emission charges suitable for a EIS 2035 scenario was adopted. D detailed discussion of the CENTRELINE COC model is provided in [111].

The actual COC assessment was performed for the PFC and R2035 aircraft as presented in Section 7.3 and reported in detail in [111]. Accordingly, the PFC aircraft is predicted exhibit by $9.5 \%$ increased DMC relative to the R2035, due to the additional FF and the turboelectric power train and the increased weights of key airframe components (cf. Table 15). Airport charges are increased due to the noise characteristics according to Section 7.4.2. The reduced fuel consumption and emissions of the PFC aircraft have positive effect of COC which is amplified when aspects such as possible fuel taxation or carbon pricing and offsetting cost for and EIS 2035 are taken into account. The result of a parametric study of design mission COC against a range of fuel prices is presented in Figure 40.

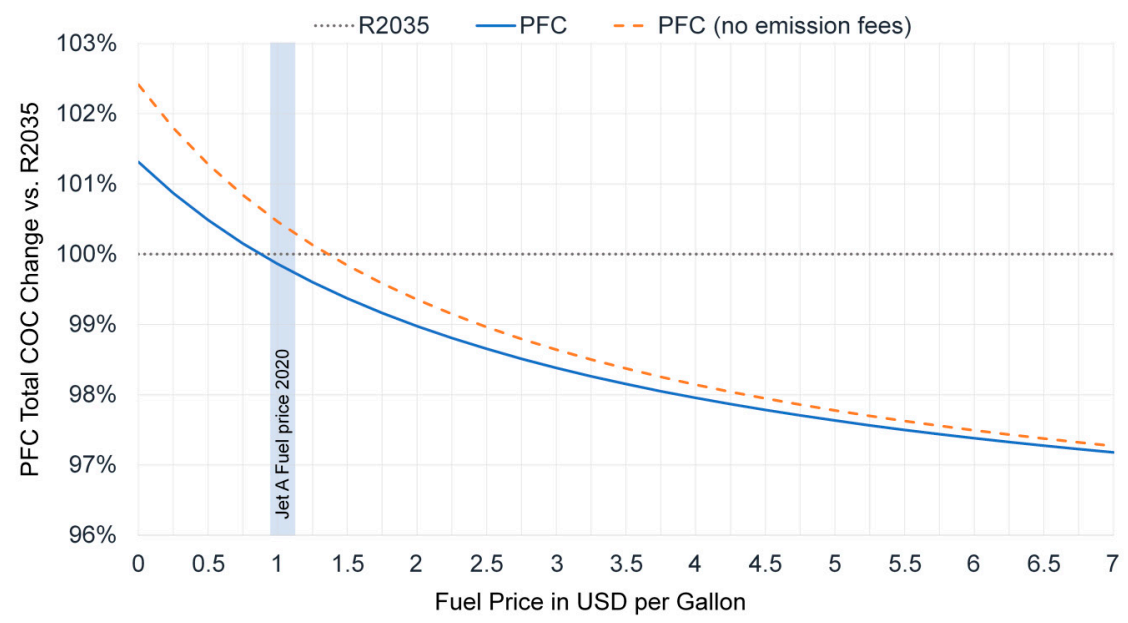

Figure 40. Fuel price study of CENTRELINE PFC versus R2035 design mission COC (adapted from [111]).

It can be observed that the PFC features reduced COC relative to the R2035, in case the fuel price of increases beyond US\$ 1.5 per gallon. If a scenario of possible fuel taxation or carbon pricing and offsetting cost for and EIS 2035 are taken into account, this threshold drops to approximately 1.0 US\$ per gallon, which corresponds an average Jet-A1 price in the year 2020. With future fuel prices, especially for sustainable aviation fuels, expected to rise considerably above current values, the PFC aircraft may be expected to feature lower COC than the R2035.

\subsubsection{Preliminary Assessment of More Advanced PFC Power Train Technology}

To round off, a preliminary study of alternative FF power train conceptual paradigms was conducted at a lower TRL basis. Two basic technology scenarios were considered: A 
turbo-electric power transmission using high temperature superconducting (HTS) technology and FF mechanical drive train. For the HTS technology case, a scenario with a cryogenic heat sink was considered to be available on-board the aircraft. This could be in the form of liquid hydrogen $\left(\mathrm{LH}_{2}\right)$ fuel, used as an energy source for the aircraft subsystems (cf. [25]) or as a primary fuel for propulsion purposes. Given the superior specific weights and dramatically reduced losses enabled by the HTS-specific current and flux densities in electrical machinery [122,123], target settings for an HTS turbo-electric transmission system were stipulated including a total power train efficiency of $\eta_{\mathrm{PT}, \mathrm{FF}, \mathrm{HTS}}=96 \%$ and a total specific power of $\mathrm{SP}_{\mathrm{PT}, \mathrm{FF}, \mathrm{HTS}}=5 \mathrm{~kW} / \mathrm{kg}$. The high design complexity and the system behavioral patterns specially in abnormal modes of operation involved with the application of HTS technology have not been considered. At the same time, further potential synergy effects between the PFC and hydrogen fuel technology, such as emanating from an increased fuselage wetted area when $\mathrm{LH}_{2}$ fuel is stored inside the fuselage, have not been accounted for, in the first instance. For the case of a mechanical FF drive train, efficiency, and specific power targets were set to $\eta_{\mathrm{PT}, \mathrm{FF}, \text { mech }}=98 \%$ and $\mathrm{SP}_{\mathrm{PT}, \mathrm{FF}, \text { mech }}=10 \mathrm{~kW} / \mathrm{kg}$. Specific architectural implications such as a detailed assessment of the aero-structural integration of the aft-fuselage BLI propulsive device have not been undertaken as part of this preliminary study. A specifically elaborated conceptual solution was presented to TRL 2 as part of the DisPURSAL project (cf. [25]). In Table 18, the aircraft-integrated results obtained for the HTS and mechanical FF power train scenarios are compared to the baseline turbo-electric transmission developed to TRL 3 in CENTRELINE. The aircraft-level evaluation for the results in the table refers to the approach introduced in Section 7.4.1. Specifically, Steps 8 and 9 of the incremental analysis are presented.

Table 18. PFC assessment results for more advanced power train technology.

\begin{tabular}{ccccc}
\hline Parameter & Unit & $\begin{array}{c}\text { Baseline } \\
\text { Turbo-Electric }\end{array}$ & $\begin{array}{c}\text { HTS } \\
\text { Turbo-Electric }\end{array}$ & Mechanical \\
\hline$\eta_{\mathrm{PT}, \mathrm{FF}}$ & - & $0.919^{*}$ & 0.96 & 0.98 \\
$\begin{array}{c}\mathrm{SP} \text { PT,FF } \\
\text { Fuel benefit }\end{array}$ & $\mathrm{kW} / \mathrm{kg}$ & $2.1^{*}$ & 5.0 & 10 \\
$\begin{array}{c}\text { (Step 8) } \\
\text { Fuel benefit } \\
(\text { Step 9 }\end{array}$ ) & $\%$ & 4.7 & 7.2 & 8.4 \\
\hline
\end{tabular}

* Cf. Table 15. ${ }^{* *}$ Nominal scenario acc. to Section 7.4.1.

The results of the preliminary evaluation of the considered more radical technology concepts for the FF power supply indicate improvements in the all integrated PFC fuel benefit (Step 9) over the R2035 aircraft of additional 2.0\% for the HTS and 3.0\% for the mechanical scenarios relative to the baseline turbo-electric design. For the fuel assessment at the level of 2D PFC aerodynamic design (Step 8), the evaluated reduction potentials against the R2035 yield 7.2\% and 8.4\% for the HTS and mechanical cases, respectively. These results are in basic agreement with results obtained during the DisPURSAL project [124].

\section{Conclusions and Further Work}

Novel propulsion technology and propulsion-airframe integration play a key role in enabling aviation's long-term sustainability. Strong improvements of vehicular propulsive efficiency can be achieved by fuselage wake-filling propulsion integration. The presented research aimed at maximizing these benefits under realistic systems design and operating conditions. A key objective of the design, analysis and experimental testing activities discussed in this paper was to perform the proof of concept for a most straightforward approach to fuselage BLI - the so-called PFC. The investigated PFC configuration specifically featured a turbo-electric transmission in order to drive the aft-fuselage BLI fan through power offtakes from the underwing podded main engines. The interdisciplinary team of researchers addressed all main challenges associated with a turbo-electric PFC aircraft. A thorough understanding of the aerodynamic effects of $360^{\circ}$ fuselage BLI has been devel- 
oped through extensive aero-numerical simulations and low-speed experimental testing. Optimized aerodynamic pre-designs have been produced for the FF as well as for the fuselage and FF nacelle bodies. Conceptual solutions for the aero-structural integration of the BLI propulsive device and the TEPT have been elaborated. Important heuristics for PFC aircraft design have been deduced from multi-disciplinary design optimization. The developed design solutions have been either analytically or experimentally verified to demonstrate TRL 3 for the PFC technology. Initial steps towards experimental validation in a laboratory environment have been taken.

Assessments of fuel burn, $\mathrm{NO}_{\mathrm{x}}$ emissions and noise were presented for the PFC aircraft and benchmarked against advanced conventional technology for an EIS in 2035. The PFC design fuel burn benefit for a fully integrated multi-disciplinary aircraft design and performance synthesis based on the 2D optimized PFC aero-shaping is $4.7 \%$ against a similarly advanced aircraft without fuselage BLI propulsion. The all-integrated PFC fuel benefit including a preliminary assessment of the PFC 3D aerodynamic design impact yields $3.2 \%$. The $\mathrm{NO}_{\mathrm{x}}$ emission assessment performed for LDI combustor technology shows emission benefits for the PFC aircraft relative to the R2035 at all high power conditions, including take-off, climb, and cruise. The high-level $P F C \mathrm{NO}_{\mathrm{x}}$ reduction potentials were predicted as $64 \%$ relative to the year 2000 reference. PFC certification noise were found to be similar to the R2035, meaning a cumulative noise reduction of $12 \mathrm{EPNdB}$ compared to the R2000. The design mission COC for the PFC aircraft was assessed to be lower than for the R2035 as soon as the fuel price increases beyond US\$ 1.5 per gallon, even if fuel taxation or carbon pricing and offsetting cost for an EIS 2035 are neglected. Important steps to be taken by follow-on research and innovation activities have been outlined that would facilitate a speedy maturation of the PFC technology towards a target TRL 6.

Author Contributions: Conceptualization: A.S., F.P., F.T., A.C.P., B.D.C., M.K., X.Z., J.B. and G.W.; Methodology, A.S., A.L.H., F.P., F.T., A.C.P., B.D.C., M.v.S., M.K., X.Z., T.G., J.B. and G.W.; Validation: A.S., A.L.H., F.P., A.C.P., B.D.C., M.v.S., M.K., X.Z., J.B. and G.W.; Formal analysis: A.S., A.L.H., F.P., M.K., X.Z., J.B. and G.W.; Investigation: A.S., F.T., A.C.P., B.D.C., M.v.S., M.K., X.Z., J.B. and G.W.; Data curation: A.S., A.L.H., F.P. and F.T.; Writing—original draft preparation: A.S., A.L.H., F.P., A.C.P., B.D.C., M.v.S., M.K., X.Z. and G.W.; Writing-review and editing: A.S., A.L.H., A.C.P. and J.B.; Supervision: A.S., Z.G. and T.G.; Visualization: A.S., A.L.H., F.P., A.C.P., B.D.C., M.v.S., M.K., X.Z. and G.W.; Project administration, A.S.; Funding acquisition: A.S., Z.G., T.G., J.B., and G.W. All authors have read and agreed to the published version of the manuscript.

Funding: This research was funded by the European Union's Horizon 2020 research and innovation programme under grant agreement no. 723242.

Acknowledgments: This paper is based on the work performed by the CENTRELINE project consortium comprising Airbus, Bauhaus Luftfahrt, Chalmers Tekniska Hoegskola, MTU Aero Engines, Politechnika Warszawska, Rolls Royce, Delft University of Technology, University of Cambridge, and ARTTIC. The authors would like express their gratitude to the following individuals for their support during the CENTRELINE project (in alphabetical order): Anders Lundbladh, André Denis Bord, Arvind Gangoli Rao, Bartlomiej Goliszek, Cesare Hall, Daniel Reckzeh, Frank Meller, Jasper van Wensween, Lars Jørgensen, Marc Engelmann, Mark Voskuijl, Markus Nickl, Martin Dietz, Maxime Flandrin, Michael Lüdemann, Michaël Meheut, Michael Shamiyeh, Olaf Brodersen, Olivier Petit, Philipp Maas, Rasmus Merkler, Sebastian Samuelsson, Sophie Rau, and Stefan Biser.

Conflicts of Interest: The authors declare no conflict of interest. The funders had no role in the design of the study; in the collection, analyses, or interpretation of data; in the writing of the manuscript, or in the decision to publish the results. 


\section{Nomenclature}

Abbreviation/Acronym Description

ACARE

AC

ADP

AECMA

AIP

ALiCyA

APD

APSS

APU

AR

ATA

BLADE

BLI

BLISS

CAD

CENTRELINE

\section{CFD}

CFRP

COC

CS

$\mathrm{CV}$

DC

DEN

DLR

DMC

EC

EINO $_{x}$

EIS

EPNL

ETOPS

FEM

FF

FHA

FL

FNN

FPR

FPT

FTA

GTF

HTS

ICAO

ISA

HPC

HTS

IPC

LDI

LHS

LP

LPT

LRC

MIT

MLW
Advisory Council for Aviation Research and Innovation in Europe

Alternating Current

Aerodynamic Design Point

European Association of Aerospace Industries

Aerodynamic Interface Plane

Aircraft Life Cycle Assessment

Aircraft Preliminary Design

Aircraft Propulsion System Simulation

Auxiliary Power Unit

Aspect Ratio

Air Transport Association

Breakthrough Laminar Aircraft Demonstrator in Europe

Boundary Layer Ingestion

Bi-Level Integrated System Synthesis

Computer-Aided Design

ConcEpt validatioN sTudy foR fusElage wake-filLIng

propulsioN integration

Computational Fluid Dynamics

Carbon Fiber Reinforced Polymer

Cash Operating Costs

Certification Specification

Control Volume

Direct Current

Denver International Airport

Deutsches Zentrum für Luft- und Raumfahrt

Direct Maintenance Costs

European Commission

Nitrogen Oxide Emission Index

Entry Into Service

Effective Perceived Noise Level

Extended-range Twin-engine Operation(al) Performance Standards

Finite Element Method

Fuselage Fan

Function Hazard Assessment

Flight Level

Feedforward Neural Network

Fan Pressure Ratio

Free Power Turbine

Failure Tree Analysis

Geared TurboFan

High Temperature Superconducting

International Civil Aviation Organization

International Standard Atmosphere

High Pressure Compressor

High Temperature Superconducting

Intermediate Pressure Compressor

Lean Direct Injection

Latin Hypercube Sampling

Low Pressure

Low Pressure Turbine

Long-Range Cruise

Massachusetts Institute of Technology

Maximum Landing Weight 


\begin{tabular}{|c|c|c|}
\hline MLW & & Maximum Landing Weight \\
\hline MTOW & & Maximum Take-Off Weight \\
\hline NPF & & Net Propulsive Force \\
\hline NURBS & & Non-Uniform Rational B-splines \\
\hline OEW & & Operating Empty Weight \\
\hline OGV & & Outlet Guide Vanes \\
\hline ONERA & & Office National d'Etudes et de Recherches Aérospatiales \\
\hline OPR & & Overall Pressure Ratio \\
\hline PAX & & Passengers \\
\hline PFC & & Propulsive Fuselage Concept \\
\hline PIV & & Particle Image Velocimetry \\
\hline PSC & & Power Saving Coefficient \\
\hline PSSA & & Preliminary System Safety Assessment \\
\hline RANS & & Reynolds-Averaged Navier-Stokes \\
\hline SAP & & Safety Assessment Process \\
\hline SFC & & Specific Fuel Consumption \\
\hline SL & & Sea Level \\
\hline SLST & & Sea-Level Static Thrust \\
\hline SKF & & Svenska Kullagerfabriken \\
\hline SRIA & & Strategic Research and Innovation Agenda \\
\hline SST & & Shear Stress Transport \\
\hline TAB & & Technical Advisory Board \\
\hline TLAR & & Top Level Aircraft Requirements \\
\hline ToC & & Top-of-Climb \\
\hline TOFL & & Take-Off Field Length \\
\hline TRL & & Technology Readiness Level \\
\hline TU Delft & & Delft University of Technology \\
\hline UHBR & & Ultra-High Bypass Ratio \\
\hline WUT & & Warsaw University of Technology \\
\hline Symbol & Unit & Description \\
\hline$\alpha$ & $\circ$ & Angle of attack \\
\hline$\beta$ & $\circ$ & Sideslip angle \\
\hline$\delta$ & $\mathrm{m}$ & Local boundary layer thickness \\
\hline$\Delta \eta$ & - & Change in stage isentropic efficiency \\
\hline$\eta_{p d, e f f}$ & - & Effective propulsive device efficiency \\
\hline$\eta_{p o l, F F}$ & - & FF polytropic efficiency \\
\hline$\eta_{P T, F F}$ & - & FF power train efficiency \\
\hline$\Theta$ & $\circ$ & Azimuthal angle \\
\hline$A_{12}$ & $\mathrm{~m}$ & FF fan face area \\
\hline$A_{18}$ & $\mathrm{~m}$ & FF nozzle exit area \\
\hline$A R$ & - & Aspect Ratio \\
\hline$C_{L, \max }$ & - & Maximum lift coefficient \\
\hline$D$ & $\mathrm{kN}$ & Drag \\
\hline$D_{F F}$ & $\mathrm{~m}$ & FF rotor inlet tip diameter \\
\hline$D_{\text {Ref,fus }}$ & $\mathrm{kN}$ & Reference fuselage drag \\
\hline$F$ & $\mathrm{kN}$ & Force \\
\hline$F_{P F C, \text { bare }}$ & $\mathrm{kN}$ & Bare PFC surface forces \\
\hline$F_{F F \text {,disc }}$ & $\mathrm{kN}$ & FF disc force \\
\hline$F_{N}$ & $\mathrm{kN}$ & Net thrust \\
\hline$f_{\eta, P F C, \text { bare }}$ & - & Bare PFC efficiency factor \\
\hline$L_{\text {fus }}$ & $\mathrm{m}$ & Fuselage length \\
\hline$\dot{m}_{\text {corr }}$ & $\mathrm{kg} / \mathrm{s}$ & Corrected mass flow \\
\hline$N P F_{P F C, \text { bare }}$ & $\mathrm{kN}$ & Bare PFC Net Propulsive Force \\
\hline
\end{tabular}




\begin{tabular}{lll}
$p_{0}$ & $\mathrm{~Pa}$ & Freestream total pressure \\
$p_{A I P}$ & $\mathrm{~Pa}$ & Local total pressure at FF AIP \\
\hline$p_{A I P}$ & $\mathrm{~Pa}$ & Mean total pressure at FF AIP \\
$p_{18}$ & $\mathrm{~Pa}$ & Mass flow averaged total pressure at FF nozzle throat \\
$p_{2}$ & $\mathrm{~Pa}$ & Mass flow averaged total pressure at FF rotor inlet \\
$p_{3}$ & $\mathrm{~Pa}$ & Total pressure at HPC exit \\
$p_{\text {s,amb }}$ & $\mathrm{Pa}$ & Ambient static pressure \\
$P_{c o, e f f}$ & $\mathrm{MW}$ & Effectvie core engine excess power \\
$P_{\text {disc,FF }}$ & $\mathrm{MW}$ & FF disc power \\
$P_{F F \text { Shaft }}$ & $\mathrm{MW}$ & FF shaft power \\
$P C$ & - & Total pressure coefficient \\
$P S C$ & - & Power saving coefficient \\
$r_{f u s}$ & $\mathrm{~m}$ & Radius of fuselage centre section \\
$r_{h u b}$ & $\mathrm{~m}$ & FF hub radius \\
$r_{t i p}$ & $\mathrm{~m}$ & FF tip radius \\
$S P_{P T, F F}$ & $\mathrm{~kW} / \mathrm{kg}$ & FF power train specific weight \\
$T_{3}$ & $\mathrm{~K}$ & Total temperature at HPC exit \\
$V_{0}$ & $\mathrm{~m} / \mathrm{s}$ & Freestream velocity \\
$W_{2}$ & $\mathrm{~kg} / \mathrm{s}$ & FF mass flow rate \\
$x_{F F}$ & $\mathrm{~m}$ & FF axial position \\
$y$ & $\mathrm{~m}$ & Radial coordinate from fuselage centreline \\
& &
\end{tabular}

\section{References}

1. European Commission. Flightpath 2050 Europe's Vision for Aviation-Report of the High Level Group on Aviation Research; European Commission: Luxembourg, 2011.

2. Air Transport Action Group. Recuding Emissions from Aviation through Carbonneutral Growth from 2020; Working Paper Developed for the 38th ICAO Assembly September/October; Air Transport Action Group: Geneva, Switzerland, 2013.

3. Advisory Council for Aviation Research and Innovation in Europe (ACARE). Strategic Research and Innovation Agenda (SRIA)Volume 1; ACARE: Brussels, Belgium, 2012.

4. Smith, L.H. Wake ingestion propulsion benefit. J. Propuls. Power 1993, 9, 74-82. [CrossRef]

5. Steiner, H.-J.; Seitz, A.; Wieczorek, K.; Plötner, K.; Isikveren, A.T.; Hornung, M. Multi-disciplinary Design and Feasibility Study of Distributed Propulsion Systems. In Proceedings of the 28th International Congress of the Aeronautical Sciences, Brisbane, Australia, 23-28 September 2012.

6. Smith, A.M.O.; Roberts, H.E. The jet airplane utilizing boundary layer air for propulsion. J. Aerosol Sci. 1947, 14, 97-109. [CrossRef]

7. Goldschmied, F.R. A Theoretical Aerodynamic Analysis of a Boundary Layer Controlled Airship Hull. Goodyear Aircr. Rep. GER-6251 1954.

8. Drela, M. Power Balance in Aerodynamic Flows. AIAA J. 2009, 47, 1761-1771. [CrossRef]

9. Betz, A.; Ackeret, J. Verfahren zur Verminderung des Widerstandes eines Körpers in Flüssigkeiten oder Gasen. German Patent No 513116, 5 September 1923.

10. Heppner, F.A.M. Improvements relating to Jet-Propelled Aircraft. GB Patent GB577950, 31 December 1941.

11. Cerreta, P.A. Wind-Tunnel Investigation of the Drag of a Proposed Boundary-Layer Controlled Airship; David Taylor Model Basin Aero Report 914; Cornell University: Ithaca, NY, USA, 1957.

12. Atinault, O.; Carrier, G.; Grenon, R.; Verbecke, C. Numerical and Experimental Aerodynamic Investigations of BLI for Improving Propulsion Efficiency of Future Air Transport. In Proceedings of the 31st AIAA Applied Aerodynamics Conference, San Diego, CA, USA, 24-27 June 2013.

13. Lv, P.; Ragni, D.; Hartuc, T.; Veldhuis, L.; Rao, A.G. Experimental Investigation of the Flow Mechanisms Associated with a Wake-Ingesting Propulsor. AIAA J. 2017, 55, 1-11. [CrossRef]

14. Uranga, A.; Drela, M.; Greitzer, E.M.; Titchener, N.; Lieu, M.; Siu, N.; Huang, A.; Gatlin, G.M.; Hannon, J. Preliminary Experimental Assessment of the Boundary Layer Ingestion Benefit for the D8 Aircraft, AIAA 2014-0906, AIAA SciTech 52nd. In Proceedings of the Aerospace Sciences Meeting, National Harbor, MA, USA, 13-17 January 2014.

15. Gunn, E.J.; Hall, C.A. Aerodynamics of Boundary Layer Ingesting Fans. In Proceedings of the ASME Turbo Expo 2014, Dusseldorf, Germany, 16-20 June 2014.

16. De LaRosa, E.; Hall, C.; Crichto, D. Special session-Towards a silent aircraft challenges in the silent aircraft engine design. In Proceedings of the 45th AIAA Aerospace Sciences Meeting and Exhibit, Reno, NE, USA, 8-11 January 2007. 
17. Felder, J.L.; Kim, H.D.; Brown, G.V. Turboelectric Distributed Propulsion Engine Cycle Analysis for Hybrid-Wing-Body Aircraft. In Proceedings of the AIAA 2009-1132, 47th AIAA Aerospace Sciences Meeting Including The New Horizons Forum and Aerospace Exposition, Orlando, FL, USA, 5-8 January 2009.

18. Bolonkin, A. A high efficiency fuselage propeller ('Fusefan') for subsonic aircraft. In Proceedings of the World Aviation Conference, San Francisco, CA, USA, 19-21 October 1999.

19. Drela, M. Development of the D8 Transport Configuration. In Proceedings of the AIAA 2011-3970, 29th AIAA Applied Aerodynamics Conference, Honolulu, HI, USA, 27-30 June 2011.

20. Seitz, A. Flugzeugantriebssystem. German Patent DE200810024463, 21 May 2008.

21. Stückl, S.; van Toor, J.; Lobentanzer, H. VoltAir-The All Electric Propulsion Concept Platform-A Vision for Atmospheric Friendly Flight. In Proceedings of the 28th International Congress of the Aeronautical Sciences (ICAS), Brisbane, Australia, 23-28 September 2012.

22. Bradley, M.K.; Droney, C.K. Subsonic Ultra Green Aircraft Research Phase II: N+4 Advanced Concept Development. NASA/CR2012-217556, 1 May 2012.

23. Welstead, L.; Felder, J. Conceptual Design of a Single-Aisle Turboelectric Commercial Transport with Fuselage Boundary Layer Ingestion. In Proceedings of the AIAA-2016-1027, 54th AIAA Aerospace Sciences Meeting (SciTech), San Diego, CA, USA, 4-8 January 2016.

24. Welstead, J.; Felder, J.; Guynn, M.; Haller, B.; Tong, M.; Jones, S.; Gray, J.S.; Ordaz, I.; Quinlan, J.; Mason, B.; et al. Overview of the NASA STARC-ABL (Rev. B) Advanced Concept. NF1676L-26767, 22 March 2017.

25. Isikveren, A.T.; Seitz, A.; Bijewitz, J.; Mirzoyan, A.; Isyanov, A.; Grenon, R.; Atinault, O.; Godard, J.-L.; Stückl, S. Distributed propulsion and ultra-high by-pass rotor study at aircraft level. Aeronaut. J. 2015, 119, 1327-1376. [CrossRef]

26. Gray, J.S.; Mader, C.A.; Kenway, G.K.; Martins, J.R.R.A. Modeling Boundary Layer Ingestion Using a Coupled Aeropropulsive Analysis. J. Aircr. 2018, 55, 3. [CrossRef]

27. Kenway, G.K.; Kiris, C.C. Aerodynamic Shape Optimization of the STARC-ABL Concept for Minimal Inlet Distortion. In Proceedings of the AIAA 2018-1912, AIAA/ASCE/AHS/ASC Structures, Structural Dynamics, and Materials Conference, Kissimmee, FL, USA, 8-12 January 2018.

28. Yildirim, A.; Gray, J.S.; Mader, C.A.; Martins, R.R.A.J. Aeropropulsive Design Optimization of a Boundary Layer Ingestion System. In Proceedings of the AIAA 2019-3455, AIAA Aviation Forum, Dallas, TX, USA, 17-21 June 2019.

29. Martínez Fernández, A.; Smith, H. Effect of a fuselage boundary layer ingesting propulsor on airframe forces and moments. Aerosp. Sci. Technol. 2020, 100, 105808. [CrossRef]

30. Budziszewski, N.; Friedrichs, J. Modelling of a Boundary Layer Ingesting Propulsor. Energies 2018, 11, 708. [CrossRef]

31. Provenza, A.; Duffy, K.P.; Bakhle, M.A. Aeromechanical Response of a Distortion-Tolerant Boundary Layer Ingesting Fan. J. Eng. Gas Turbines Power 2018, 141, 011011. [CrossRef]

32. Kratz, J.L.; Thomas, G.L. Dynamic Analysis of the STARC-ABL Propulsion System. In Proceedings of the AIAA 2019-4182, AIAA Propulsion and Energy Forum, Indianapolis, IN, USA, 19-22 August 2019.

33. Heinlein, G.; Chen, J.; Bakhle, M. Aerodynamic Behavior of a Coupled Boundary Layer Ingesting Inlet-Distortion Tolerant Fan. In Proceedings of the AIAA 2020-3780, AIAA Propulsion and Energy Forum, Virtual Event, 24-28 August 2020.

34. Romani, G.; Ye, Q.; Avallone, F.; Ragni, D.; Casalino, D. Numerical analysis of fan noise for the NOVA boundary-layer ingestion configuration. Aerosp. Sci. Tech. 2020, 96, 105532. [CrossRef]

35. Wernick, A.R.; Chen, J.-P. Rotor Blade Design Optimization for Boundary Layer Ingesting Inlet Fan. In Proceedings of the AIAA 2020-0131, AIAA Scitech Forum, Orlando, FL, USA, 6-10 January 2020.

36. Celestina, M.L.; Long-Davis, M.J. Large-scale Boundary Layer Ingesting Propulsor Research. In Proceedings of the ISABE Conference 2019, Canberra, Australia, 24-27 September 2019.

37. Seitz, A.; Bijewitz, J.; Kaiser, S.; Wortmann, G. Conceptual investigation of a propulsive fuselage aircraft layout. Aircr. Eng. Aerosp. Technol. 2014, 86, 464-472. [CrossRef]

38. DisPURSAL Consortium. Report on the Technology Roadmap for 2035; Public Project Deliverable D1.2, Grant Agreement No. 323013; DisPURSAL Consortium; European Commission Directorate General for Research and Innovation: Brussels, Belgium, 2015.

39. Peter, F.; Bijewitz, J.; Habermann, A.; Lüdemann, M.; Plötner, K.; Troeltsch, F.; Seitz, A. Specification of the CENTRELINE Reference Aircraft and Power Plant Systems; Virtual Event; Deutscher Luft- und Raumfahrtkongress: Garching, Germany, 2020.

40. Kaiser, S.; Seitz, A.; Donnerhack, S.; Lundbladh, A. Composite Cycle Engine Concept with Hectopressure Ratio. J. Propuls. Power 2016, 32, 1413-1421. [CrossRef]

41. Seitz, A.; Nickl, M.; Stroh, A.; Vratny, P.C. Conceptual study of a mechanically integrated parallel hybrid electric turbofan. Proc. Inst. Mech. Eng. Part G J. Aerosp. Eng. 2018, 232, 2688-2712. [CrossRef]

42. Bijewitz, J.; Seitz, A.; Hornung, M. Power Plant Pre-Design Exploration for a Turbo-Electric Propulsive Fuselage Concept. In Proceedings of the AIAA 2018-4402, AIAA Propulsion and Power Forum 2018, Cincinnati, OH, USA, 9-11 July 2018.

43. Seitz, A.; Peter, F.; Bijewitz, J.; Habermann, A.; Goraj, Z.; Kowalski, M.; Castillo Pardo, A.; Hall, C.; Meller, F.; Merkler, R.; et al. Concept validation study for fuselage wake-filling propulsion integration. In Proceedings of the 31st Congress of the International Council of the Aeronautical Sciences (ICAS), Belo Horizonte, Brazil, 9-14 September 2018. 
44. Meller, F.; Kocvara, F. Specification of Propulsive Fuselage Aircraft Layout and Design Features; Public Project Deliverable D1.02, Grant Agreement No. 723242; CENTRELINE Consortium; European Commission Directorate-General for Research and Innovation: Brussels, Belgium, 2018.

45. Habermann, A.L.; Bijewitz, J.; Seitz, A.; Hornung, M. Performance bookkeeping for aircraft configurations with fuselage wake-filling propulsion integration. CEAS Aeronaut. J. 2019, 11, 529-551. [CrossRef]

46. Arntz, A. Civil Aircraft Aero-thermo-propulsive Performance Assessment by an Exergy Analysis of High-Fidelity CFD-RANS Flow Solutions. Ph.D. Thesis, Universite de Lille, Lille, France, 2014.

47. Della Corte, B.; van Sluis, M.; Gangoli Rao, A.; Veldhuis, L.L.M. Experimental Power Balance Analysis of an Axisymmetric Fuselage with an Integrated Boundary-Layer-Ingesting Fan. AIAA J. 2020. in review.

48. Della Corte, B.; van Sluis, M.; Gangoli Rao, A. Results of the Overall Configuration Wind Tunnel Testing; Public Project Deliverable D3.02, Grant Agreement No. 723242; CENTRELINE Consortium; European Commission Directorate-General for Research and Innovation: Brussels, Belgium, 2020.

49. Graichen, J.; Gores, S.; Herold, A. Überarbeitung des Emissionsinventars des Flugverkehrs; ISSN-1862-4804; Umweltbundesamt: Dessau-Roßlau, Germany, 2010.

50. Seitz, A.; Habermann, A.L.; Van Sluis, M. Optimality considerations for propulsive fuselage power savings. Proc. Inst. Mech. Eng. Part G J. Aerosp. Eng. 2020. [CrossRef]

51. Piegl, L. On NURBS: A Survey. IEEE Comput. Graph. Appl. 1991, 11, 55-71. [CrossRef]

52. Derksen, R.W.; Rogalsky, T. Optimum Airfoil Parametrization for Aerodynamic Design. Comput. Aided Optim. Des. Eng. 2009, 106. [CrossRef]

53. Van Sluis, M.; Della Corte, B.; Rao, A.G. Aerodynamic Design Space Exploration of a Fuselage Boundary Layer Ingesting Aircraft Concept. 2021. to be published.

54. Hofer, D.; D'Errico, J.; Schwarz, M.D. Matlab to Ansys ICEM/Fluent and Spline Drawing Toolbox. Available online: http: //mathworks.com/matlabcentral/fileexchange/66215 (accessed on 17 April 2019).

55. Menter, F.R. Two-equation eddy-viscosity turbulence models for engineering applications. AIAA J. 1994, 32, 1598-1605. [CrossRef]

56. Shields, M.D.; Zhang, J. The generalization of Latin hypercube sampling. Reliab. Eng. Syst. Saf. 2016, 148, 96-108. [CrossRef]

57. Chang, C.C.; Lin, C.J. LIBSVM: A Library for Support Vector Machines. ACM Trans. Intell. Syst. Technol. 2011, 2, 27. [CrossRef]

58. Van Sluis, M.; Della Corte, B. Final PFC Aircraft Aerodynamic Design and Performance; Public Project Deliverable D3.03, Grant Agreement No. 723242; CENTRELINE Consortium; European Commission Directorate-General for Research and Innovation: Brussels, Belgium, 2020.

59. Van Oudheusden, B.W.; Steenaert, C.B.; Boermans, L.M.M. Attachment-Line Approach for Design of a Wing-Body Leading-Edge Fairing. J. Aircr. 2004, 41, 238-246. [CrossRef]

60. Brandvik, T.; Pullan, G. An Accelerated 3D Navier-Stokes Solver for Flows in Turbomachines. J. Turbomach. 2010, 133, 021025. [CrossRef]

61. Spalart, P.; Allmaras, S. A one-equation turbulence model for aerodynamic flows. Rech. Aerosp. 1994, 1, 5-21.

62. Castillo Pardo, A.; Hall, C.A. Design of a Transonic Boundary Layer Ingesting Fuselage Fan. Paper ID: GPPS-CH-2020-0042, to be published. In Proceedings of the Global Power and Propulsion Society, GPPS, Chania, Greece, 7-9 September 2020.

63. Serpieri, J. Cross-Flow Instability: Flow Diagnostics and Control of Swept Wing Boundary Layers. Ph.D. Thesis, Delft University of Technology, Delft, The Netherlands, 2018.

64. Castillo Pardo, A.; Hall, C.A. Aerodynamics of Boundary Layer Ingesting Fuselage Fans. In Proceedings of the ISABE-2019-24162, 24th ISABE Conference, Canberra, Australia, 22-27 September 2019.

65. Taylor, J.V. Complete flow conditioning gauzes. Exp. Fluids 2019, 60, 35. [CrossRef]

66. Goraj, Z.; Kowalski, M.; Goliszek, B.; van Sluis, M. Interim Report on Fuselage and Nacelle Aero-Structural Pre-Design; Public Project Deliverable D2.06, Grant Agreement No. 723242; CENTRELINE Consortium; European Commission Directorate-General for Research and Innovation: Brussels, Belgium, 2018.

67. Goraj, Z.; Kowalski, M.; Goliszek, B. Optimisation of the loading structure for Propulsive Fuselage Concept. In Proceedings of the 24th ISABE Conference, International Society for Air Breathing Engines, Canberra, Australia, 22-27 September 2019.

68. Federal Aviation Administration. Design considerations for minimizing hazards caused by uncontained turbine engine and auxiliary power unit rotor failure. FAA Advis. Circ. 1997.

69. Habermann, A.; Troeltsch, F.; Peter, F.; Maas, P.; van Sluis, M.; Kowalski, M.; Wortmann, G.; Bijewitz, B.; Seitz, A. Summary Report on Multi-Disciplinary Design Results; Public Project Deliverable D2.11, Grant Agreement No. 723242; CENTRELINE Consortium; European Commission Directorate-General for Research and Innovation: Brussels, Belgium, 2020.

70. Seitz, A. Advanced Methods for Propulsion System Integration in Aircraft Conceptual Design. Ph.D. Thesis, Institut für Luftund Raumfahrt, Technische Universität München, München, Germany, 2012.

71. Grieb, H. Projektierung von Turboflugtriebwerken; Birkhäuser Verlag: Basel, Switzerland; Boston, MA, USA; Berlin, Germany, 2004.

72. Kurzke, J. GasTurb 11: Design and Off-Design Performance of Gas Turbines; GasTurb GmbH: Aachen, Germany, 2007.

73. Kurzke, J. Gasturb Details 6; Software compiled with Delphi XE4, 2013.

74. Wittel, H.; Muhs, D.; Jannasch, D.; Voßiek, J. Roloff/Matek Maschinenelemente, Normung, Berechnung, Gestaltung, 20th ed.; Vieweg und Teubner Verlag: Wiesbaden, Germany, 2011; ISBN 978-3-8348-1454-8. 
75. Stroh, A.; Wortmann, G.; Seitz, A. Conceptual Sizing Methods for Power Gearboxes in Future Gas Turbine Engines; Document ID 450100; Deutscher Luft- und Raumfahrtkongress: Garching, Germany, 2017.

76. European Aviation Safety Agency. Certification Specifications and Acceptable Means of Compliance for Large Aeroplanes CS-25, 23rd ed.; European Aviation Safety Agency: Cologne, Germany, 2019.

77. Stotler, C.L.; Coppa, A.P. Containment of Compososite Fan Blades; General Electric, NASA Contractor Report 159544; NASA Lewis Research Center: Cleveland, OH, USA, 1979.

78. Goraj, Z.; Kowalski, M.; Goliszek, B. Passenger Aircraft Composite Centre Wing Box Structure Optimization. In Proceedings of the Aerospace Europe Conference, Bordeaux, France, 25-28 February 2020.

79. Goraj, Z.; Kowalski, M.; Goliszek, B. The use of Finite Element Method and semi-empirical equations for weight estimation of the passenger aircraft utilizing innovative technological solutions. In Proceedings of the Research and Education in Aircraft Design (READ) Conference, Rzeszów, Poland, 21-23 October 2020.

80. Kowalski, M.; Goraj, Z.; Goliszek, B. The use of FEA and semi-empirical equations for weight estimation of a passenger aircraft. Aircr. Eng. Aerosp. Technol. J. 2020. submitted.

81. Wortmann, G. Electric Machinery Preliminary Design Report; Public Project Deliverable D4.04, Grant Agreement No. 723242; CENTRELINE Consortium; European Commission Directorate-General for Research and Innovation: Brussels, Belgium, 2018.

82. Wortmann, G. Electric Generator Final Design Report; Confidential Project Deliverable D4.06, Grant Agreement No. 723242; CENTRELINE Consortium; European Commission Directorate-General for Research and Innovation: Brussels, Belgium, 2019.

83. Wortmann, G. Final Design and Performance of FF Electric Drive Motor; Confidential Project Deliverable D4.07, Grant Agreement No. 723242; CENTRELINE Consortium; European Commission Directorate-General for Research and Innovation: Brussels, Belgium, 2019.

84. Wortmann, G. Final Design of the Electric Fuselage Drive Train System; Confidential Project Deliverable D4.08, Grant Agreement No. 723242; CENTRELINE Consortium; European Commission Directorate-General for Research and Innovation: Brussels, Belgium, 2019.

85. Kellermann, H.; Habermann, A.; Vratny, P.; Hornung, M. Assessment of fuel as alternative heat sink for future aircraft. Appl. Therm. Eng. 2020, 170, 114985. [CrossRef]

86. Kellermann, H.; Habermann, A.L.; Hornung, M. Assessment of Aircraft Surface Heat Exchanger Potential. Aerospace $2019,7,1$. [CrossRef]

87. Kurzke, J. Compressor and Turbine Maps for Gas Turbine Performance Computer Programs-Issue 3; GasTurb GmbH: Aachen, Germany, 2013.

88. Zhao, X. Power Plant System Final Design and Performance Characteristics; Public Project Deliverable D4.03, Grant Agreement No. 723242; CENTRELINE Consortium; European Commission Directorate-General for Research and Innovation: Brussels, Belgium, 2020.

89. Merkler, R. Power Plant Integration Concept for Electric Generator; Public Project Deliverable D4.05, Grant Agreement No. 723242; CENTRELINE Consortium; European Commission Directorate-General for Research and Innovation: Brussels, Belgium, 2020.

90. Campbell, C.E.; Welna, H.J. Preliminary Evaluation of Turbine Performance with Variable-Area Turbine Nozzles in a Turbojet Engine; National Advisory Committee for Aeronautics: Washington, DC, USA, 1960.

91. Schum, H.J.; Moffitt, T.P.; Behning, F.P. Effect of Variable Stator Area on Performance of a Single-Stage Turbine Suitable for Air Cooling: III. Turbine Performance with 130 Percent Design Stator Area; NASA: Cleveland, OH, USA, 1968.

92. Karstensen, K.W.; Wiggins, J.O. A Variable-Geometry Power Turbine for Marine Gas Turbines. J. Turbomach. 1990, 112, 165-174. [CrossRef]

93. Sobieszczanski-Sobieski, J.; Agte, J.; Sandusky, R. Bi-level integrated system synthesis (BLISS). AIAA 98-4916. In Proceedings of the 7th AIAA/USAF/NASA/ISSMO Symposium on Multidisciplinary Analysis and Optimization, St. Louis, MO, USA, 4 September 1998.

94. Sobieszczanski-Sobieski, J.; Emiley, M.; Agte, J.; Sandusky, R., Jr. Advancement of Bi-Level Integrated System Synthesis (BLISS); NASA/TM-2000-210305; NASA Technical Memorandum, Langley Research Center: Hampton, VA, USA, 2000.

95. McKay, M.; Beckman, R.; Conover, W. A comparison of three methods for selecting values of input variables in the analysis of output from a computer code. Technometrics 1979, 21, 239-245.

96. Shamiyeh, M. Definition of Multidisciplinary Interfacing Strategy; Public Project Deliverable D2.01, Grant Agreement No. 723242; CENTRELINE Consortium; European Commission Directorate-General for Research and Innovation: Brussels, Belgium, 2018.

97. Troeltsch, F.; Bijewitz, J.; Seitz, A. Design Trade Studies for Turbo-electric Propulsive Fuselage Integration. In Proceedings of the 24th ISABE Conference, International Society for Air Breathing Engines, Canberra, Australia, 22-27 September 2019.

98. PACE Aerospace Engineering \& Information Technology GmbH. Pacelab Aircraft Preliminary Design. Version 3.0.1. Software. 2012.

99. Torenbeek, E. Synthesis of Subsonic Airplane Design: An Introduction to the Preliminary Design of Subsonic General Aviation and Transport Aircraft, with Emphasis on Layout, Aerodynamic Design, Propulsion and Performance, 1st ed.; Kluwer: Dordrecht, The Netherlands, 1996.

100. Gologan, C. A Method for the Comparison of Transport Aircraft with Blown Flaps. Ph.D. Thesis, Technische Universität München, München, Germany, 2010.

101. Pornet, C. Conceptual Design Methods for Sizing and Performance of Hybrid-Electric Transport Aircraft. Ph.D. Thesis, Technische Universität München, München, Germany, 2018. 
102. Vratny, P. Conceptual Design Methods of Electric Power Architectures for Hybrid Energy Aircraft. Ph.D. Thesis, Technische Universität München, München, Germany, 2019.

103. Society of Automotive Engineers. ARP4761, Guidelines and Methods for Conducting the Safety Assessment Process on Civil Airborne Systems and Equipment; SAE International: Warrendale, PA, USA, 1996.

104. Society of Automotive Engineers. ARP4754 Certification Considerations for Highly-Integrated or Complex Aircraft Systems; SAE International: Warrendale, PA, USA, 1996.

105. Kritzinger, D. Aircraft System Safety. Assessments for Initial Airworthiness Certification; Woodhead Publishing: Duxford, UK, 2016.

106. Castillo Pardo, A. Results of the Fuselage-Fan Rig Testing; Public Project Deliverable D3.05, Grant Agreement No. 723242; CENTRELINE Consortium; European Commission Directorate-General for Research and Innovation: Brussels, Belgium, 2020.

107. Gubisch, M. Why Airbus Foresees Laminar Wings on Next-Gen Aircraft. Flight Global. 2018. Available online: https:// www.flightglobal.com/analysis / analysis-why-airbus-foresees-laminar-wings-on-next-gen-aircraft/128247.article?adredir=1 (accessed on 3 March 2020).

108. AIRBUS S.A.S. A340-500/-600 Aircraft Characteristics Airport and Maintenance Planning. AIRBUS S.A.S. Blagnac Cedex, France (Revision No. 19-Jun 01/20). Available online: https:/ /www.airbus.com/aircraft/support-services/airport-operations-andtechnical-data/aircraft-characteristics.html (accessed on 4 November 2020).

109. Peter, F.; Castillo Pardo, A.; Della Corte, B.; Goliszek, B.; Kowalski, M.; van Sluis, M.; Wortmann, G.; Zhao, X. Propulsive Fuselage Technology Roadmap towards TRL6 in 2030; Public Project Deliverable D5.06, Grant Agreement No. 723242; CENTRELINE Consortium; European Commission Directorate-General for Research and Innovation: Brussels, Belgium, 2021.

110. International Civil Aviation Organization. Aerodrome Standards-Aerodrome Design and Operations. ICAO Annex 14, 3rd ed.; International Civil Aviation Organization: Montreal, QC, Canada, 1999.

111. Seitz, A.; Engelmann, M. Multi-Disciplinary Evaluation of the Optimized Propulsive Fuselage Aircraft; Public Project Deliverable D2.03, Grant Agreement No. 723242; CENTRELINE Consortium; European Commission Directorate-General for Research and Innovation: Brussels, Belgium, 2020.

112. Green, J.E. Greener by Design—the Technology Challenge. Aeronaut. J. 2002, 106, 57-113. [CrossRef]

113. Tacina, K.M.; Wey, C. NASA Glenn High Pressure Low NOx Emissions Research; NASA/TM-2008-214974; National Aeronautics and Space Administration: Cleveland, OH, USA, 2008.

114. Grönstedt, T.; Dax, A.; Kyprianidis, K.; Ogaji, S. Low-Pressure System Component Advancements and its Influence on Future Turbofan Engine Emissions; GT2009-59950; ASME Turbo Expo: Orlando, FL, USA, 2009; pp. 505-516.

115. Depitre, A. Noise Certification Workshop, Session 2: EPNdB Metric; International Civil Aviation Organization: Montreal, QC, Canada, 2006.

116. Zhao, X. Benchmark of the Propulsive Fuselage Concept against the Y2035 SRIA Targets; Confidential Project Deliverable D1.04, Grant Agreement No. 723242; CENTRELINE Consortium; European Commission Directorate-General for Research and Innovation: Brussels, Belgium, 2021.

117. ICAO. Aircraft Engine Emissions Databank; International Civil Aviation Organization: Montreal, QC, Canada, 2020.

118. Clark, I.A.; Thomas, R.H.; Guo, Y. Noise Reduction Approaches for the NASA D8 Subsonic Transport Concept. In Proceedings of the 22nd Workshop of the Aeroacoustics Specialists Committee of the CEAS, Netherlands Aerospace Center, Amsterdam, The Netherlands, 6-7 September 2018.

119. Association of European Airlines. Operating Economy of AEA Airlines; Association of European Airlines: Brussels, Belgium, 2007.

120. Plötner, K.O.; Schmidt, M.; Baranowski, D.; Isikveren, A.T.; Hornung, M. Operating Cost Estimation for Electric-Powered Transport Aircraft. In Proceedings of the Aviation Technology, Integration, and Operations Conference, AIAA 2013-4281, Los Angeles, CA, USA, 12-14 August 2013.

121. Plötner, K.; Wesseler, P.; Phleps, P. Identification of key aircraft and operational parameters affecting airport charges. Int. J. Aviat. Manag. 2013, 2, 91-115. [CrossRef]

122. Gieras, J.F. Superconducting electrical machines-state of the art. Prz. Elektrotechniczny 2009, 12, 1-21.

123. Grilli, F.; Benkel, T.; Hänisch, J.; Lao, M.; Reis, T.; Berberich, E.; Wolfstädter, S.; Schneider, C.; Miller, P.; Palmer, C.; et al. Superconducting motors for aircraft propulsion: The Advanced Superconducting Motor Experimental Demonstrator project. J. Phys. Conf. Ser. 2020, 1590, 012051. [CrossRef]

124. Seitz, A.; Isikveren, A.T.; Bijewitz, J.; Mirzoyan, A.; Isyanov, A.; Godard, J.-L.; Stückl, S. Summary of Distributed Propulsion and Ultra-high By-pass Rotor Study at Aircraft Level. In Proceedings of the 7th European Aeronautics Days 2015, London, UK, 20-23 October 2015. 